\title{
ANALYSIS OF BEST PRACTICE PROCEDURES TO PREVENT SUDDEN DEATH IN HIGH SCHOOL ATHLETICS: A REGIONAL ASSESSMENT.
}

\author{
A Dissertation \\ Presented to \\ The Faculty of the Graduate School \\ at the University of Missouri - Columbia \\ In Partial Fulfillment \\ of the Requirements for the Degree \\ Doctor of Education \\ By \\ Kyle R. Schneider \\ Dr. Bret D. Cormier, Ed.D. Dissertation Supervisor \\ May 2019
}


The undersigned, appointed by the dean of the Graduate School, have examined the dissertation entitled:

\section{ANALYSIS OF BEST PRACTICE PROCEDURES TO PREVENT SUDDEN DEATH IN HIGH SCHOOL ATHLETICS: A REGIONAL ASSESSMENT.}

Presented by Kyle R. Schneider, a candidate for the degree Doctor of Education and hereby certify that, in their opinion, it is worthy of acceptance.

Dr. Bret D. Cormier, Chair

Dr. C. P. Gause

Dr. Seidu Sofo

Dr. Jeremy Heider 


\section{Acknowledgements}

I would like to fist acknowledge Alicia Pike and the Korey Stringer Institute at the University of Connecticut for their assistance and support with this important research and distributing the survey to the listserv. Without them I would not have been able to complete this project. So for that I am extremely grateful.

I would also like to acknowledge the support of my fiancé Amanda. You have supported me and tolerated my stress and helped me deal with the late nights of writing, researching, and editing. Thank you!

Also, to my committee; the support and guidance I got from the members of the committee, Dr. Cormier, Dr. Gause, Dr. Heider, and Dr. Sofo was paramount to me finishing this project. 


\section{Table of Contents}

Acknowledgments....................................................... ii

Abstract............................................................. v

Section One: Introduction................................................ 1

Background........................................................ 2

Statement of the Problem............................................... 6

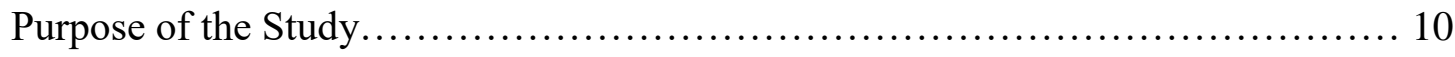

Research Questions................................................... 10

Conceptual/Theoretical Framework...................................... 11

Design of the Study................................................. 14

Definition of Key Term............................................... 22

Section Two: Practitioner Setting ......................................... 30

Section Three: Review of Literature .................................... 35

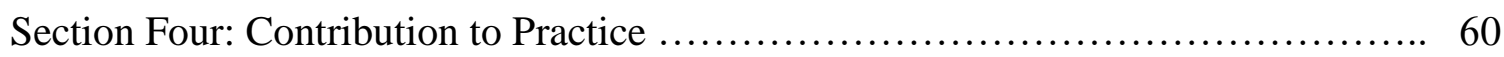

Plan for Dissemination............................................. 61

Policy Alternatives................................................. 62

Section Five: Contribution to Scholarship ................................. 75

Target Journal and Rationale........................................ 76

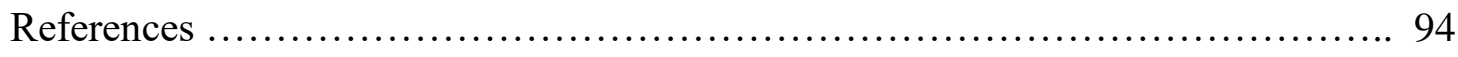

Section 6: Scholarly Practitioner Reflection ................................. 113

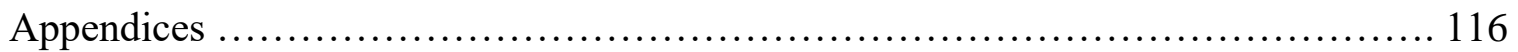

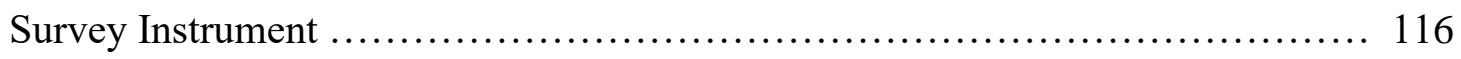

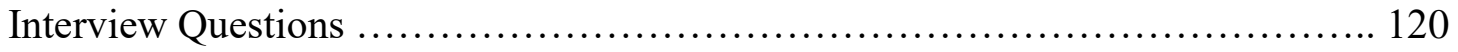


Qualitative Themes

Athletic Trainer by RUCA............................................... 129

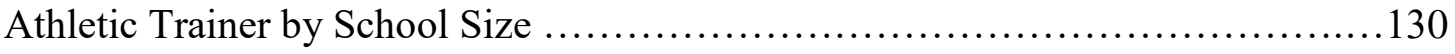

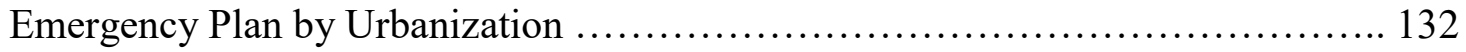

Emergency Action Plan by School Size ................................. 133

Number of AEDs by School Size .......................................... 134

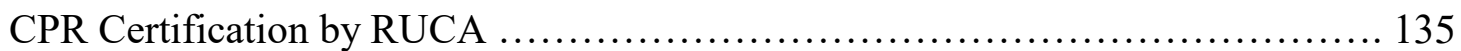

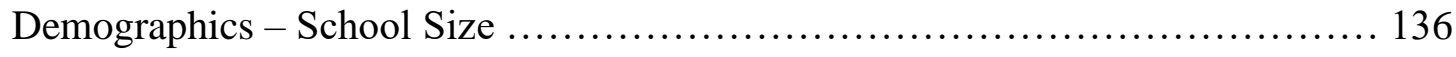

Demographics - Ethnic Majority ..................................... 137

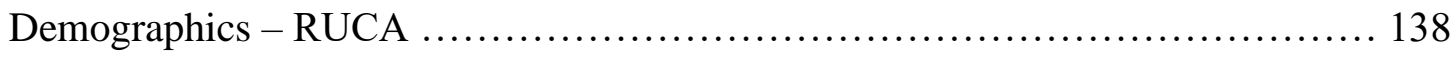

Demographics - Title I School ...................................... 139

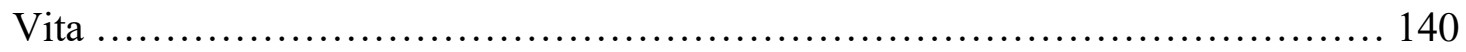




\title{
ANALYSIS OF BEST PRACTICE PROCEDURES TO PREVENT SUDDEN DEATH IN HIGH SCHOOL ATHLETICS: A REGIONAL ASSESSMENT.
}

\begin{abstract}
Objective: The analyze the adherence to best practice recommendations through the implementation of specific policies and procedures to prevent sudden death and identify barriers preventing implementation. Design and Setting: This is a mixed methods research design utilizing a survey and semi-structured interviews to provide data. This study examined secondary schools in District V of the NATA (Iowa, Kansas, Missouri, Nebraska, North Dakota, Oklahoma, South Dakota). Subjects: Participants were athletic administrators in secondary school athletic programs in the 7-state region. $(n=151)$ Measurements: Surveys were distributed and collected utilizing Qualtrics and results were analyzed using one-way ANOVAs. Interviews were transcribed and coded to identify commonality in the themes. Results: Significant difference existed in the availability of personnel when considering the urbanization classification and enrollment size of the school. Financial constraints and time availability severely impacted the implementation of best practice recommendations. Conclusions: Legislative policies regarding the implementation of best practices to prevent sudden death are needed to improve adherence and protect student athletes from serious life-threatening injuries and to protect the school from potential liability.
\end{abstract}


Section I

INTRODUCTION OF THE STUDY 


\section{Background}

The National Federation of High School Sports (NFHS) reports approximately 8 million student athletes participate in high school sports every year and that number is expected to grow in the future (NFHS, 2016). In contrast, according to data released by the National Collegiate Athletic Association (NCAA), only approximately 480,000 student athletes continue to compete at the collegiate level (NCAA,2017). This number continues to drop with less than $1 \%$ of high school athletes receiving a contract to play professionally (NCAA, 2017). Despite this low percentage, student athletes continue to dream of receiving a professional contract and the subsequent wealth that comes with professional contracts. This ambition is commonly shared by the parents of the children. It has been reported that approximately $26 \%$ of parents with kids in high school hope their child will play professionally, with an even higher number of those parents possessing that ambition in the lower socioeconomic groups (Kelto, 2015). Parents and children with unchecked ambition to play professionally can potentially heighten the risk of sport participation. Miles and Prasad (2016) describe this heightened risk through the utilization of the term, uninformed consent, which highlights that parents and students either ignore the risks of sports, or they simply fail to comprehend the potential harm that can arise during sports participation (Cournoyer, 2014). This naivety and lack of understanding of the risks of sports carries with it the potential for catastrophic events to occur.

One potential harm associated with participation in athletics among youth that is rapidly becoming a public health concern is the increased rate of sudden cardiac death. Sudden cardiac death among apparently healthy teenagers who are participating in 
athletics has been widely described in the literature in an effort to raise awareness of this phenomenon (Maron, Haas, Murphy, Ahluwalia \& Rutten-Ramos, 2014; Schmeid \& Borjesson, 2014). In the first six months of 2017, numerous deaths linked to participation in athletics were highlighted in news stories. This includes an 18-year-old freshman at Kent State University who died suddenly after collapsing on the field (Alexander, 2017), a Georgia teen who died suddenly after completing conditioning drills (Shapiro, 2017), a Kentucky teen who died after having a medical emergency during open gym activities (Spears, 2017), a Michigan teenager who died suddenly during offseason basketball tryouts (Herndon, 2017) and a Pennsylvania teen who died suddenly after playing in a hockey game (Bond, 2017).

Although the rates of sudden death among youth athletes are not reported consistently across the literature, rates have been reported to occur as often as one in 44,000 athletes per year in children and adolescents (Harmon, Asif, Klossner, \& Drezner, 2011) with many of these deaths occurring in high school athletes while participating in interscholastic athletics (Maron, Doerer, Haas, Tierney, \& Mueller, 2009). Despite the inconsistencies in literature, Maron et al (2009) describe the rate to be consistently around 1:40,000 - 80,000 in studies with better methodology and is more prevalent in the African American population. Other authors have detailed the role of age in increasing the risk, stating that the risk is higher in the younger population and decreases with age (Chandra, Bastiaenen, Papadakis, \& Sharma, 2013;Emery \& Kovacs, 2018).

As the numbers describe, the reality of this becoming a major health concern that requires immediate attention and intervention cannot be ignored. According to the Youth Sports Safety Alliance (n.d.) there have been over 40 deaths each year since 2008 during 
sports, with rates reported to be as high as 120 in a single year. While these numbers may prompt some individuals to consider sudden death in sports a rarity when compared to other conditions, student athletes in the United States have a significantly higher rate of injury and death when compared to non-athletic populations according to researchers who have addressed this issue (Casa et al, 2013; Chandra et al 2013).

It is commonly recognized that participation in sports carries an increased risk of injury, especially orthopedic injuries and concussions. Fletcher, McKenzie, and Comstock (2014) reported over 1.5 million visits to the emergency room over a five-year period from athletes as a direct result of participation in interscholastic sports. This information is further supported by Kerr et al (2015), who documented over half a million visits to the emergency department over a 3-year period. The rates at which athletes are sustaining sports injuries and having medical emergencies have signified a need for increased planning, improved medical care, and improved education for coaches on how to deal with an injury when it occurs, both life-threatening and non-lifethreatening.

As the participation in sports has increased, the attention to injury prevention and prevention of sudden death has become more prevalent. Numerous organizations have adopted recommendations addressing the need for improved care to student athletes in secondary schools. The National Athletic Trainers Association (NATA) (Casa et al., 2013), the American Medical Association (AMA) (1998), and the American Academy of Family Physicians (AAFP) (2012) have all advocated or published these recommendations. These recommendations include providing athletic trainers as part of the sports medicine staff in the schools, and the implementation of Emergency Action 
Plans (EAPs) to reduce the risk of sudden death and provide a mechanism to treat all injuries as they occur.

These recommendations are supported with legal precedents which have directly addressed the issue of improved care and the services that student-athletes are entitled to when participating in interscholastic activities. The courts have ruled that schools have a duty to protect the participant through emergency planning, implementation of appropriate policies, appropriate equipment being present, and training coaches and other staff in first aid (Beach, 2003; Greenfield, 2013). Two landmark cases, Gathers v Layola Marymount and Kleinkenecht v. Gettysburg College (Anderson, Courson, Kleiner, \& McLoda, 2002) further defined the duties owed to student athletes by the school and reiterated the need for training and emergency procedures to be implemented in a timely manner.

Despite these recommendations and legal precedents, the lack of certified athletic trainers (ATCs) in secondary schools is a widely documented issue, with approximately $50 \%$ of schools reporting some access to an athletic trainer, and an even lower percentage having full-time access to a medical provider (Pike, Pryor, Vandermark, Mazerolle, \& Casa, 2017). When there is no athletic trainer present, the coach, assistant coach, or another designated staff member is required to assume the role of the medical provider and facilitate the care for the injured athlete. The argument could be made that this action fails to address the planning component described in Kleinkenecht Gettysburg College and opens the school up to legal liability and negligence issues under the current law (Anderson et al, 2002). Authors have documented a lack of knowledge among coaches regarding injury prevention, injury recognition, first aid principles, and heat 
related illness (Ransone \& Dunn-Bennett, 1999; Valvovich Mcleod, Schwartz, \& Bay, 2007). Matthews and Waller (2016) also reported that coaches tend to act in an unethical manner regarding injuries, due to a lack of knowledge and training and not through purposeful acts. The disparities in knowledge are further described by Baron et al. (2009), who reported that only $5 \%$ of coaches received a passing score on a first aid assessment, and Schneider, Meeteer, Nolan, and Campbell (2017) who reported that only $33 \%$ of coaches possess current Cardiac Pulmonary Resuscitation (CPR) and First Aid (FA) certification in West Virginia.

Many states have recognized the disparities and potential liability risk and thus numerous efforts have been made to improve these issues regarding student safety and well-being while participating in sports. Lawmakers have recognized the need to address sudden cardiac events and have made efforts requiring states to include emergency action plans (EAPs) and have Automated External Defibrillators (AEDs) present at all sporting events and practices; however, this has not become a national requirement and funding for emergency equipment continues to be cited as a constraint (Buxton et al., 1995) prohibiting many schools from meeting these requirements (Johnson et al., 2017). Alternatively, in states that have implemented laws requiring AEDs to be accessible and EAPs to be written and present there has been a significant decrease in deaths from the sudden cardiac events and an increased rate of survival those individuals (Drezner, Rao, Heistand, Bloomingdale, \& Harmon, 2009).

Education of student athletes and coaches has also shown to have positive results in decreasing the injury rate and preparing those individuals for a potential event. Kerr et al (2015) found that an education program focusing on concussions was effective in 
reducing the number of injuries in American football. This was further demonstrated by Belski et al. (2018) who found that coaches' knowledge and confidence in nutrition issues facing athletes was significantly improved after a brief 20-minute nutrition education program embedded in their mandatory training. These results are similar to the findings of Kerr et al (2015) which found that educational interventions decreased injury rates in youth football when coaches were informed and educated on practice restrictions for youth sports.

The findings above demonstrating the decrease in significant injuries and/or death in athletes after simple policy implementations demonstrate the need to improve emergency preparedness in athletic programs across the United States.

\section{Statement of the Problem}

The underlying problem facing secondary school athletic programs is inadequate planning, training, equipment, and personnel to address medical emergencies arising from interscholastic athletic participation. While the risk of an athlete suffering a lifethreatening cardiac event may be relatively low when compared to the risk of orthopedic injuries; the impact sudden death has on the athlete, the family, and the community is significant and cannot be ignored. Numerous organizations, including the NATA, have advocated for increased medical care to be provided to secondary school athletic programs and these organizations have provided best practice recommendations (Courson et al., 2014). These recommendations include: having an ATC present at all sporting events, each school possessing a detailed emergency action plan that describes and delineates each person's responsibility in the event of an emergency, practicing and rehearsing the emergency action plan on a planned and regular basis, first aid and CPR 
training, and a working AED always present near the sporting activity (Courson et al., 2014). Despite these recommendations being published, there are still significant deficiencies in secondary school athletic programs regarding emergency preparedness. Compounding the lack of preparation is the fact that the National Federation of HighSchool Sports (NFHS) acts primarily as an advisory board and each state has different requirements dictating the measures each school should take to reduce the risk of injury. Injury in sports has always been regarded as an inevitable risk associated with athletic participation. These injury rates are widely reported and vary greatly in the literature in relation to gender, age, sporting activity, and level of competition (Powerll \& BarberFoss, 2000; Rechel, Yard, \& Comstock, 2008). The reporting of concussions, anterior cruciate ligament injuries, and ankle sprains in sports has brought increased attention to injury prevention principles and regulations regarding education on return to play criteria specific to concussions, yet sudden death has often been neglected due to the underestimated incidence and lack of reporting. While the exact rate of sudden death has some discrepancies, Meredith et al. (2013) identified the rates of sudden death in sports as one in seven adolescents in schools with a student population over 1,000 students (and 1 in 12 overall). While certain states that have implemented specific policies addressing emergency preparedness have seen a decrease in sudden death associated with sports, not all 50 states have adopted the same policies and no nationwide policy exists. This is further described by Lear, Hoang, and Zynaksi (2015), who reported a survival rate of $60 \%$ after the state implemented AED legislation. Despite these statistics, the lack of AEDs and trained medical staff to manage injuries continues to be a significant concern across the country. 
While the literature is abundant with information on best practices recommendations to improve health and safety of the student athletes, there is a scarcity in the extent to which schools meet the best practice recommendations provided by Casa et al. (2012) and the mitigating factors preventing the school from implementing those practices. One of the areas that has been researched is the presence of athletic trainers in public secondary schools (Pryor et al. 2015) and in private secondary schools (Pike, Pryor, Mazerolle, Stearns, \& Casa, 2016). This theme is consistent in the literature, recognizing the need for an athletic trainer or medical provider and the issues that can arise when a coach is required to take on the role of healthcare professional while coaching. Apart from the lack of knowledge in coaches described earlier, it has also been reported that many coaches will underestimate the seriousness of an injury (Barron et al., 2009; Ransone et al., 2009) and that many lack information on emergency action planning and fail to rehearse that plan on a regular and planned basis (Schneider et al., 2017).

Another aspect that deserves consideration is the discrepancies in healthcare provisions between schools with a larger enrollment and schools with a smaller enrollment coupled with the location of the school, rural, suburban, urban. It has been documented that schools in a rural community have fewer AEDs (Wasilko \& Lisle, 2013; Schneider et al., 2017) and those communities have a higher likelihood to suffer from cardiac events (Skinner \& Slifkin, 2007). This risk is further compounded with the increased distance of points of care, such as emergency rooms, and a lack of availability of medical services common in the rural community (Skinner \& Slifkin, 2007). 


\section{Purpose of the Study}

The purpose of this study is to examine the level to which secondary schools in the region (a) provide Athletic Trainers to athletic programs, (b) provide administrative support to the athletic programs in order to prevent injury or sudden death (i.e. policies and procedures in place to prevent issues from occurring and to deal with issues as they arise), and (c) make basic lifesaving equipment readily available if and when needed.

\section{Research Questions}

The research questions guiding this study are:

1. What differences exist between rural, large rural/micropolitan, and urban/metropolitan schools regarding personnel, administrative procedures and policies, and equipment available for their respective athletic programs?

2. What differences exist in the enrollment size of the secondary school regarding personnel, administrative procedures, and equipment available for their respective athletic programs?

3. What perceived barriers exist in secondary school athletic programs that prohibit the implementation of desired administrative policies and procedures, equipment, and providing personnel for their respective athletic programs?

4. What perceptions exist regarding the policies that are currently in place regarding health and safety for secondary school athletic programs? 


\section{Null Hypotheses}

The study tested the following null hypotheses:

$\mathrm{H}_{0} 1 \mathrm{a}$. There will be no differences between (a) rural, (b) large rural/micropolitan and (c) urban/metropolitan schools regarding qualified medical personnel available for their respective athletic programs.

$\mathrm{H}_{0} 1 \mathrm{~b}$. There will be no differences between (a) rural, (b) large rural/micropolitan, and (c) urban/metropolitan schools regarding administrative procedures and policies in place for their respective athletic programs.

$\mathrm{H}_{0} 1 \mathrm{c}$. There will be no differences between (a) rural, (b) large rural/micropolitan, and (c) urban/metropolitan schools regarding emergency equipment available for their respective athletic programs.

$\mathrm{H}_{0} 2 \mathrm{a}$. There will be no differences between schools of different enrollment levels regarding qualified medical personnel available for their respective athletic programs.

$\mathrm{H}_{0} 2 \mathrm{~b}$. There will be no differences between schools of different enrollment levels regarding administrative procedures and policies in place for their respective athletic programs.

$\mathrm{H}_{0} 2 \mathrm{c}$. There will no differences between schools of different enrollment levels regarding emergency equipment available for their respective athletic programs.

\section{Conceptual/Theoretical Framework}

This study will utilize the theory of negligence and liability regarding sports participation to establish the importance of secondary schools establishing and 
implementing effective policies and procedures regarding medical coverage and emergency preparedness for their interscholastic athletic programs. Negligence has been defined in the literature as the failure to exercise the care that an ordinarily prudent individual would exercise in similar situations (Posner, 1972). Given the definition, negligence has been identified as a potential legal charge that can be brought against a school or school district after an athlete sustains an injury as a result of athletic participation (Walker, 1994). The United States legal system allows for individuals to be compensated for any damages a complainant sustains due to a supervisor's negligence or misconduct. Keeton, William, Dobbs, Keeton, and Owen (1984) have further broken down the concept of negligence into four requirements that must be proven by the complainant to demonstrate negligence exists: (1) There must be a recognized duty of care present, (2) there must be a breach of the recognized duty, (3) damages must occur to the individual, and (4) there must be a causation between the injury and the breach of duty.

Although best practice recommendations exist detailing the expectations and procedures for dealing with emergency situations, often these recommendations are not met (Johnson et al., 2017; Rothemeier, Drezner, \& Harmon, 2007). The concern arises that without proper education and specific policies that are rehearsed on a regular basis, the school is potentially creating a situation where they are vulnerable for either misfeasance, the act of committing a wrongful act against an individual, or, nonfeasance, the failure to act when there is a legal duty to do so (Reider, 1993). Upon further examination of this definition of nonfeasance, it could be theorized that the failure to provide a safe environment for participants, proper training to all members of the 
athletics coaching staff, and a failure to adequately prepare for an emergency could all be considered a negligent act.

This theory is supported by the publication of "Fourteen Legal Duties of a Coach" which was published by the National Federation of High Schools (NFHS) and the National Interscholastic Athletic Administrator Association (NIAAA). The duties outlined in this document require: (1) A duty to plan, (2) a duty to supervise, (3) a duty to assess athletes readiness for practice and competition, (4) a duty to maintain safe playing conditions, (5) a duty to provide safe equipment, (6) a duty to instruct properly, (7) a duty to match athletes, (8) a duty to condition properly, (9) a duty to warn, (10) a duty to ensure that athletes are covered by insurance, (11) a duty to provide emergency care, (12) a duty to design a proper emergency response plan, (13) a duty to provide proper transportation, and (14) a duty to select, train, and supervise coaches.

The concept of negligence has been widely reported in the literature identifying numerous legal cases brought against coaches, schools, and administrators arising from injuries related to sports participation. Kleinknecht v. Gettysburg College and Gathers v. Loyola Marymount are two landmark cases which defined the concept of legal liability a school possesses at the university along with the expectation that the sponsoring institution ensures safety and well-being of all individuals participating in interscholastic sports. In the case of Kleinknecht v. Gettysburg College the court ruled that schools have a legal responsibility to provide safety to athletic participants under their care through the implementation of an emergency action plan and access to an automated external defibrillator (Casa et al., 2012). In the case of Gathers v. Loyola Marymount, the courts ruled that if proper training had been given to coaches, specifically training in AED, 
CPR, and First Aid, basketball player Hank Gathers would have been more likely to live through his sudden cardiac event (Casa et al., 2012).

Apart from the university level, the notion of negligence has been examined at the secondary school level where a variety of cases have been brought against school districts and coaches because of injuries sustained during athletic participation. A failure of the school system to provide the basic recommendations for risk management further demonstrates this risk of liability and potential cases of negligence arising in the court system. This is especially true when examining secondary school systems, as often the school system is seen to have custodial care of the individual, especially when they are a minor, increasing the expectation of care (Blanchard, 2012). This was first described in the case of Knight v. Jewett (1992) when the Supreme Court ruled that younger athletes are owed a higher standard of care. Despite this initial ruling, there have been inconsistent rulings in the court system regarding young athletes and liability cases brought against school districts and coaches with school districts prevailing approximately $78 \%$ of the time (Blanchard, 2012). However, legal liability and negligence laws vary from state to state, making it difficult to fully identify a universal standard for negligence to be brought against the school system.

\section{Design of the Study}

An explanatory sequential mixed methods design was utilized for this study. Creswell (2014) describes mixed method designs as an approach utilizing both quantitative and qualitative data to achieve a more robust and complex understanding of the problem being investigated. Specifically, in the explanatory sequential mixed methods design the researcher completes the quantitative portion of the data collection 
first and then follows up for further explanation with the qualitative data collection (Creswell, 2014)

Setting. The researcher identified secondary schools that offer interscholastic sports through their state athletic association in the following states: Missouri, Illinois, Kansas, Nebraska, Oklahoma, Iowa, North Dakota, and South Dakota. These states were identified as members of the National Athletic Trainers Association District V (Mid-America Region) (NATA, 2018). The selection of these states allowed a regional assessment of emergency preparedness in multiple schools to make comparisons between varying states and schools of different sizes and locations.

Participants: All secondary schools who offered interscholastic sports through their respective state athletic association in 2018 were identified and contacted to participate in this study $(N=2,470)$. This identification was done in conjunction with the Korey Stringer Institute at the University of Connecticut and the Athletic Training Location and Services (ATLAS) whom identified the contact information for all the public secondary schools in the United States. The athletic administrator was identified as the contact person for each of the public schools in the region. This was similar to previous studies, examining the level of medical care to secondary school athletic programs (Dewitt, Unruh, \& Seshardi, 2012; Schneider et al., 2017). Participants were informed they would not be compensated for participation in this study, however any participant was provided the opportunity to review the findings of this study. 


\section{Data Collection Tools.}

Quantitative A survey was distributed to all participants utilizing Qualtrics data collection software (Provo, Utah). This survey was designed to analyze the best practice recommendations regarding medical care for secondary school athletic programs as defined by Casa et al. (2013). The survey instrument was adopted from previous literature (Dewitt, Unruh, \& Seshardi, 2012; Schneider et al., 2017) and refined to address the specific recommendations described in the research questions, specifically to focus on medical personnel, facilities and equipment, and policies and procedures regarding emergency planning (See Appendix A). This instrument was further subdivided into five sections. Section 1 addressed demographic information on the school (i.e., population, ethnicity of school, socioeconomic status, location, and information regarding the participant). Section 2 further addressed the demographics of the interscholastic sports being offered on the campus, specifically addressing the number of sports and if the school offered interscholastic football as a competitive sport. Section 3 addressed the presence of policies and procedures addressing some of the best practice recommendations such as heat, lightning, and emergency planning. Section 4 addressed the presence of specific emergency equipment during athletic participation. Section 5 addressed the personnel who was responsible for the medical provisions of the athletic program. Sections $3-5$, which address the individual research questions, asked participants to respond to the statement utilizing a five-point Rating Scale with 1 representing always and 5 representing never.

Rural/Urban Classification Utilizing the survey instrument, each participant was asked to identify the postal code the school resides in. The postal code each 
participant provided was utilized to categorize the school into one of the three distinct categories: Metropolitan/urban, large rural/micropolitan, and small town/rural. This classification was standardized and completed utilizing the United States Department of Agriculture's Rural Urban Commuting Area (RUCA) codes. The RUCA codes were developed by the U.S. Department of Agriculture based on the 2010 census data and are utilized to categorize the distinct regions of the United States (USDA, 2019). The RUCA codes consider population density, urbanization, number of citizens commuting to a place of employment, and the demographics of the closest urban center to the postal code.

Each community postal code is assigned a number ranging from 1 to 10 ; with 1 representing a large metropolitan and urbanized area with a citizen flow remaining in the urbanized zone, and 10 representing an isolated rural community with the primary citizen flow outside of an urbanized area or small urban community. This study has grouped the participants into three groups utilizing the RUCA Codes to answer the research question. The groups consist of metropolitan/urban zones, large rural/micropolitan, and small town/rural groupings.

School Size Classification Each participant was asked to provide a range of the student enrollment at their school when completing the survey instrument. The instrument utilized a range of seven distinct enrollment classifications: a) less than 150 , b) $151-300$, c) $301-500$,d) $501-750$,e) $751-1,000$, f) 1,001-1,500, and g) greater than 1,500. This study re-classified the responses into four groups: a) small schools with an enrollment less than $150(n=24), b)$ small schools with an enrollment between 151 $300(n=46), c)$ medium sized schools with an enrollment from $301-750(n=37)$, and d) large schools with an enrollment greater than 750 students $(n=42)$. 
Quantitative Data Analysis Quantitative data were collected from the survey instrument and grouped according to the underlying theme of the research question being investigated, policies and procedures, emergency equipment, and medical personnel available. The average responses from each of the items on the instrument were compared based on the research questions with the independent variables of urbanization classification, school enrollment size, and state utilized to make comparisons between the groups.

\section{Qualitative}

Once the initial quantitative data collection was completed the researcher conducted semi-structured interviews to gather further information regarding the athletic directors' perceptions of the emergency preparedness policies in place at their respective schools.

\section{Data Collection}

Five athletic directors were selected from those individuals who agreed to participate in the follow-up qualitative portion of the research design. These individuals were all male and all participants had been in their current position for over 10 years. These participants were sent an e-mail invitation to participate in the qualitative component of this study. The e-mail invitation included a personalized letter, information about the study, and contact information for the researcher. Upon verification for continuation in the study, participants were interviewed over a phone conversation and recorded utilizing a voice recorder at a time that was convenient and agreed upon between the researcher and participant. A cross-section of athletic directors 
from various states was the goal of this research however, due to the anonymous nature of the survey instrument only individuals who volunteered were selected.

\section{Interview Protocol}

Each interview followed a semi-structured interview protocol (Appendix 2) completed over the phone and lasted approximately 20-30 minutes. Additional prompts were utilized to solicit more information regarding the level of implementation of the emergency policies in place at their respective school. The interview protocol consisted of five initial questions and sub-prompts to guide the conversation after the initial answer. In questions regarding the current policies in place for students and coaches, participants were asked an open-ended question, "If resources were available to implement more policies and training, what would you implement?" These questions were designed to elicit a more detailed response and to assess the desire for improvement of the current policies in place.

\section{Data Analysis}

Transcripts of the five interviews were analyzed by the primary researcher utilizing an inductive reasoning approach. Merriam and Tisdell (2015) describe inductive reasoning as an approach to search for patterns through a result of observations, starting with a broad theme and deducing subthemes as saturation is achieved. The interviews were coded and identified themes focused on the most common policies or strategies in place that specific participants had taken to facilitate emergency planning in their respective schools. This process was repeated through each of the participants, at which point data saturation occurred. In addition to the prominent themes, some common sub- 
themes were developed. Upon completion of identifying the themes, the themes and quotes were peer-reviewed to check for consistency.

\section{Significance of the Study}

This study will look to fill the gap in the literature regarding emergency preparedness in schools across the Midwest region of the United States by identifying deficiencies in the best practice recommendations in secondary school athletic programs. The National Federation of State High School Associations estimates there are over 8 million athletes participating in sponsored interscholastic activities on a yearly basis. Increasing the knowledge and awareness of emergency preparedness at the secondary school level can encourage the development of improved policies and procedures regarding health and safety while participating in secondary school athletic programs.

Specific attention should be given to the disparities between urbanized communities, large rural/micropolitan communities, and small town/rural communities. Previous literature has directly linked the level of healthcare a person receives and the preventative services they seek to the socio-economic status of the induvial (Lynch, Smith, Kaplan, \& House, 2000) and the proximity to a large urbanized center (Reschovsky \& Staiti, 2005). This is further described specifically relating to secondary school athletic programs by Long, Scifers, and Ailbacher (2017), who identified that more affluent school districts were more likely to employ athletic trainers when compared to schools in a lower socio-economic neighborhood. While this study does not directly assess the access to health services provided to the community, the lack of preventative and diagnostic healthcare provided by a licensed athletic trainer could potentially increase the chance of a sudden cardiac death in sports by eliminating one 
more access point for a patient to seek medical care (Batra \& Hohn, 2003; Skinner \& Skiffin, 2007).

The implementation of specific policies designed to require schools to implement the best practice recommendations specific to policies and procedures, coaching education and professional development, and adequate provision of medical personnel and services is necessary to reduce the risk of injury to the students participating. The argument could also be made that the implementation and adherence to these best practice recommendations will reduce the overall risk of liability and decrease the potential for a school district or coach being found negligent in the case of an injury sustained during participation.

\section{Summary}

Overall, the importance of implementing a comprehensive plan to deal with emergencies is essential to reducing the risk of sudden cardiac death and injuries in young athletes. This public health concern has recently been receiving more attention, with national news media discussing the stories and providing the information to a wider audience. While it is understandable that economic factors may preclude a school district or individual school from hiring an athletic trainer on a full-time basis to provide care for the competitive athletes, other preventative and preparatory methods should be examined. 


\section{Definition of Key Terms}

Athletic Training: Athletic training is recognized as an allied health care profession by the American Medical Association, Health Resource Services, and the Department of Health and Human Services and is responsible for the examination, diagnosis, treatment, and rehabilitation of injuries and medical conditions. (NATA, 2019)

National Athletic Trainers Association (NATA): The NATA is the national organization representing the profession of athletic training with the primary focus of promoting the profession and protecting the members. (NATA, 2019)

National Federation of State High School Associations (NFHS): The NFHS is the national organization overseeing interscholastic athletic competition. The mission of the NFHS is to emphasize health and safety and provide administrative support to member secondary schools.

Sudden Cardiac Death (SCD): Sudden cardiac death is defined as a sudden unexpected death, within one hour, stemming from a previously unknown cardiovascular abnormality (Maron, Goman, \& Aeppli, 1998). 


\section{References}

Alexander, E. (2017, June 16). Kent State football player Tyler Henitz primary cause of death ruled hyperthermia. Retrieved from

http://www.cleveland.com/sports/college/index.ssf.2014/06/hypothermia_and_foo $\underline{\text { tball_a_dan.html }}$

Andersen, J. C., Courson, R. W., Kleiner, D. M., \& McLoda, T. A. (2002). National Athletic Trainers' Association position statement: emergency planning in athletics. Journal of Athletic Training, 37(1), 99.

Barron, M.J., Powell, J. W., Weing, M. E., Nogle, S. E., \& Branta, C. F. (2009). First aid and injury prevention knowledge of youth basketball, football, and soccer coaches. International Journal of Coaching Science. 3(1). 55-67.

Batra, A. S., Hohn, A. R. (2003). Consultation with the specialist populations, syncope, and sudden cardiac death in children: who's at risk? Pediatrics in Review, 24(8),269-275.

Beach, A. F. (2003). Dying to play: School liability and immunity for injuries that occur as a result of school-sponsored athletic events. Sports Lawyers Journal 10, 275294.

Blanchard, J. (2012). A comparative study of K-12 and higher education sport related negligence litigation. Journal for the Study of Sports and Athletes in Education, 6(2), 201-220.

Bonza, J. E., Fields, S. K., Yard, E. E., \& Dawn Comstock, R. (2009). Shoulder injuries among United States high school athletes during the 2005-2006 and 2006-2007 school years. Journal of athletic training, 44(1), 76-83. 
Buxton, B. P., Okasaki, E. M., Ho, K. W., McCarthy, M. R. (1995). Legislative funding of athletic training positions in public secondary schools. Journal of Athletic Training, 30(2), 115.

Cournoyer, J., \& Tripp, B. L. (2014) Concussion knowledge in high school football players. Journal of Athletic Training, 49(5), 654-658.

Casa, D. J., Almquist, J., Anderson, S. A., Baker, L., Bergeron, M. F., Biagioli, B., ... Valentine, V. (2013). The inter-association task force for preventing sudden death in secondary school athletic programs: Best practice recommendations. Journal of Athletic Training, 48 (4), 546-553.

Casa, D. J., Anderson, S. A., Baker, L., Bennett, S., Bergeron, M. F., Connollly, D., ... \& Fleck, S. (2015). The inter-association task force for preventing sudden death in collegiate conditioning sessions: best practice recommendations. Journal of Athletic Training, 48(4), 546-553.

Casa, D. J., Guskiewicz, K. M., Anderson, S. A., Courson, R. W., Heck, J. F., Jimenez, C. C., ... Walsh, K. M. (2012). National Athletic Trainers Association position statement: preventing sudden death in sports. Journal of Athletic Training, 47(1), 96-118.

Courson, R., Goldenberg, M., Adams, K. G., Anderson, S. A., Colgatell, B., Cooper, L., ... Turbak, G. (2014). Inter-association consensus statement on best practices for sports medicine management for secondary schools and colleges. Journal of Athletic Training, 49(1). 128-137.

Dewitt, T. L., Unruh, S. A., \& Seshadri, S. (2012). The level of medical services and secondary school aged athletes. Journal of Athletic Training, 47(1) 91-95. 
Drezner, J. A., Rao, A. L., Heistand, J., Bloomingdale, M. K. \& Harmon, K. G. (2009). Effectiveness of emergency response planning for sudden cardiac arrest in United States high schools with automated external defibrillators. Circulation, 120(6), $518-525$.

Fletcher, E. N., McKenzie, L. B., \& Comstock, R. D. (2014) Epidemiological comparison of injured high school basketball athletes reporting to emergency departments and the athletic training setting. Journal of Athletic Training 49(3), 381-388.

Greenfield, S. (2013). Law's impact on youth sport: should coaches be 'concerned about litigation'? Sports Coaching Review 2(2) 114-123.

Guskiewicz, K. M., Weaver, N. L., Padua, D. A., \& Garrett, W. E. (2000). Epidemiology of concussion in collegiate and high school football players. The American journal of sports medicine, 28(5), 643-650.

Harmon, K. G., Asif, I. M., Klossner, D., Drezner, J. A. (2011). Incidence of sudden cardiac death in National Collegiate Athletic Association athletes. Circulation, $123,1594-1600$.

Harmon, K. G., Drezner, J. A., Wilson, M. G. \& Sharma (2014). Incidence of sudden cardiac death in athletes: a state of the art review. British Journal of Sports Medicine, doi doi:10.1136/bjsports-2014-093872

Herndon, D. (2017, March 21). School mourns as Lincoln Park sophomore dies during basketball tryout. News Harold. Retrieved from http://www.thenewsherald.com/news/school-mourns-as-lincoln-park-sophomoredies-during-basketball-tryout/article_cb062f02-0e74-11e7-afad0740425baa35.html 
Johnson, S. T., Norcross, M. F., Bovbjerg, V. E., Hoffman, M. A., Chang, E. \& Koester, M. C., (2017). Sports-related emergency preparedness in Oregon high schools. Sports Health, 9(2), 181-184.

Keeton, P. W., Dobbs, W. L., Keeton, R. E., Owen, D. G. (1984). Prosser and Keeton on the law of torts, USA: West Pub Co.

Kelto, A. (2015, September 4). How likely is it, really, that your athletic kid will turn pro? NPR. Retrieved from http://www.npr.org/sections/healthshots/2015/09/04/432795481/how-likely-is-it-really-that-your-athletic-kid-will$\underline{\text { turn-pro }}$

Kerr, Z. Y., Dompier, T. P., Dalton, S. L., Miller, S. J., Hayden, R., \& Marshall, S. W. (2015). Methods and descriptive epidemiology of services provided by athletic trainers in high schools: the National Athletic Treatment, Injury and outcomes Network study. Journal of Athletic Training, 50(12), 1310-1318.

Lear, A., Hoang, M., \& Zyzanski, S. J. (2015). Preventing sudden cardiac death: automated external defibrillators in Ohio High Schools. Journal of Athletic Training 50(10), 1054-1058.

Long, A., Scifers, J. R., Eilbacher, C. (2017). How do economic variables predict access to athletic training services? Athletic Training and Sports Health Care, 9(2), 6470.

Lynch, J., Smith G.D., Harper, S. A., Hillemeier, M., Ross, N., Kaplan, G. A., \& Wolfson, M. (2004). Is income inequality a determinant of population health? Part 1. A systematic review. The Milbank Quarterly, 82(1) 5-99. 
Marar, M., McIlvain, N. M., Fields, S. K., \& Comstock, R. D. (2012). Epidemiology of concussions among United States high school athletes in 20 sports. The American journal of sports medicine, 40(4), 747-755.

Maron, B. J., Doerer, J. J., Haas, T. S., Tierney, D.M., \& Mueller, F. O. (2009). Sudden deaths in young competitive athletes: Analysis of 1866 deaths in the United States, 1980-2006. Circulation, 119(8), 1085-1092.

Maron, B. J., Haas, T. S., Murphy, C. J., Ahluwalia, A., \& Rutten-Ramos, S. (2014). Incidence and causes of sudden death in US college athletes. Journal of the American College of Cardiology, 63(16), 1636-1643.

Matthews, T. J., \& Waller, L. (2016). Coaches and the law: a study of the training of coaches in the United States. Mediterranean Journal of Social Sciences 7(1), 475479.

McCrea, M., Hammeke, T., Olsen, G., Leo, P., \& Guskiewicz, K. (2004). Unreported concussion in high school football players: implications for prevention. Clinical Journal of Sport Medicine, 14(1), 13-17.

Meredith, M. L., Watson, A. M., Gregory, A., Givens, T. G., Abramo, T. J., \& Kannankeril, P. J. (2013). Sudden cardiac arrests, automated external defibrillators, and medical response plans in Tennessee high schools. Pediatric Emergency Care 29(3). 352-356.

Miles, S. H., \& Prasad, S. (2016). Medical Ethics and School Football. The American Journal of Bioethics, 16, 6-10. doi: 10.1080/15265161.2016.1128751

NATA. (n.d.) Retrieved from http://www.nata.org 
Pike, A., Pryor, R. R., Mazerolle, S. M., Stearns, R. L., \& Casa, D. J. (2016). Athletic trainer services in US private secondary schools. Journal of Athletic Training 51(9), 717-726.

Pike, A., Pryor, R. R., Vandermark, L. W., Mazerolle, S. M., \& Casa, D. J. (2017). Athletic trainer services in public and private secondary schools. Journal of Athletic Training 52(1), 5-11.

Pryor, R. R., Casa, D. J., Vandermark, L. W., Stearns, R. L., Attanasio, S. M., Fontaine, G. J., Wafer, A. M. (2015). Athletic training services in public secondary schools: A benchmark study. Journal of Athletic Training 50(2), 156-162.

Powell, J. W., \& Barber-Foss, K. D. (2000). Sex-related injury patterns among selected high school sports. The American Journal of Sports Medicine, 28(3), 385-391.

Ransone, J., \& Dunn-Bennett, L.R. (1999). Assessment of first-aid knowledge and decision making of high school athletic coaches. Journal of Athletic Training. 34(3), 267-271.

Rechel, J. A., Yard, E. E., \& Comstock, R. D. (2008) An epidemiologic comparison of high school sports injuries sustained in practice and competition. Journal of Athletic Training, 43(2), 197-204.

Rieder, R. W., \& Woodward Jr, W. B. (1993). University liability for sports injuries. NASPA Journal, 31(1), 56-63.

Rothmier, J. D., Drezner, J. A., \& Harmon, K. G. (2007). Automated external defibrillators in Washington state schools. British Journal of Sports Medicine, 41(5), 301-305. 
Schmied, C., \& Borjesson, M. (2014). Sudden cardiac death in athletes. Journal of internal medicine, 275(2), 93-103.

Schneider, K. R., Meeteer, W., Nolan, J. A., \& Campbell, H. D. (2017). Health care in high school athletics in West Virginia. Rural and Remote Health. 17 (3879).

Skinner, A. C., \& Slifkin, R. T. (2007). Rural/urban differences in barriers to and burden of care for children with special health needs. The Journal of Rural Health, 23(2), $150-157$.

Swenson, D. M., Collins, C. L., Best, T. M., Flanigan, D. C., Fields, S. K. \& Comstock, R. D., (2013). Epidemiology of knee injuries among US high schools athletes 2005/2006-2010/11. Medicine and Science in sports and exercise, 45(3), 462.

Tjong, V. K., Murnaghan, M. L., Nyhof-Young, J. M., \& Ogilvie-Harris, D. J. (2014). A qualitative investigation of the decision to return to sport after anterior cruciate ligament reconstruction: to play or not to play. The American journal of sports medicine, 42(2), 336-342.

Valovich McLeod, T. C., Schwartz, C., \& Bay, C. (2007). Sport related concussion misunderstanding among youth coaches. Clinical Journal of Sports Medicine. 17(2), 140-142.

Wasilko, S. M., \& Lisle, D. K. (2013) Automated external defibrillators and emergency planning for sudden cardiac arrest in Vermont high schools: a rural states perspective. Sports Health, 5(6), 548-552. 
Section II:

Practitioner Setting for the Study 


\section{Section II:}

\section{Practitioner Setting for the Study}

The National Federation of High School Associations (NFHS) was founded in 1923 as the National Federation of State High School Athletic Associations (NFHS, 2017). The original organization was composed of members from the states of Iowa, Illinois, Wisconsin, Michigan and Indiana. The stated mission of the original five-state body was to provide sponsorship to high school athletics and create and establish norms and develop consistent policies and procedures governing eligibility and safety of student athletes (NFHS, 2017). This organization has continued to evolve since 1923 and has since developed more rules governing competition, administrative guidelines, and worked to develop initiatives specific to health and safety. As of 1969 all 50 states and the District of Columbia have representation in the organization (NFHS, 2018). The NFHS has also expanded to include representation of all interscholastic competitive activities such as the performing arts, debate teams, and others. Upon the inclusion of these other activities in the 1970s, the organization changed its name to the current National Federation of High School Associations eliminating the word "athletic" from the title to provide a better reflection of the groups encompassed in the organization (NFHS, 2017).

According to the NFHS member handbook (2017), the organizational leadership of the NFHS is composed of a 12-member board of directors and a national council. The Board of Directors is made up of eight members, one from each of the eight identified regions in the United States and four at-large members elected by the National Council. The National Council is comprised of a representative from each high school state 
association, providing equal representations from each of the 50 member states and the District of Columbia. The council functions as the sole legislative body of the NFHS and possesses the power to enact legislation, establish by-laws, and amend the body's constitution.

The NFHS has also established a mission statement published on their website which reads:

The organization serves its members by providing leadership for the administration of education-based high school athletics and activities through the writing of playing rules that emphasize health and safety, educational programs that develop leaders, and administrative support to increase opportunities and promote sponsorship (NFHS, 2017).

The function of the NFHS has primarily been to establish rules regarding participation in activities and the rules governing the sport and interscholastic offerings, however beginning in 2001the NFHS published a Sports Medicine Handbook. This handbook was designed to provide policies regarding the healthcare students receive while participating in sponsored activities and specifically minimize the risk to the athletic population. This publication came in response to a safety initiative regarding the use of anabolic steroids in athletes and weight loss management policies affecting sports with very specific weight restrictions, such as gymnastics and wrestling. The NFHS has since enhanced their Sports Medicine Handbook and established more safety initiatives for high school coaches and athletic administrators such as the online education program "Concussion in Sports," which was launched in 2010 (NFHS, 2017). 
In addition to the publication of the Sports Medicine Handbook, the NFHS has also created a Sports Medicine Advisory Committee (SMAC) with a stated mission to "Provide information, vision, and guidance to the National Federation of State High School Associations while emphasizing the health and safety of students participating in interscholastic sports and activities (NFHS, 2018). The SMAC has diligently worked to provide a safe environment and implement improved health related safety initiatives including providing position statements, analyzing injury reporting data, and proving a sports medicine handbook through their website. They have also worked to increase the safety by requesting that each state develop a state-wide Sports Medicine Advisory Committee that will work with individual school districts and athletic conferences to develop to develop improved sports medicine policies. As of 2018, the NFHS states that 49 states and the District of Columbia all have a SMAC; the only exception is the state of Michigan.

The SMAC also provides information and recommendations to the membership, the board of directors, and the other stakeholders regarding the current sports medicine issues in the form of position statements. There are currently 12 different position statements published providing guidance on a variety of issues including weather-related concerns, concussions, headgear, and anabolic steroid use (NFHS, 2018). However, these position statements are considered advisory in nature and are not considered to be a rule that directs practice among athletic departments. Despite the fact multiple position statements are published and distributed, the lack of administrative authority to enact and enforce these policies is a significant barrier facing the organization. 


\section{References}

NFHS (2017). Sports Medicine. Retrieved from https://www.nfhs.org/resources/sportsmedicine/

NFHS (2016). Participation Statistics. Retrieved from

http://www.nfhs.org/Participation- Statistics/ParticipationStatistics/ 
Section III:

Scholarly Review of Literature 
Section III:

Scholarly Review of Literature

\section{Introduction}

Participation in secondary school athletics has consistently risen over the last decade, with an estimated 8 million registered athletes participating in high school sports during the 2014-2015 academic year (NFHS, 2016). As participation numbers have increased in high school activities, the risk of these students sustaining an injury during participation and seeking medical care of athletic-related injuries has increased proportionally (Swenson et al., 2013).

\section{Epidemiology Rates in Secondary School Athletics}

Numerous authors have detailed the epidemiology rates of injuries associated with participation in interscholastic sports. Fletcher et al. (2014) reported over 1.5 million basketball players reported to the emergency room over a five-year period due to injuries directly associated with participating in the sport. This was further documented by Kerr et al. (2015), in which it was reported that 557,381 injured athletes visited an emergency room during a three-year period stemming from an injury sustained during athletic participation. Attempts have been made to further delineate the injuries student athletes sustain into specific categories detailing the type and extent of the injury. Authors have identified the most commonly reported injuries involve concussions and orthopedic injuries.

Injuries to the brain (concussions) have been widely researched across a variety of sports. It is estimated that there are over 300,000 sports-related concussions occurring on a yearly basis (Marar, McIlvain, \& Fields, 2012) with a 62\% increase in emergency room 
visits for concussions from $2001-2009$ (Broglio et al., 2014). Authors have agreed that a majority of these concussive injuries occurred in football despite the significant efforts to make football safer through enhanced equipment and training (Guskiewicz et al., 2000); however, women's soccer, wrestling, and basketball also had higher rates of concussions when compared to other competitive sports (Marar et al., 2012). Although these authors have examined epidemiology rates of concussions, perhaps the more concerning information lies in athletes who fail to report the concussion to the coach or medical provider. McRea, Hammeke, Olsen, Leo, and Guskiewicz (2004) reported that under $50 \%$ of athletes reported concussion symptoms to the coach or athletic trainer during practices and games.

While head injuries may receive more media attention and an increased focus on prevention, orthopedic injuries have commonly been identified and accepted as an inherent risk of sports participation. Orthopedic injuries sustained during participation in sport is the most prominent reason for emergency room visits in athletes (Fletcher et al., 2004). Numerous authors have attempted to provide injury rates specific to sports, gender, age, and anatomical region of the body. Swenson et al. (2014) reported an incidence of over 5,000 knee injuries in a five-year period, with a majority occurring during practice. The authors further identified female sports as a higher risk factor for knee injuries when compared to the equivalent male counterpart. Injuries to the knee are especially significant, as many individuals who suffer an injury, specifically to the anterior cruciate ligament (ACL), do not return to participation (Tjong, Murnaghan, Nyhof-Young, \& Ogilbie-Harris, 2014) and the cost of these surgeries can place a significant financial burden on the individual's family (Ingram, Fields, Yard, \& 
Comstock, 2008). Bonza, Fields, Yard, and Comstock (2009) have also provided similar information regarding injuries to the shoulder among high school athletes, reporting that an estimated 232,000 shoulder injuries will occur nationwide in a 3-year period.

While orthopedic injuries and concussions are the most commonly reported injuries associated with sports, a significant number of fatalities associated with participation in sports have also been reported. Sudden cardiac death (SCD) has been defined as an unexpected death within one hour of the onset of symptoms (Semsarian, Sweeting, \& Ackerman, 2015). While numerous causes of SCD exist, authors have classified these into three distinct categories: structural, electrical, and acquired (Chandra et al., 2013). Chandra et a. (2013) defined structural abnormalities as inherited or adapted irregularities affecting the internal organ's structure, electrical abnormalities as affecting the heart's ability to function properly at the neurological level, and acquired abnormalities as anomalies arising from an outside force or blow to the body.

Perhaps, the most concerning issue associated with this phenomenon is the fact that the structural abnormalities are normally underlying causes that are not identified until an issue arises (Maron, Haas, Ahluwalia, Murphy, \& Garberich, 2016). It is generally understood that participation in competitive sports increases the risk of SCD in adolescents (Corrado \& Zorzi, 2017). This phenomenon of SCD is the leading cause of death in seemingly healthy young individuals (Harmon, Drezner, Wilson, \& Sharma, 2014). This creates a major challenge for medical providers, school systems, and coaches because the actual defect and the cause of this phenomenon is not identified until after a cardiac event or fatality occurs (Corrado et al., 2013). 
Authors have struggled to identify a precise number to describe the prevalence and rates of sudden death in young athletes. The literature has reported numbers ranging from one in 500 to one in 3,000 in other populations (Semarsian et al., 2015). These inconsistencies and wide ranges arise from the lack of a common reporting procedure and lack of a national database that tracks these events (Baron, Murphy, Haas, Ahluwalia, \& Garberich, 2014). Despite the absence of a national database to track and report actual rates, an analysis completed by Boden, Breit, and Beachler (2013) reported there to be a prevalence of approximately 12 fatalities per year in American football.

Authors have sought to determine the primary cause of this condition and have identified hypertrophic cardiomyopathy (HCM), or an abnormally enlarged and muscular left ventricle of the heart, as one of the primary risk factors and contributors to sudden death in adolescents (Semsarian et al., 2015). Maron et al. (2016) reported that HCM contributed to over $39 \%$ of the sudden deaths in the athletic population. This information is even more alarming after it was reported that $\mathrm{HCM}$ has been identified in approximately 1 in every 200 individuals (Chandra, Bastiaenen, Papadakis, \& Sharma, 2013), and is statistically more significant to occur in African American males (Maron et al., 2003). In contrast, Maron et al. (2016) identified the leading cause of death in female athletes to be coronary artery abnormalities, accounting for approximately one-third of the deaths in this population.

Sickle Cell Trait (SCT) has also been identified as a potential risk factor for sudden death in the athletic population. SCT is a genetic disorder affecting the hemoglobin in red blood cells, effectively limiting the ability of the red blood cells to carry oxygen to other parts of the body (Lonergan, Cline, \& Abbondanzo, 2001). SCT is 
also more prevalent in the African American population with approximately $8 \%$ of the identified population carrying the trait (Harris, Haas, Eichner, \& Maron, 2012).

However, it is important to inform the population that this is also prevalent in individuals who have a Mediterranean ancestry and can be carried in other ethnic ancestries (Harris et al., 2012). This pathology has been identified as the cause of death in approximately $5 \%$ of athletic-related deaths (Harmon, Drezner, Klossner, \& Asif, 2012) and was further supported by Harris et al. (2012), who identified SCT as the cause of death in 1 in 14 football-related deaths. Despite the prevalence of this condition and the dangers and potential risks associated with athletics, the individual is permitted to participate in sports and recommendations are provided to prevent a sickle cell attack such as avoiding exercise in high heat environments and high intensity activities (Pretzlaff, 2002).

\section{Best Practice Recommendations}

In response to the increased injury rate coupled with the increased attention to sudden death in athletics, the increased reporting of life-threatening conditions, and the substantial risk of athletic participation, numerous medical organizations including the National Athletic Trainers Association (NATA), the American Academy of Family Physicians (AAFP), and the American Medical Association have published position statements regarding the appropriate level of healthcare for high school sports addressing the need for a medical provider (Almquist et al., 2008). These inter-association consensus statements and position statements have detailed specific policies and provided best practice recommendations for all levels of sport competition addressing a wide variety of health-related concerns. These recommendations and policy statements have been provided to reduce legal liability to the school district, coaches, and institutions as 
well as to provide cost-effective and reasonable policies to prevent the risk of serious injury to the athlete (Almquist et al., 2008).

Casa et al., (2012) published a statement outlining the best practices titled: "National Athletic Trainers Position Statement: Preventing Sudden Death in Sports" in an effort to provide recommendations to schools and healthcare providers on the leading causes of sudden death including SCT, heat-related injuries, sudden cardiac arrest, and head injuries. One major component of this position statement is the inclusion of an emergency action plan (EAP). Andersen et al., (2002) published a position statement regarding emergency action planning which detailed the specific components that should be outlined and included in every emergency plan for athletics. One specific recommendation encourages organizations to rehearse and educate all individuals involved in the EAP on an annual basis at minimum. Positive outcomes and correlations regarding emergency care in schools have been reported in those organizations that implemented the EAP programming and also rehearsed those components on a planned and regular basis with members of the team (Drezner et al., 2009). Although many schools in the United States are compliant with providing an emergency action plan of incidents during the traditional school day (Olympia, Wan, \& Avner, 2005), the compliance of the EAP for athletic-related events and the rehearsal of this plan tends to be lacking in the policy and procedures manuals for secondary schools (Olympia, Dixon, Brady, \& Avner, 2007). These authors demonstrate the need for an athletic-based emergency action plan to be implemented and rehearsed with all members of the athletic department staff on a regular basis. 
Apart from emergency action planning, further position statements have been developed to address other aspects of preventative care for secondary school athletic programs. Casa et al., (2015) published a position statement addressing environmental concerns titled "National Athletic Trainers' Position Statement: Exertional Heat Illness." This position statement was produced to address the need for proper procedures and education to prevent death from heat-related illness through the provision of a 48statement document to assist the coach and medical provider in managing environmentally-related concerns in the athlete. These recommendation regarding heat illness have been further expanded by providing acclimatization guidelines for athletes participating in high heat environments (Casa et al., 2009). These guidelines have been adopted by the National Collegiate Athletic Association (NCAA) and the National Federation of High Schools (NFHS) and implemented in their respective organizations. These guidelines specifically target the acclimatization policies for the athlete when beginning participation in high-heat environments, which is common during the preseason football season. These guidelines consist of a 14-day protocol detailing the amount of time that can be spent in practice, the personal protective equipment and clothing that can be worn during practice, the number of practices that are permitted daily, the amount and duration of rest periods between each sponsored event, as well as nutrition and hydration recommendations (Casa et al., 2009). Despite these recommendations being published and adopted by the national organization, many programs across the United States still fail to comply with all 17 guidelines, with a majority only complying with 10 of the guidelines, or less than $60 \%$ (Kerr, Marshall, Comstock, \& Casa, 2014). 
Authors have also sought to provide recommendations regarding best practices for treating and managing head injuries or concussions (Broglio et al., 2014; Harmon et al., 2013; McCrory et al., 2013). In addition, the Centers for Disease Control has also initiated programs to educate coaches and athletic staff members on the seriousness of head injuries as well as the signs and symptoms and proper identification of concussions (Couvassin, Elbin, \& Sarimento, 2012). These best practice recommendations outlined in the statements are delineated into the following categories: education and prevention, documentation and legal aspects, evaluation and return to play, and other considerations (Broglio et al., 2014). The significant number of concussions among athletes combined with these published best practice recommendations have inspired many states to draft initial legislative efforts regarding return to play after a concussion, appropriate treatment of concussions, and education of the parents, coaches, and athletes regarding signs and symptoms of head injuries (Tomei, Doe, Pretigiacomo, \& Ghandi, 2012). Although concussion education is encouraged in all states that have passed legislation, not every state mandates or requires that all coaches receive any formal training or education on these injuries (Tomei et al., 2012).

\section{Legislation Regarding Injuries}

\section{Implementation of Best Practices}

Coaches and other athletic staff members are expected to have a wide range of knowledge regarding their respective sport as their performance is commonly evaluated in wins and losses (Hadley, Poitras, Ruggiero, \& Knowles, 2000). However, under the current climate in sports, coaches are also expected to have an in-depth knowledge of health-related behaviors, dealing with injuries, managing mental health, and establishing 
return to play criteria and decisions, especially when no athletic trainer or other healthcare provider is present (Clover \& Wall, 2010).

Despite the legal requirement of many states to provide education regarding concussions, along with the best practice recommendations provided by McCrory et al. (2013), coaches, parents, and students still have limited knowledge regarding head injuries. This lack of knowledge is demonstrated by Shenouda, Hendrickson, Davenport, Barber, and Bell (2012), who reported that gaps in knowledge still existed after concussion education legislation was passed in Washington, with many respondents unable to accurately describe the signs and symptoms of concussions. Students have also been found to underreport concussions due to influences from parents and coaches, specifically in male athletes (Cusimano et al., 2017).

This lack of knowledge was also highlighted regarding one of the other best practice recommendations mentioned above (Casa et al., 2012) and reiterated by the Korey Stringer Institute at the University of Connecticut (2017), which encourages coaches to be trained in CPR and First Aid. However, Barron et al. (2009) found that only $5 \%$ of coaches obtained a passing score on a first aid assessment despite being trained in the content. This finding was further supported by Schneider, Meeteer, Nolan, and Campbell (2017), who reported that less than 33\% of schools in West Virginia required coaches to have current CPR certification.

Another recommendation that has risen from the inter-association task forces regarding best practices in secondary school athletic programs states that an athletic trainer should be present and accessible at all practices and competitive events to provide an appropriate level of health care to the student athlete (Casa et al., 2007). Authors have 
recognized the benefits athletic trainers provide to athletic programs by providing immediate care to an injured athlete (Kerr et al., 2015), increasing knowledge regarding concussions to both parents and students (Wallace, Covassin, Nogle, Gould, \& Kovan, 2017), and an increase in injury reporting (Yard, Collins, \& Comstock, 2009).

Although an argument exists that athletic training services have improved when compared to previous data in the literature, the current data reporting does not support that conclusion. Lyznicki et al. (1999) reported that approximately $35 \%$ of secondary schools utilized the services of an athletic trainer compared to Pryor et al. (2015) who reported 16 years later that only $37 \%$ of public schools in the United States had full-time access to an athletic trainer at all sporting events. These data signify approximately a $2 \%$ increase in athletic training services to secondary schools over that period. This percentage is even lower when comparing private schools. Pike, Pryor, Mazerolle, Stearns, and Casa (2016) reported that only $28 \%$ of privately funded school systems had access to a full-time athletic trainer on site. Additionally, secondary schools in rural communities have less access to athletic trainer in both the public and private school setting, when compared to their suburban counterparts (Pike, Pryor, Vandermark, Mazerolle, \& Casa, 2017). Despite the lack of athletic trainers in the high school setting, athletic directors have consistently realized the need and expressed the desire to hire athletic trainers, yet face significant barriers implementing this concept and recommendation (Schneider et al., 2017). It has been further documented that the barriers to implementing the recommendation to hire athletic trainers stems from the departments' lack of ability to make personnel hiring decisions, budget concerns, and a 
lack of qualified individuals to provide this service in the immediate vicinity (Mazerolle, Raso, Pagnotta, Stearns, \& Casa, 2015).

Negligence and Legal Issues

Negligence Theory The most common framework for liability and negligence in sports arises when a participant is injured as a direct result of participation in the athletic activity (Hekmat, 2001). Establishing negligence requires four distinct actions to be present: (1) A duty that requires a person to conform to a specific standard of care, (2) a breach of duty, (3) a causal relationship between the breach of duty and resulting injury, and (4) damages resulting from the action (McCaskey \& Biedzynski, 1996).

Labuschange and Skea (1999) identify four basic duties that coaches have - protecting the individual from any further harm, attempting to maintain or restore life to the injured person, comforting and reassuring the individual, and immediately activating the Emergency Medical Services (EMS) system. Numerous legal cases have been brought against coaches and athletic departments, resulting in a wide variety of definitions and precedents of negligence and the expectations, duties, and responsibilities of coaches. These concepts have been further defined by Mirsafian (2016) as misfeasance, or the act of performing improperly outside of the individual's training, and nonfeasance, or the act of failing to complete a duty or act when that duty is present.

Legal Cases and Precedent Establishing the exact duty owed to the individual on behalf of the coach or athletic department is widely varied, however some responsibilities have been identified in the literature. Doleschal (2012) established 14 legal duties a coach possesses when taking charge of an athletic team, many of which have been reported previously in alternate publications. Doleschal (2012) identified one legal duty 
of the coach as the duty to ensure safety and make efforts to reduce the amount of harm that could result from participation in sports. Defining this duty to ensure safety has been the topic of many legal battles in the United States and has resulted in multiple additional duties being ascribed to members of the coaching staff. Specifically, including proper instructions to the participant regarding safety procedures to follow throughout participation. This principle was emphasized in the case of Thompson v. Seattle Public School District 47 (Mitten, 2012). The courts found in this case that the football coaching staff was negligent and responsible for the injuries sustained by the athlete by failing to properly instruct safe tackling mechanics. This duty to educate student athletes was further emphasized in the case of Baker v. Briarcliff School District (Mitten, 2012), in which a lacrosse coach was found negligent for failing to provide the appropriate education regarding mouthguard use during participation.

While the duty to provide instruction regarding safety has been established in the literature, coaches have also been assigned the duty to provide adequate instructions and to prepare the athlete for participation in his or her desired sport (Engelhorn, 2017). However, coaches still need to exercise caution when preparing the student athlete for participation in competitive sponsored sports. Vargo v. Svitchan is another court case in which a negligence claim was filed against the athletic director, the football coach, and the school for injuries sustained during a weight training session at the school (Mitten, 2012). This case was further compounded by the fact that the coach was attempting to pressure the athletes into performing at a level higher than regularly expected. The duty for safety was further described in the case brought against a coach, David Stinson, who 
was coaching players through a series of conditioning drills while wearing football equipment in a high heat environment which resulted in the death of the individual.

In addition to the aforementioned responsibilities of coaches, the duty to provide care in the case of an emergency and adequately prepare for emergencies has also been described in the literature (Doleschal, 2012,; Labuschange \& Skea, 1999; Quandt, Mitten, \& Black, 2009). As previously described, when no athletic trainer or alternative medical provider is present the coach must take the responsibility to provide medical care to the athlete in an emergency situation in a timely manner and maintain that care until more advanced medical support arrives (Engelhorn, 2018).

The courts have substantiated this responsibility by finding coaching staffs negligent for failing to provide appropriate medical care to an overheated athlete for almost two hours in the case of Mogabgab v. Orleans Parish School Board (Mitten, 2012). The court system has also provided guidance on emergency planning as a duty owed to the athlete when participating in sports. In the case of Kleinknecht v. Gettysburg College, the courts ruled the college as negligent for failing to provide an appropriate response to an athlete who sustained a cardiac arrest during participation (Andersen et al., 2002). The Kleinkencht v. Gettysburg College case is widely considered the landmark case in which the need for improved policies and procedures regarding emergency planning was established (Mitten, 2012). This duty to possess an appropriate emergency action plan that is rehearsed was further described in the court case of Gathers v. Loyola Marymount, in which Hank Gathers passed away in 1989 from a sudden cardiac event during a basketball game and no AED was present (Anderson, 2002). 
While there is a strong consensus that coaches have a duty to provide this care when no medical providers are present; they must take efforts to ensure they do not go beyond their training and administer care that they are unqualified to provide (Mirsafian, 2016). It is reported in the literature that coaches describe feeling confident in their skills pertaining to providing care to athletes who are injured (Stapleton, 1984). Coaches also have a tendency to act unethically in an unintentional manner by returning injured athletes to participation without adequately recognizing the extent of the injury (Miles \& Prasad, 2016). This type of action can potentially facilitate a case of misfeasance against the coach as described by Mirsafian (2016). The concept of misfeasance is widely cited in the literature regarding negligence claims against school districts and coaches (Johnson \& Easter, 2007). While it is widely accepted that coaches are not expected to provide advanced medical care, diagnose injuries, or take the place of a medical provider, there remains an expectation that the coach act prudently and not provide services that can further harm an athlete (Doleschal, 2012). There have been numerous legal cases that have supported this statement and provided a precedent regarding misfeasance. In the case of Harper v. Vayo, a coach-initiated treatment and manipulated the knee of an injured athlete, leading to further damages of the joint and constituting a negligent act on his behalf (Mitten, 2012). This concept was further described in the case of Jarreau v. Orleans School Board in which the coaching staff was found negligent for allowing injured athletes to return to play when injured, especially when the original injury was exacerbated by this decision (Mitten, 2012).

One method many organizations have implemented aspiring to reduce this risk of liability is an assumption of risk document (Drago, 2001). Assumption of risk documents 
have been used in a variety of settings to, in practice, limit and waive the liability and negligence claims that could potentially be brought against the school district, athletics department, or coach. However, one problem that has been identified with this form is that the document is very limited in scope and pertains only to the injuries that are deemed inherent risks associated with sports participation and does not protect the coach or school district from liability or negligence claims if wrongdoing is established or it is ruled that there was a failure to perform specific responsibilities required by the policies in place (Drago, 2001; Misarfian, 2016). This precedent was established in the case of Sharon v. City of Newton, in which the Massachusetts Supreme Court ruled that coaches could not be held liable for injuries sustained during athletic participation if the parents or legal guardian signed an assumption of risk document waiving liability for the athlete who was a minor (Mitten, 2012). However, as is similar with other aspects of negligence case law relating to athletic-related injuries, the rulings in the court system have not been consistent. In the case of Wagenblast v. Odessa School District, the court system ruled that the release of liability waiver did not protect the coach or the school district based on the fact that a signed document was required in order for the student athlete to be eligible for participation (Mitten, 2012).

While the assumption of risk document and principle is a concept commonly utilized to reduce the prospect of legal liability the coach or school system may face, by mandating that each participant sign the document, with or without proper education and information, stating they understand the inherent risks of participating in sports and do so under their own volition, significant concern regarding the legal protection still remains. Miles and Prasad (2016) have described this assumption of risk document as "uninformed 
consent," attempting to detail and describe the inadequacies present in this form, and the failure to educate the parent or the student properly on the risks associated with athletic participation. This problem is further compounded in the fact that many parents hold on to the hope that their child will gain fame and potentially receive a professional contract and significantly increase their income, especially in communities with lower socioeconomic status (Kelto, 2015). This ungrounded and potentially flawed hope that there will be a professional contract and fame can cause significant ethical dilemmas and the potential for undue risks. It is reported that less than $1 \%$ of high school athletes will continue their athletic career past high school and obtain a professional contract (NCAA, 2017). This reality is in direct contradiction to the expectation of $26 \%$ of parents who believe their child will eventually receive this professional contract and the financial gains that come alongside (Kelto, 2015). 


\section{References}

Alexander, E. (2017, June 16). Kent State football player Tyler Henitz primary cause of death ruled hyperthermia. Retrieved from

http://www.cleveland.com/sports/college/index.ssf.2014/06/hypothermia_and_foo $\underline{\text { tball_a_dan.html }}$

Andersen, J. C., Courson, R. W., Kleiner, D. M., \& McLoda, T. A. (2002). National Athletic Trainers' Association position statement: emergency planning in athletics. Journal of Athletic Training, 37(1), 99.

Barron, M.J., Powell, J. W., Weing, M. E., Nogle, S. E., \& Branta, C. F. (2009). First aid and injury prevention knowledge of youth basketball, football, and soccer coaches. International Journal of Coaching Science. 3(1). 55-67.

Batra, A. S., Hohn, A. R. (2003). Consultation with the specialist populations, syncope, and sudden cardiac death in children: who's at risk? Pediatrics in Review, 24(8),269-275.

Beach, A. F. (2003). Dying to play: School liability and immunity for injuries that occur as a result of school-sponsored athletic events. Sports Lawyers Journal 10, 275294.

Blanchard, J. (2012). A comparative study of K-12 and higher education sport related negligence litigation. Journal for the Study of Sports and Athletes in Education, 6(2), 201-220.

Bonza, J. E., Fields, S. K., Yard, E. E., \& Dawn Comstock, R. (2009). Shoulder injuries among United States high school athletes during the 2005-2006 and 2006-2007 school years. Journal of athletic training, 44(1), 76-83. 
Buxton, B. P., Okasaki, E. M., Ho, K. W., McCarthy, M. R. (1995). Legislative funding of athletic training positions in public secondary schools. Journal of Athletic Training, 30(2), 115.

Cournoyer, J., \& Tripp, B. L. (2014) Concussion knowledge in high school football players. Journal of Athletic Training, 49(5), 654-658.

Casa, D. J., Almquist, J., Anderson, S. A., Baker, L., Bergeron, M. F., Biagioli, B., ... Valentine, V. (2013). The inter-association task force for preventing sudden death in secondary school athletic programs: Best practice recommendations. Journal of Athletic Training, 48 (4), 546-553.

Casa, D. J., Anderson, S. A., Baker, L., Bennett, S., Bergeron, M. F., Connollly, D., ... \& Fleck, S. (2015). The inter-association task force for preventing sudden death in collegiate conditioning sessions: best practice recommendations. Journal of Athletic Training, 48(4), 546-553.

Casa, D. J., Guskiewicz, K. M., Anderson, S. A., Courson, R. W., Heck, J. F., Jimenez, C. C., ... Walsh, K. M. (2012). National Athletic Trainers Association position statement: preventing sudden death in sports. Journal of Athletic Training, 47(1), 96-118.

Courson, R., Goldenberg, M., Adams, K. G., Anderson, S. A., Colgatell, B., Cooper, L., ... Turbak, G. (2014). Inter-association consensus statement on best practices for sports medicine management for secondary schools and colleges. Journal of Athletic Training, 49(1). 128-137.

Dewitt, T. L., Unruh, S. A., \& Seshadri, S. (2012). The level of medical services and secondary school aged athletes. Journal of Athletic Training, 47(1) 91-95. 
Drezner, J. A., Rao, A. L., Heistand, J., Bloomingdale, M. K. \& Harmon, K. G. (2009). Effectiveness of emergency response planning for sudden cardiac arrest in United States high schools with automated external defibrillators. Circulation, 120(6), $518-525$.

Fletcher, E. N., McKenzie, L. B., \& Comstock, R. D. (2014) Epidemiological comparison of injured high school basketball athletes reporting to emergency departments and the athletic training setting. Journal of Athletic Training 49(3), 381-388.

Greenfield, S. (2013). Law's impact on youth sport: should coaches be 'concerned about litigation'? Sports Coaching Review 2(2) 114-123.

Guskiewicz, K. M., Weaver, N. L., Padua, D. A., \& Garrett, W. E. (2000). Epidemiology of concussion in collegiate and high school football players. The American journal of sports medicine, 28(5), 643-650.

Harmon, K. G., Asif, I. M., Klossner, D., Drezner, J. A. (2011). Incidence of sudden cardiac death in National Collegiate Athletic Association athletes. Circulation, $123,1594-1600$.

Harmon, K. G., Drezner, J. A., Wilson, M. G. \& Sharma (2014). Incidence of sudden cardiac death in athletes: a state of the art review. British Journal of Sports Medicine, doi doi:10.1136/bjsports-2014-093872

Herndon, D. (2017, March 21). School mourns as Lincoln Park sophomore dies during basketball tryout. News Harold. Retrieved from http://www.thenewsherald.com/news/school-mourns-as-lincoln-park-sophomoredies-during-basketball-tryout/article_cb062f02-0e74-11e7-afad0740425baa35.html 
Johnson, S. T., Norcross, M. F., Bovbjerg, V. E., Hoffman, M. A., Chang, E. \& Koester, M. C., (2017). Sports-related emergency preparedness in Oregon high schools. Sports Health, 9(2), 181-184.

Keeton, P. W., Dobbs, W. L., Keeton, R. E., Owen, D. G. (1984). Prosser and Keeton on the law of torts, USA: West Pub Co.

Kelto, A. (2015, September 4). How likely is it, really, that your athletic kid will turn pro? NPR. Retrieved from http://www.npr.org/sections/healthshots/2015/09/04/432795481/how-likely-is-it-really-that-your-athletic-kid-will$\underline{\text { turn-pro }}$

Kerr, Z. Y., Dompier, T. P., Dalton, S. L., Miller, S. J., Hayden, R., \& Marshall, S. W. (2015). Methods and descriptive epidemiology of services provided by athletic trainers in high schools: the National Athletic Treatment, Injury and outcomes Network study. Journal of Athletic Training, 50(12), 1310-1318.

Lear, A., Hoang, M., \& Zyzanski, S. J. (2015). Preventing sudden cardiac death: automated external defibrillators in Ohio High Schools. Journal of Athletic Training 50(10), 1054-1058.

Long, A., Scifers, J. R., Eilbacher, C. (2017). How do economic variables predict access to athletic training services? Athletic Training and Sports Health Care, 9(2), 6470.

Lynch, J., Smith G.D., Harper, S. A., Hillemeier, M., Ross, N., Kaplan, G. A., \& Wolfson, M. (2004). Is income inequality a determinant of population health? Part 1. A systematic review. The Milbank Quarterly, 82(1) 5-99. 
Marar, M., McIlvain, N. M., Fields, S. K., \& Comstock, R. D. (2012). Epidemiology of concussions among United States high school athletes in 20 sports. The American journal of sports medicine, 40(4), 747-755.

Maron, B. J., Doerer, J. J., Haas, T. S., Tierney, D.M., \& Mueller, F. O. (2009). Sudden deaths in young competitive athletes: Analysis of 1866 deaths in the United States, 1980-2006. Circulation, 119(8), 1085-1092.

Maron, B. J., Haas, T. S., Murphy, C. J., Ahluwalia, A., \& Rutten-Ramos, S. (2014). Incidence and causes of sudden death in US college athletes. Journal of the American College of Cardiology, 63(16), 1636-1643.

Matthews, T. J., \& Waller, L. (2016). Coaches and the law: a study of the training of coaches in the United States. Mediterranean Journal of Social Sciences 7(1), 475479.

McCrea, M., Hammeke, T., Olsen, G., Leo, P., \& Guskiewicz, K. (2004). Unreported concussion in high school football players: implications for prevention. Clinical Journal of Sport Medicine, 14(1), 13-17.

Meredith, M. L., Watson, A. M., Gregory, A., Givens, T. G., Abramo, T. J., \& Kannankeril, P. J. (2013). Sudden cardiac arrests, automated external defibrillators, and medical response plans in Tennessee high schools. Pediatric Emergency Care 29(3). 352-356.

Miles, S. H., \& Prasad, S. (2016). Medical Ethics and School Football. The American Journal of Bioethics, 16, 6-10. doi: 10.1080/15265161.2016.1128751

NATA. (n.d.) Retrieved from http://www.nata.org 
Pike, A., Pryor, R. R., Mazerolle, S. M., Stearns, R. L., \& Casa, D. J. (2016). Athletic trainer services in US private secondary schools. Journal of Athletic Training 51(9), 717-726.

Pike, A., Pryor, R. R., Vandermark, L. W., Mazerolle, S. M., \& Casa, D. J. (2017). Athletic trainer services in public and private secondary schools. Journal of Athletic Training 52(1), 5-11.

Pryor, R. R., Casa, D. J., Vandermark, L. W., Stearns, R. L., Attanasio, S. M., Fontaine, G. J., Wafer, A. M. (2015). Athletic training services in public secondary schools: A benchmark study. Journal of Athletic Training 50(2), 156-162.

Powell, J. W., \& Barber-Foss, K. D. (2000). Sex-related injury patterns among selected high school sports. The American Journal of Sports Medicine, 28(3), 385-391.

Ransone, J., \& Dunn-Bennett, L.R. (1999). Assessment of first-aid knowledge and decision making of high school athletic coaches. Journal of Athletic Training. 34(3), 267-271.

Rechel, J. A., Yard, E. E., \& Comstock, R. D. (2008) An epidemiologic comparison of high school sports injuries sustained in practice and competition. Journal of Athletic Training, 43(2), 197-204.

Reschovsky, J. D., \& Staiti, A. B. (2005). Access and quality: does rural America lag behind?. Health Affairs, 24(4), 1128-1139.

Rieder, R. W., \& Woodward Jr, W. B. (1993). University liability for sports injuries. NASPA Journal, 31(1), 56-63. 
Rothmier, J. D., Drezner, J. A., \& Harmon, K. G. (2007). Automated external defibrillators in Washington state schools. British Journal of Sports Medicine, 41(5), 301-305.

Schmied, C., \& Borjesson, M. (2014). Sudden cardiac death in athletes. Journal of internal medicine, 275(2), 93-103.

Schneider, K. R., Meeteer, W., Nolan, J. A., \& Campbell, H. D. (2017). Health care in high school athletics in West Virginia. Rural and Remote Health. 17 (3879).

Skinner, A. C., \& Slifkin, R. T. (2007). Rural/urban differences in barriers to and burden of care for children with special health needs. The Journal of Rural Health, 23(2), $150-157$.

Swenson, D. M., Collins, C. L., Best, T. M., Flanigan, D. C., Fields, S. K. \& Comstock, R. D., (2013). Epidemiology of knee injuries among US high schools athletes 2005/2006-2010/11. Medicine and Science in sports and exercise, 45(3), 462.

Tjong, V. K., Murnaghan, M. L., Nyhof-Young, J. M., \& Ogilvie-Harris, D. J. (2014). A qualitative investigation of the decision to return to sport after anterior cruciate ligament reconstruction: to play or not to play. The American journal of sports medicine, 42(2), 336-342.

United States Department of Agriculture. (2016, October). Rural Urban Commuting Area Codes. Retrieved from https://www.ers.usda.gov/data-products/rural-urbancommuting-area-codes.aspx

Valovich McLeod, T. C., Schwartz, C., \& Bay, C. (2007). Sport related concussion misunderstanding among youth coaches. Clinical Journal of Sports Medicine. 17(2), 140-142. 
Valovich Mcleod, T.C., Cardenas, J.F. (2018). Emergency Preparedness of Secondary School Athletic Programs in Arizona. Journal of Athletic Training. 53(11).

Wasilko, S. M., \& Lisle, D. K. (2013) Automated external defibrillators and emergency planning for sudden cardiac arrest in Vermont high schools: a rural states perspective. Sports Health, 5(6), 548-552. 
Section IV:

Contribution to Practice 


\section{Section IV:}

\section{Contribution to Practice}

\section{Plan for Dissemination}

This research is designed to assist athletic directors and secondary school athletic organizations in making better decisions in the adherence to best practice recommendations regarding the prevention of sudden death. The goal is to create an understanding of what aspects of the recommendations that schools are doing well, as well as identify what areas may need improvement. The National Federation of High Schools (NFHS) serves as the governing body that oversees individual state athletic and activity associations, however they serve purely as an advisory board and have no legislative authority outside of playing rules for the respective sports. Despite the fact that this board has advisory powers only, they have the ability to disseminate information to the masses and to individual state athletic associations and athletic directors in individual schools.

\section{Type of Document and Rationale}

This research would most easily be presented to practitioners in the form of a policy brief. The presentation of data pertaining to what schools are doing well and areas for improvement can have a direct impact on the emergency preparedness of the respective schools. Also, providing recommendations to overcome the commonly stated barriers can directly impact the implementation of these policy recommendations and enable all schools to potentially meet the best practice recommendations. 


\section{Adherence to Best Practice Recommendations in}

\section{Secondary School Athletic Programs}

\section{The Current Problem}

The most common framework for liability and negligence in sports arises when a participant is injured as a direct result of participation in the athletic activity (Hekmat, 2001). Establishing negligence requires four distinct actions to be present: (1) A duty that requires a person to conform to a specific standard of care, (2) a breach of duty, (3) a causal relationship between the breach of duty and resulting injury, and (4) damages resulting from the action (McCaskey \& Biedzynski, 1996). Labuschange and Skea (1999) identify four basic duties that coaches have - protecting the individual from any further harm, attempting to maintain or restore life to the injured person, comforting and reassuring the individual, and immediately activating the Emergency Medical Services (EMS) system. Numerous legal cases have been brought against coaches and athletic departments, resulting in a wide variety of definitions and precedents of negligence and the expectations, duties, and responsibilities of coaches. These concepts have been further defined by Mirsafian (2016) as misfeasance, or the act of performing improperly outside of the individual's training, and nonfeasance, or the act of failing to complete a duty or act when that duty is present.

Legal Cases and Precedent Establishing the exact duty owed to the individual on behalf of the coach or athletic department is widely varied, however some responsibilities have been identified in the literature. Doleschal (2012) established 14 legal duties a coach possesses when taking charge of an athletic team, many of which have been reported previously in alternate publications. Doleschal (2012) identified one legal duty 
of the coach as the duty to ensure safety and make efforts to reduce the amount of harm that could result from participation in sports. Defining this duty to ensure safety has been the topic of many legal battles in the United States and has resulted in multiple additional duties being ascribed to members of the coaching staff. Specifically, including proper instructions to the participant regarding safety procedures to follow throughout participation. This principle was emphasized in the case of Thompson v. Seattle Public School District 47 (Mitten, 2012). The courts found in this case that the football coaching staff was negligent and responsible for the injuries sustained by the athlete by failing to properly instruct safe tackling mechanics. This duty to educate student athletes was further emphasized in the case of Baker v. Briarcliff School District (Mitten, 2012), in which a lacrosse coach was found negligent for failing to provide the appropriate education regarding mouthguard use during participation.

While the duty to provide instruction regarding safety has been established in the literature, coaches have also been assigned the duty to provide adequate instructions and to prepare the athlete for participation in his or her desired sport (Engelhorn, 2017). However, coaches still need to exercise caution when preparing the student athlete for participation in competitive sponsored sports. Vargo v. Svitchan is another court case in which a negligence claim was filed against the athletic director, the football coach, and the school for injuries sustained during a weight training session at the school (Mitten, 2012). This case was further compounded by the fact that the coach was attempting to pressure the athletes into performing at level higher than regularly expected. The duty for safety was further described in the case brought against a coach, David Stinson, who 
was coaching players through a series of conditioning drills while wearing football equipment in a high heat environment which resulted in the death of the individual.

In addition to the aforementioned responsibilities of coaches, the duty to provide care in the case of an emergency and adequately prepare for emergencies has also been described in the literature (Doleschal, 2012,; Labuschange \& Skea, 1999; Quandt, Mitten, \& Black, 2009). As previously described, when no athletic trainer or alternative medical provider is present the coach must take the responsibility to provide medical care to the athlete in an emergency situation in a timely manner and maintain that care until more advanced medical support arrives (Engelhorn, 2018).

The courts have substantiated this responsibility by finding coaching staffs negligent for failing to provide appropriate medical care to an overheated athlete for almost two hours in the case of Mogabgab v. Orleans Parish School Board (Mitten, 2012). The court system has also provided guidance on emergency planning as a duty owed to the athlete when participating in sports. In the case of Kleinknecht v. Gettysburg College, the courts ruled the college as negligent for failing to provide an appropriate response to an athlete who sustained a cardiac arrest during participation (Andersen et al., 2002). The Kleinkencht v. Gettysburg College case is widely considered the landmark case in which the need for improved policies and procedures regarding emergency planning was established (Mitten, 2012). This duty to possess an appropriate emergency action plan that is rehearsed was further described in the court case of Gathers v. Loyola Marymount, in which Hank Gathers passed away in 1989 from a sudden cardiac event during a basketball game and no AED was present (Anderson, 2002). 
While there is a strong consensus that coaches have a duty to provide this care when no medical providers are present, they must take efforts to ensure they do not go beyond their training and administer care that they are unqualified to provide (Mirsafian, 2016). It is reported in the literature that coaches describe feeling confident in their skills pertaining to providing care to athletes who are injured (Stapleton, 1984). Coaches also have a tendency to act unethically in an unintentional manner by returning injured athletes to participation without adequately recognizing the extent of the injury (Miles \& Prasad, 2016). This type of action can potentially facilitate a case of misfeasance against the coach as described by Mirsafian (2016). The concept of misfeasance is widely cited in the literature regarding negligence claims against school districts and coaches (Johnson \& Easter, 2007). While it is widely accepted that coaches are not expected to provide advanced medical care, diagnose injuries, or take the place of a medical provider, there remains an expectation that the coach act prudently and not provide services that can further harm an athlete (Doleschal, 2012). There have been numerous legal cases that have supported this statement and provided a precedent regarding misfeasance. In the case of Harper v. Vayo, a coach-initiated treatment and manipulated the knee of an injured athlete, leading to further damages of the joint and constituting a negligent act on his behalf (Mitten, 2012). This concept was further described in the case of Jarreau v. Orleans School Board in which the coaching staff was found negligent for allowing injured athletes to return to play when injured, especially when the original injury was exacerbated by this decision (Mitten, 2012). 


\section{What does the Research say?}

Casa et al., (2012) published a statement outlining the best practices titled: "National Athletic Trainers Position Statement: Preventing Sudden Death in Sports" in an effort to provide recommendations to schools and healthcare providers on the leading causes of sudden death including SCT, heat-related injuries, sudden cardiac arrest, and head injuries. One major component of this position statement is the inclusion of an emergency action plan (EAP). Andersen et al., (2002) published a position statement regarding emergency action planning which detailed the specific components that should be outlined and included in every emergency plan for athletics. One specific recommendation encourages organizations to rehearse and educate all individuals involved in the EAP on an annual basis at minimum. Positive outcomes and correlations regarding emergency care in schools have been reported in those organizations that implemented the EAP programming and also rehearsed those components on a planned and regular basis with members of the team (Drezner et al., 2009). Although many schools in the United States are compliant with providing an emergency action plan of incidents during the traditional school day (Olympia, Wan, \& Avner, 2005), the compliance of the EAP for athletic-related events and the rehearsal of this plan tends to be lacking in the policy and procedures manuals for secondary schools (Olympia, Dixon, Brady, \& Avner, 2007). These authors demonstrate the need for an athletic-based emergency action plan to be implemented and rehearsed with all members of the athletic department staff on a regular basis.

Apart from emergency action planning, further position statements have been developed to address other aspects of preventative care for secondary school athletic 
programs. Casa et al., (2015) published a position statement addressing environmental concerns titled "National Athletic Trainers' Position Statement: Exertional Heat Illness." This position statement was produced to address the need for proper procedures and education to prevent death from heat-related illness through the provision of a 48statement document to assist the coach and medical provider in managing environmentally-related concerns in the athlete. These recommendations regarding heat illness have been further expanded by providing acclimatization guidelines for athletes participating in high heat environments (Casa et al., 2009). These guidelines have been adopted by the National Collegiate Athletic Association (NCAA) and the National Federation of High Schools (NFHS) and implemented in their respective organizations. These guidelines specifically target the acclimatization policies for the athlete when beginning participation $\mathrm{n}$ high-heat environments, which is common during the preseason football season. These guidelines consist of a 14-day protocol detailing the amount of time that can be spent in practice, the personal protective equipment and clothing that can be worn during practice, the number of practices that are permitted daily, the amount and duration of rest periods between each sponsored event, as well as nutrition and hydration recommendations (Casa et al., 2009). Despite these recommendations being published and adopted by the national organization, many programs across the United States still fail to comply with all 17 guidelines, with a majority only complying with 10 of the guidelines, or less than 60\% (Kerr, Marshall, Comstock, \& Casa, 2014).

Authors have also sought to provide recommendations regarding best practices for treating and managing head injuries or concussions (Broglio et al., 2014; Harmon et al., 
2013; McCrory et al., 2013). In addition, the Centers for Disease Control has also initiated programs to educate coaches and athletic staff members on the seriousness of head injuries as well as the signs and symptoms and proper identification of concussions (Couvassin, Elbin, \& Sarimento, 2012). These best practice recommendations outlined in the statements are delineated into the following categories: education and prevention, documentation and legal aspects, evaluation and return to play, and other considerations (Broglio et al., 2014). The significant number of concussions among athletes combined with these published best practice recommendations have inspired many states to draft initial legislative efforts regarding return to play after a concussion, appropriate treatment of concussions, and education of the parents, coaches, and athletes regarding signs and symptoms of head injuries (Tomei, Doe, Pretigiacomo, \& Ghandi, 2012). Although concussion education is encouraged in all states that have passed legislation, not every state mandates or requires that all coaches receive any formal training or education on these injuries (Tomei et al., 2012).

\section{Policy Alternative 1: Increase/Secure funding to provide improved medical care and services to secondary school athletes.}

The first recommendation for policy change is to increase funding structure specifically allocated towards the health and safety of student athletes. This research described the significant budgetary constraints that all athletic departments face regarding implementing the best practice recommendations. All of the participants identified the desire to add more to increase student safety, but it was also mentioned that this was prohibited due to the budgetary constraints placed on them. 
One method to improve and secure funding is to encourage athletic directors to look outside of the school system for potential grants, community programs, and fundraising opportunities that may potentially provide funding for these services. This research found that some of the schools utilized the sports medicine staff and physicians to complete physicals for a nominal cost and the proceeds went to the sports medicine budget. Others sought out hospital-based funding programs and local businesses (e.g. Casinos) to provide community support in the form of AEDs and other equipment. Policy Alternative 2: Mandate athletic pre-participation educational programs for students, parents, coaches, and administrators.

The second recommendation for policy change is for there to be a state level mandate to require specific educational programming for all people who are stakeholders in the athletics programs on campus (Administrators, Coaches, Parents, Students). One of the primary concerns highlighted in the literature is the lack of knowledge many of these individuals have regarding the potential risks associated with participation, yet they continue to sign assumption of risk documents and informed consent documents without being properly educated.

The implementation of educational programs has been shown to have mixed results in the retention of knowledge among coaches, however the presence of some knowledge is better than being uninformed and lacking the knowledge. Because the NFHS is limited in the legislative authority, and individual states have different requirements regarding educating student athletes, there are major inconsistencies across the United States regarding the extent to which participants are informed. At minimum, students should be required to be informed and educated on concussion, heat illness 
safety, and the recognition of signs and symptoms of cardiac issues. While a majority of states have enacted concussion legislation, this has only happened because of a reactive policy due to the increased awareness of concussions in the national media.

\section{Summary}

It is highly recommended that secondary schools examine their medical coverage and health and safety policies to ensure that they are meeting best practice recommendations. Ideally, hiring athletic trainers to provide medical care to the secondary sports program would be the ultimate goal; however, this is not always possible due to budgetary constraints and the availability of the qualified personnel in the region. Because of this issue, alternative methods should be taken to ensure that safety and health are considered the primary focus of the athletics department. This can include improved policies specifically addressing the components of the recommendations they are not meeting as well as improved education for all individuals involved in the athletics program. States and schools should be proactive in developing policies and procedures to prevent sudden death or injuries from occurring instead of reactive and implementing guidelines after an event has occurred. 


\section{References}

Andersen, J. C., Courson, R. W., Kleiner, D. M., \& McLoda, T. A. (2002). National Athletic Trainers' Association position statement: emergency planning in athletics. Journal of Athletic Training, 37(1), 99.

Broglio, S. P., Cantu, R. C., Gioia, G. A., Guskiewicz, K. M., Kutcher, J., Palm, M., \& McLeod, T. C. V. (2014). National Athletic Trainers' Association position statement: management of sport concussion. Journal of athletic training, 49(2), 245-265.

Casa, D. J., Almquist, J., Anderson, S. A., Baker, L., Bergeron, M. F., Biagioli, B., ... Valentine, V. (2013). The inter-association task force for preventing sudden death in secondary school athletic programs: Best practice recommendations. Journal of Athletic Training, 48 (4), 546-553.

Casa, D. J., Anderson, S. A., Baker, L., Bennett, S., Bergeron, M. F., Connollly, D., ... \& Fleck, S. (2015). The inter-association task force for preventing sudden death in collegiate conditioning sessions: best practice recommendations. Journal of Athletic Training, 48(4), 546-553.

Casa, D. J., Guskiewicz, K. M., Anderson, S. A., Courson, R. W., Heck, J. F., Jimenez, C. C., ... Walsh, K. M. (2012). National Athletic Trainers Association position statement: preventing sudden death in sports. Journal of Athletic Training, 47(1), 96-118.

Covassin, T., Elbin, R. J., Harris, W., Parker, T., \& Kontos, A. (2012). The role of age and sex in symptoms, neurocognitive performance, and postural stability in 
athletes after concussion. The American journal of sports medicine, 40(6), 13031312.

Drezner, J. A., Rao, A. L., Heistand, J., Bloomingdale, M. K. \& Harmon, K. G. (2009). Effectiveness of emergency response planning for sudden cardiac arrest in United States high schools with automated external defibrillators. Circulation, 120(6), $518-525$.

Harmon, K. G., Asif, I. M., Klossner, D., Drezner, J. A. (2011). Incidence of sudden cardiac death in National Collegiate Athletic Association athletes. Circulation, $123,1594-1600$.

Harmon, K. G., Drezner, J. A., Wilson, M. G. \& Sharma (2014). Incidence of sudden cardiac death in athletes: a state of the art review. British Journal of Sports Medicine, doi doi:10.1136/bjsports-2014-093872

Hekmat, R. R. (2001). Malpractice during practice: Should NCAA coaches be liable for negligence. Loy. LA Ent. L. Rev., 22, 613.

Johnson, M. V. M., \& Easter, B. A. (2007). Legal liability for cheerleading injuries: Implications for universities and coaches. J. Legal Aspects Sport., 17, 213.

Labuschagne, J. M., \& Skea, J. M. (1999). The Liability of a Coach for a Sport Participant's Injury. Stellenbosch L. Rev., 10, 158.

Maron, B. J., Doerer, J. J., Haas, T. S., Tierney, D.M., \& Mueller, F. O. (2009). Sudden deaths in young competitive athletes: Analysis of 1866 deaths in the United States, 1980-2006. Circulation, 119(8), 1085-1092. 
Maron, B. J., Haas, T. S., Murphy, C. J., Ahluwalia, A., \& Rutten-Ramos, S. (2014). Incidence and causes of sudden death in US college athletes. Journal of the American College of Cardiology, 63(16), 1636-1643.

McCaskey, A. S., \& Biedzynski, K. W. (1996). A guide to the legal liability of coaches for a sports participant's injuries. Seton Hall J. Sport L., 6, 7.

McCrory, P., Meeuwisse, W. H., Aubry, M., Cantu, R. C., Dvorak, J., Echemendia, R. J., ... \& Sills, A. (2013). Consensus statement on concussion in sport - the 4th International Conference on Concussion in Sport held in Zurich, November 2012. $P M \& R, 5(4), 255-279$.

Miles, S. H., \& Prasad, S. (2016). Medical Ethics and School Football. The American Journal of Bioethics, 16, 6-10. doi: 10.1080/15265161.2016.1128751

Mirsafian, H. (2016). Legal duties and legal liabilities of coaches toward athletes. Physical culture and sport. Studies and Research, 69(1), 5-14.

Mitten, M. J., \& Opie, H. (2012). "Sports law": implications for the development of international, comparative, and national law and global dispute resolution. In Lex Sportiva: What is Sports Law? (pp. 173-222). TMC Asser Press.

Olympia, R. P., Wan, E., \& Avner, J. R. (2005). The preparedness of schools to respond to emergencies in children: a national survey of school nurses. Pediatrics, 116(6), e738-e745.

Quandt, E. F., Mitten, M. J., \& Black, J. S. (2009). Legal liability in covering athletic events. Sports Health, 1(1), 84-90. 
Stapleton, K. L., Tomlinson, C. M., Shepard, K. F., \& Coon, V. A. (1984). High school coaches' perceptions of their responsibilities in managing their athletes' injuries. Journal of Orthopaedic \& Sports Physical Therapy, 5(5), 253-260.

Tomei, K. L., Doe, C., Prestigiacomo, C. J., \& Gandhi, C. D. (2012). Comparative analysis of state-level concussion legislation and review of current practices in concussion. Neurosurgical focus, 33(6), E11. 


\section{Section V:}

Contribution to Scholarship 


\section{Section V:}

\section{Contribution to Scholarship}

\section{Target Journal and Rationale}

The most appropriate journal to submit this research would be to the Journal of Athletic Training. This is the premier journal for the professional membership association for certified athletic trainers. The Journal of Athletic Training has a stated mission to "enhance communication among professionals interested in the quality of health care for the physically active through education and research in prevention, evaluation, management, and rehabilitation of injuries.” (NATA, 2019). The NATA, which publishes this journal, has recently initiated the ATLAS project with a goal to map all of the athletic training services provided at the secondary school level in the United States. This initiative as part of the organization makes this journal an ideal choice to reach an audience that has the ability to advocate for student athlete healthcare and assist in making changes at the Secondary School level. 


\title{
ANALYSIS OF BEST PRACTICE PROCEDURES TO PREVENT SUDDEN DEATH \\ IN HIGH SCHOOL ATHLETICS: A REGIONAL ASSESSMENT.
}

\author{
Kyle Schneider MSEd, ATC \\ Southeast Missouri State University \\ One University Plaza MS 7650 \\ Cape Girardeau, MO 63701 \\ $573-651-5193$ \\ $\underline{\text { kschneider@semo.edu }}$
}




\title{
ANALYSIS OF BEST PRACTICE PROCEDURES TO PREVENT SUDDEN DEATH IN HIGH SCHOOL ATHLETICS: A REGIONAL ASSESSMENT.
}

\begin{abstract}
Objective To analyze the adherence to best practice recommendations through the implementation of specific policies and procedures to prevent sudden death and identify barriers preventing implementation. Design and Setting This is a mixed methods research design utilizing a survey and semi-structured interviews to provide data. This study examined secondary schools in District V of the NATA (Iowa, Kansas, Missouri, Nebraska, North Dakota, Oklahoma, South Dakota). Subjects Participants $(n=151)$ were athletic administrators in secondary school athletic programs in the seven-state region. Measurements Surveys were distributed and collected utilizing Qualtrics and results were analyzed using one-way ANOVAs. Interviews were transcribed and coded to identify commonality in the themes. Results Significant difference existed in the availability of personnel when considering the urbanization classification and enrolment size of the school. Financial constraints and time availability severely impacted the implementation of best practice recommendations. Conclusions Legislative policies regarding the implementation of best practices to prevent sudden death are needed to improve adherence and protect student athletes from serious life-threatening injuries and to protect the school from potential liability.
\end{abstract}

Key Words: Secondary Schools, EAP, Negligence theory 


\section{Introduction}

The National Federation of High School Sports (NFHS) reports approximately 8 million student athletes participate in high school sports every year and that number is expected to grow in the future (NFHS, 2016). In contrast, according to data released by the National Collegiate Athletic Association (NCAA), only approximately 480,000 student athletes continue to compete at the collegiate level (NCAA,2017). This number continues to drop with less than $1 \%$ of high school athletes receiving a contract to play professionally (NCAA, 2017). Despite this low percentage, student athletes continue to dream of receiving a professional contract and the subsequent wealth that comes with professional contracts. This ambition is commonly shared by the parents of the children. It has been reported that approximately $26 \%$ of parents with kids in high school hope their child will play professionally, with an even higher number of those parents possessing that ambition in the lower socioeconomic groups (Kelto, 2015). Parents and children with unchecked ambition to play professionally can potentially heighten the risk of sport participation. Miles and Prasad (2016) describe this heightened risk through the utilization of the term, uninformed consent, which highlights that parents and students either ignore the risks of sports, or they simply fail to comprehend the potential harm that can arise during sports participation (Cournoyer, 2014). This naivety and lack of understanding of the risks of sports carries with it the potential for catastrophic events to occur.

One potential harm associated with participation in athletics among youth that is rapidly becoming a public health concern is the increased rate of sudden cardiac death. Sudden cardiac death among apparently healthy teenagers who are participating in 
athletics has been widely described in the literature in an effort to raise awareness to this phenomenon (Maron, Haas, Murphy, Ahluwalia \& Rutten-Ramos, 2014; Schmeid \& Borjesson, 2014). In the first six months of 2017, numerous deaths linked to participation in athletics were highlighted in news stories. This includes an 18 year old freshman at Kent State University who died suddenly after collapsing on the field (Alexander, 2017), a Georgia teen who died suddenly after completing conditioning drills (Shapiro, 2017), a Kentucky teen who died after having a medical emergency during open gym activities (Spears, 2017), a Michigan teenager who died suddenly during off season basketball tryouts (Herndon, 2017) and a Pennsylvania teen who died suddenly after playing in a hockey game (Bond, 2017).

Although the rates of sudden death among youth athletes are not reported consistently across the literature, rates have been reported to occur as often as one in 44,000 athletes per year in children and adolescents (Harmon, Asif, Klossner, \& Drezner, 2011) with many of these deaths occurring in high school athletes while participating in interscholastic athletics (Maron, Doerer, Haas, Tierney, \& Mueller, 2009). Despite the inconsistencies in literature, Maron et al (2009) describes the rate to be consistently around 1:40,000 - 80,000 in studies with better methodology and is more prevalent in the African-American population. Other authors have detailed the role of age in increasing the risk, stating that the risk is higher in the younger population and decreases with age (Emery \& Kovacs, 2018; Chandra, Bastiaenen, Papadakis, \& Sharma, 2013).

As the numbers describe, the reality of this becoming a major health concern that requires immediate attention and intervention cannot be ignored. According to the Youth Sports Safety Alliance (n.d.) there have been over 40 deaths each year since 2008 during 
sports, with rates reported to be as high as 120 in a single year. While these number may prompt some individuals to consider sudden death in sports a rarity when compared to other conditions, student athletes in the United States have a significantly higher rate of injury and death when compared to other populations who have addressed this issue (Casa et al, 2013; Chandra et al 2013).

It is commonly recognized that participation in sports carries an increased risk of injury, especially orthopedic injuries and concussions. Fletcher, McKenzie, and Comstock (2014) reported over 1.5 million visits to the emergency room over a five-year period from athletes as a direct result of participation in interscholastic sports. This information is further supported by Kerr et al (2015), who documented over half a million visits to the emergency department over a 3-year period. The rates at which athletes are sustaining sports injuries and having medical emergencies have signified a need for increased planning, improved medical care, and improved education for coaches on how to deal with an injury when it occurs, both life-threatening and non-lifethreatening.

As the participation in sports has increased the attention to injury prevention and prevention of sudden death has become more prevalent. Numerous organizations have adopted recommendations addressing the need for improved care to student athletes in secondary schools. The National Athletic Trainers Association (NATA) (Casa et al., 2013), the American Medical Association (AMA) (1998), and the American Academy of Family Physicians (AAFP) (2012) have all advocated or published these recommendations. These recommendations include providing athletic trainers as part of the sports medicine staff in the schools, and the implementation of Emergency Action 
Plans (EAPs) to reduce the risk of sudden death and provide a mechanism to treat all injuries as they occur.

These recommendations are supported with legal precedents which have directly addressed the issue of improved care and the services that student-athletes are entitled to when participating in interscholastic activities. The courts have ruled that schools have a duty to protect the participant through emergency planning, implementation of appropriate policies, appropriate equipment being present, and training coaches and other staff in first aid (Beach, 2003; Greenfield, 2013). Two landmark cases: Gather v Layola Marymount and Kleinkenecht v. Gettysburg College (Anderson, Courson, Kleiner, \& McLoda, 2002) further defined the duties owed to student athletes by the school and reiterated the need for training and emergency procedures to be implemented in a timely manner.

Despite these recommendations and legal precedents, the lack of certified athletic trainers (ATCs) in secondary schools is a widely documented issue, with approximately $50 \%$ of schools reporting some access to an athletic trainer, and an even lower percentage having full-time access to a medical provider (Pike, Pryor, Vandermark, Mazerolle, \& Casa, 2017). When there is no athletic trainer present, the coach, assistant coach, or another designated staff member is required to assume the role of the medical provider and facilitate the care for the injured athlete. The argument could be made that this action fails to address the planning component described in Kleinkenecht v. Gettysburg College and opens the school up to legal liability and negligence issues under the current law (Anderson et al, 2002). Authors have documented a lack of knowledge among coaches regarding injury prevention, injury recognition, first aid principles, and heat 
related illness (Valvovich Mcleod, Schwartz, \& Bay, 2007; Ransone \& Dunn-Bennett, 1999). Matthews and Waller (2016) also reported that coaches tend to act in an unethical manner regarding injuries, due to a lack of knowledge and training and not through purposeful acts. The disparities in knowledge are further described by Baron et al. (2009), who reported that only $5 \%$ of coaches received a passing score on a first aid assessment, and Schneider, Meeteer, Nolan, \& Campbell (2017) who reported that only $33 \%$ of coaches possess current Cardiac Pulmonary Resuscitation (CPR) and First Aid (FA) certification in West Virginia.

Many states have recognized the disparities and potential liability risk and thus numerous efforts have been made to improve these issues regarding student safety and well-being while participating in sports. Lawmakers have recognized the need to address sudden cardiac events and have made efforts requiring states to include emergency action plans (EAPs) and have Automated External Defibrillators (AEDs) present at all sporting events and practices; however, this has not become a national requirement and funding for emergency equipment continues to be cited as a constraint (Buxton et al., 1995) prohibiting many schools from meeting these requirements (Johnson et al., 2017). Alternatively, in states that have implemented laws requiring AEDs to be accessible and EAPs to be written and present there has been a significant decrease in deaths from the sudden cardiac events and an increased rate of survival those individuals (Drezner, Rao, Heistand, Bloomingdale, \& Harmon, 2009).

Education of student athletes and coaches have also shown to have positive results in decreasing the injury rate and preparing those individuals for a potential event. Kerr et al (2015) found that an education program focusing on concussions was effective in 
reducing the number of injuries in American Football. This was further demonstrated by Belski et al. (2018) who found that coaches' knowledge and confidence in nutrition issues facing athletes was significantly improved after a brief 20-minute nutrition education program embedded in their mandatory training. These results are similar to the findings of Kerr et al (2015) which found that educational interventions decreased injury rates in youth football when coaches were informed and educated on practice restrictions for youth sports.

The findings above demonstrating the decrease in significant injuries and/or death in athletes after simple policy implementations demonstrate the need to improve emergency preparedness in athletic programs across the United States.

\section{Statement of the Problem}

The underlying problem facing secondary school athletic programs is inadequate planning, training, equipment, and personnel to address medical emergencies arising from interscholastic athletic participation. While the risk of an athlete suffering a lifethreatening cardiac event may be relatively low when compared to the risk of orthopedic injuries; the impact sudden death has on the athlete, the family, and the community is significant and cannot be ignored. Numerous organizations, including the NATA, have advocated for increased medical care to be provided to secondary school athletic programs and these organizations have provided best practice recommendations (Courson et al., 2014). These recommendations include: having an ATC present at all sporting events, each school possessing a detailed emergency action plan that describes and delineates each person's responsibility in the event of an emergency, practicing and rehearsing the emergency action plan on a planned and regular basis, first aid and CPR 
training, and a working AED always present near the sporting activity (Courson et al., 2014). Despite these recommendations being published, there are still significant deficiencies in secondary school athletic programs regarding emergency preparedness. Compounding the lack of preparation is the fact that the National Federation of HighSchool Sports (NFHS) acts primarily as an advisory board and each state has different requirements dictating the measures each school should take to reduce the risk of injury. Injury in sports has always been regarded as an inevitable risk associated with athletic participation. These injury rates are widely reported and vary greatly in the literature in relation to gender, age, sporting activity, and level of competition (Rechel, Yard, \& Comstock, 2008; Powerll \& Barber-Foss, 2000). The reporting of concussions, anterior cruciate ligament injuries, and ankle sprains in sports have brought increased attention to injury prevention principles and regulations regarding education on return to play criteria specific to concussions, yet sudden death has often been neglected due to the underestimated incidence and lack of reporting. While the exact rate of sudden death has some discrepancies, Meredith et al. (2013) identified the rates of sudden death in sports as one in seven adolescents in schools with a student population over 1,000 students (and 1 in 12 overall). While certain states that have implemented specific policies addressing emergency preparedness have seen a decrease in sudden death associated with sports, not all fifty states have adopted the same policies and no nationwide policy exists. This is further described by Lear, Hoang, and Zynaksi (2015), who reported a survival rate of $60 \%$ after the state implemented AED legislation. Despite these statistics, the lack of AEDs and trained medical staff to manage injuries continues to be a significant concern across the country. 
While the literature is abundant with information on best practices recommendations to improve health and safety of the student athletes, there is a scarcity in the extent to which schools meet the best practice recommendations provided by Casa et al. (2012) and the mitigating factors preventing the school from implementing those practices. One of the areas that has been researched is the presence of athletic trainers in public secondary schools (Pryor et al. 2015) and in private secondary schools (Pike, Pryor, Mazerolle, Stearns, \& Casa, 2016). This theme is consistent in the literature, recognizing the need for an athletic trainer or medical provider and the issues that can arise when a coach is required to take on the role of healthcare professional while coaching. Apart from the lack of knowledge in coaches described earlier, it has also been reported that many coaches will underestimate the seriousness of an injury (Ransone et al., 2009; Barron et al., 2009) and that many lack information on emergency action planning and fail to rehearse that plan on a regular and planned basis (Schneider et al., 2017).

Another aspect that deserves consideration is the discrepancies in healthcare provisions between schools with a larger enrollment and schools with a smaller enrollment coupled with the location of the school, rural, suburban, urban. It has been documented that schools in a rural community have fewer AEDs (Wasilko \& Lisle, 2013; Schneider et al., 2017) and those communities have a higher likelihood to suffer from cardiac events (Skinner \& Slifkin, 2007). This risk is further compounded with the increased distance of points of care, such as emergency rooms, and a lack of availability of medical services common in the rural community (Skinner \& Slifkin, 2007). 


\section{Purpose of the Study}

The purpose of this study is to examine the level to which secondary schools in the region (a) provide Athletic Trainers to athletic programs, (b) provide administrative support to the athletic programs in order to prevent injury or sudden death (i.e. policies and procedures in place to prevent issues from occurring and to deal with issues as they arise), (c) make basic lifesaving equipment readily available if and when needed.

\section{Methods}

\section{Design of the Study}

An explanatory sequential mixed methods design was utilized for this study. Creswell (2014) describes mixed method designs as an approach utilizing both quantitative and qualitative data to achieve a more robust and complex understanding of the problem being investigated. Specifically, in the explanatory sequential mixed methods design the researcher completes the quantitative portion of the data collection first and then follows up for further explanation with the qualitative data collection (Creswell, 2014)

Setting The researcher identified secondary schools that offer interscholastic sports through their state athletic association in the following states: Missouri, Illinois, Kansas, Nebraska, Oklahoma, Iowa, North Dakota, and South Dakota. These states were identified as members of the National Athletic Trainers Association District V (Mid-America Region) (NATA, 2018). The selection of these states allowed a regional assessment of emergency preparedness in multiple schools to make comparisons between varying states and schools of different sizes and locations. 
Participants All secondary schools who offered interscholastic sports through their respective state athletic association in 2018 were identified and contacted to participate in this study $(\mathrm{n}=2,470)$ and 151 individuals responded to the survey for an abnormally low response rate to this study. Identification of athletic directors was done in conjunction with the Korey Stringer Institute at the University of Connecticut and the Athletic Training Location and Services (ATLAS) whom identified the contact information for all the public secondary schools in the United States. The athletic administrator was identified as the contact person for each of the public schools in the region. This was similar to previous studies, examining the level of medical care to secondary school athletic programs (Dewitt, Unruh, \& Seshardi, 2012; Schneider et al., 2017). Participants were informed they will not be compensated for participation in this study, however any participant will be provided the opportunity to review the findings of this study.

\section{Data Collection Tools.}

\section{Quantitative}

A survey was distributed to all participants utilizing Qualtrics data collection software (Provo, Utah). This survey was designed to analyze the best practice recommendations regarding medical care for secondary school athletic programs as defined by Casa et al. (2013). The survey instrument was adopted from previous literature (Dewitt, Unruh, \& Seshardi, 2012; Schneider et al., 2017) and refined to address the specific recommendations described in the research questions, specifically to focus on medical personnel, facilities and equipment, and policies and procedures regarding emergency planning (See Appendix 1). This instrument was further sub- 
divided into five sections. Section 1 addressed demographic information on the school (i.e. population, ethnicity of school, socioeconomic status, location, and information regarding the participant). Section 2 further addressed the demographics of the interscholastic sports being offered on the campus, specifically addressing the number of sports and if the school offered interscholastic football as a competitive sport. Section 3 addressed the presence of policies and procedures addressing some of the best practice recommendations such as heat, lightning, and emergency planning. Section 4 addressed the presence of specific emergency equipment during athletic participation. Section 5 addressed the personnel who was responsible for the medical provisions of the athletic program. Sections $3-5$, which address the induvial research questions, asked participants to respond to the statement utilizing a five-point rating scale with 1 representing always and 5 representing never. The final response rate for this instrument was 151 .

\section{Rural/Urban Classification}

Utilizing the survey instrument, each participant was asked to identify the postal code the school resides in. The postal code each participant provided was utilized to categorize the school into one of the three distinct categories: Metropolitan/urban, large rural/micropolitan, and small town/rural. This classification was standardized and completed utilizing the United States Department of Agriculture's Rural Urban Commuting Area (RUCA) codes. The RUCA codes were developed by the U.S. Department of Agriculture based on the 2010 census data and are utilized to categorize the distinct regions of the United States (USDA, 2019). The RUCA codes consider 
population density, urbanization, number of citizens commuting to a place of employment, and the demographics of the closest urban center to the postal code.

Each community postal code is assigned a number ranging from 1 to 10 ; with 1 representing a large metropolitan and urbanized area with a citizen flow remaining in the urbanized zone, and 10 representing an isolated rural community with the primary citizen flow outside of a urbanized area or small urban community. This study has grouped the participants into three groups utilizing the RUCA Codes to answer the research question. The groups consist of metropolitan/urban zones, large rural/micropolitan, and small town/rural groupings.

\section{School Size Classification}

Each participant was asked to provide a range of the student enrollment at their school when completing the survey instrument. The instrument utilized a range of seven distinct enrollment classifications: a) less than 150, b) $151-300$, c) $301-500$, d) 501 750 , e) $751-1,000$, f) $1,000-1,500$, and g) greater than 1,500 . This study re-classified the responses into four groups: a) small schools with an enrollment less than $150(n=24)$, b) small schools with an enrollment between $151-300(n=46)$, c) medium sized schools with an enrollment from $301-750(\mathrm{n}=37)$, and d) large schools with an enrollment greater than 750 students $(\mathrm{n}=42)$.

\section{Quantitative Data Analysis}

Quantitative data was collected from the survey instrument and grouped according to the underlying theme of the research question being investigated, policies and procedures, emergency equipment, and medical personnel available. The average responses from each of the items on the instrument were compared based on the research 
questions with the independent variables of urbanization classification, school enrollment size, and state utilized to make comparisons between the groups. One Way ANOVAs were utilized to determine mean differences and Tukey post hoc analysis were conducted to examine differences between the individual subgroups. In groups that were nonhomogenous a Welch adjustment was completed to compensate for the unequal sample sizes in the groups and to assist with reducing the potential for Type I error.

\section{Qualitative}

Once the initial quantitative data collection was completed the researcher conducted semi-structured interviews to gather further information regarding the athletic directors' perceptions of the emergency preparedness policies in place at their respective schools.

\section{Data Collection}

Five participants were selected from those individuals who agreed to participate in the follow-up qualitative portion of the research design. These participants were sent an e-mail invitation to participate in the qualitative component of this study. The e-mail invitation included a personalized letter, information about the study, and contact information for the researcher. Upon verification for continuation in the study, participants were interviewed over a phone conversation and recorded utilizing a voice recorder at a time that was convenient and agreed upon between the researcher and participant. A cross-section of athletic directors from various states was the goal of this research however, due to the anonymous nature of the survey instrument only individuals who volunteered were selected.

\section{Interview Protocol}


Each interview followed a semi-structured interview protocol (Appendix B) and lasted approximately 20-30 minutes. Additional prompts were utilized to solicit more information regarding the level of implementation of the emergency policies in place at their respective school. The interview protocol consisted of five initial questions and sub-prompts to guide the conversation after the initial answer. In questions regarding the current policies in place for students and coaches, participants were asked an open-ended question, "If resources were available to implement more policies and training, what would you implement?" These questions were designed to elicit a more detailed response and to assess the desire for improvement of the current policies in place.

\section{Data Analysis}

Transcripts of the five interviews were analyzed by the primary researcher utilizing an inductive reasoning app. Merriam \& Tisdell (2015) describe inductive reasoning an approach to search for patterns through a result of observations, starting with a broad theme and deducing subthemes as saturation is achieved. The interviews were coded and identified themes focused on the most common policies or strategies in place that specific participants had taken to facilitate emergency planning in their respective schools. This process was repeated through each of the participants, at which point data saturation occurred. In addition to the prominent themes, some common subthemes were developed. Upon completion of identifying the themes, the themes and quotes were peer-reviewed to check for consistency. 


\section{Results}

\section{Research Question 1: What differences exist between urbanization}

\section{classification regarding personnel, administrative procedures, and the presence of}

\section{emergency equipment?}

\section{Administrative Policies}

There was a statistically significant difference between urbanization classification groups in the requirement of all coaching personnel, including volunteers, to possess current First Aid and CPR certification $(F(2,40.921)=4.454, p=.018)$. A Tukey post hoc analysis revealed the differences between small town rural communities $(M=1.38$, $S D=.744)$ and micropolitan $(M=2.26, \mathrm{SD}=1.558)$. There was also a statistically significant difference between urbanization classification groups and the presence of a written emergency action plan accessible to all members of the coaching staff at each athletic site $(F(2,50.819)=3.680, p=.032)$.

\section{Personnel}

There were no statistically significant differences between the different communities regarding the emergency equipment being available for use. However, there was a statistically significant difference between urbanization classification and the presence of an athletic trainer on campus for all home competitions $(F(2,48.897)=$ $20.364, p<.001)$ and the presence of an athletic trainer on campus during team practices $\mathrm{F}(2,43.576)=20.364, p<.001)$. Tukey post-hoc analysis revealed differences between the presence of the athletic trainer at home competitions in small town/rural communities $(M=3.22, S D=1.324)$ and both micropolitan $(M=2.11, S D=1.330)$ and metropolitan communities $(M=1.85, S D=1.091)$. Tukey post hoc analysis also revealed differences 
between the presence of athletic trainers at all practices between small town/rural communities $(M=4.23, S D=1.062)$ and both micropolitan communities $(M=3.00, S D$ $=1.667)$ and metropolitan communities $(M=2.50, S D=1.305)$. There was no significant difference between the presence of an athletic trainer between micropolitan and metropolitan communities. There was also no statistically significant difference between the different urbanization classifications and the presence of Emergency Medical Services (EMS) for the duration of all home football games $F(2,137)=2.885, p=.059)$.

\section{Research Question 2: What differences exist between enrollment size of the} school regarding personnel, administrative policies and procedures, and the presence of emergency equipment?

There was a statistically significant difference between schools of different enrollment sizes and the requirement of students who participated in sports being required to provide proof of medical insurance before participating in any activities $F(3,144)=4.280, p=.006)$. Post hoc analysis revealed the differences existed between schools with less than 150 students $(M=3.38, S D=2.12)$ and schools with 301-750 students $(M=1.78, S D=1.62)$ and schools greater than 751 students $(M=2.02, S D=$ 1.77). (See Appendix 3)

There was a statistically significant difference between schools of different enrollment sizes and the presence of a written and posted Emergency Action Plan (EAP) in an accessible location known to all members of the coaching staff $F(3,144)=2.929$, $p=.036$ ). Post hoc analysis revealed the differences existed between schools with less than 150 students $(M=3.04, S D=1.83)$ and schools with more than 750 students $(M=1.98$, $S D=1.33) .($ See Appendix 4) 
There were no significant differences in the presence of basic emergency equipment such as Automated External Defibrillators (AEDs) and a cellular phone being present to permit access to the emergency medical system. However, there was a significant difference in the school enrollment size the number of AEDs present at the school. $F(3,73.790)=5.591, p=.002)$. Post-hoc analysis revealed the differences existed between the schools with the lowest enrollment $(M=1.65, S D=.775)$ and schools with largest enrollment $(M=2.78, S D=1.53)$. (See Appendix 5)

There was a significant difference in the school enrollment size and the presence of an athletic trainer during home competitions for all teams $F(3,144)=26.866, p<$ .001). Post hoc analysis revealed significant differences between schools with the smallest enrollment size $(\mathrm{M}=3.79, S D=1.14)$ and schools with $301-750$ students $(M=$ 2.39, $S D=1.25)$ and schools larger than 750 students $(M=1.48, S D=.707)$. Differences also existed between schools of 301-750 students and all other groups. There was also a significant difference between schools of more than 750 students and schools of all other sizes with larger schools reporting having an athletic trainer more often than smaller schools (See Appendix 6)

There was a significant difference in the school enrollment size and the presence of an athletic trainer during all practices $(F 3,144)=50.182, \mathrm{p}<.001)$. Tukey post hoc analysis revealed significant differences between schools with the smallest enrollment size $(M=4.71, S D=.550)$, schools with $301-750(M=3.47, S D=1.25)$ students and schools larger than 750 students $(M=1.98, S D=1.20)$. There was also a significant difference between schools of more than 750 students and schools of all other sizes with 
a majority of the larger enrollment schools having an athletic trainer present at all practices.

Research Question 3: What barriers exist with athletic directors that prohibit the implementation of best practice recommendations for their respective athletic programs?

Four sub-themes emerged from the data collection regarding the barriers that exist in the implementation of best practice recommendations. These themes are available in Appendix 7.

\section{Professional Development}

Multiple respondents identified the current professional development structure as a barrier for implementing knowledge initiatives within their athletic department. One participant stated, “They do different professional development for teachers so it's really difficult... there is no time set aside for me." This was also reiterated by another participant who stated, “There's different professional development for teachers so it's really difficult; they are doing professional development for education." This demonstrates that the dual roles a lot of coaches assume at the secondary school level and the requirements of professional development for education may impact the amount of time that can be dedicated to training in other areas of health and safety..

Secondary to the professional development requirements of coaches who are also educators is the expectation of the coach to enhance their education pertaining to their respective sport. Participant 3 stated, "If anything comes up and our coaches want to take it and learn about it... the tackling drills and stuff like that, we'll pay for it." Participant 4 also responded similarly when asked about professional development opportunities for 
coaches by stating, "Not just safety... I think with the development of the coach we definitely lack on that."

\section{Resources/Budgeting}

When participants were asked about barriers preventing the implementation of best practice recommendations, multiple respondents identified funding and budget constraints and resources the primary issues prohibiting them from implementing current recommendations. One participant stated, "Funding is the biggest one." Another respondent stated, "It's just too costly to have someone here preventative, I wish I could." In addition to the cost of hiring an athletic trainer, respondents also mentioned the cost of equipment stating, "Funding for that comes from our athletic budget, which is sad because that stuff is expensive." Participant 4 also described a shortage of teachers that needed to be addressed before the school could hire an athletic trainer.

\section{Research Question 4: What factors influence athletic directors in the implementation of best practice recommendations for their respective athletic departments?}

\section{Mandates}

The primary factor that influenced the implementation of policies pertaining to sudden death was the presence of a state mandate or legislation that required the policy to be in place. Every respondent mentioned the state mandates when asked about the policies currently in place in their school. As one participant explained, "There's a lot that are state mandated: concussions, extreme heat, sudden cardiac," Another stated, "We have a state mandate where everyone has to do a Heads-Up concussion form that we have to do and give to each parent and we make them turn it in." 
These legislative guidelines are important factors in influencing the policy to be in place, however when no state mandate exists the extent of the policies were limited. As participant 1 stated, "All we do is follow the state guidelines in terms of what they are required to do." This was further supported by participant 4 who stated, "ImPact testing... It's not required by law to have it, its just highly suggested but we can't force them... If they choose to opt out there is nothing we can do." In contrast to states that lack state mandates regarding the presence of policy, states that enforce these policies seem to encourage athletic directors to adhere to those guidelines. This was stated by Participant 5 who stated, "We have an auditor from the state that comes in and takes a look at all those."

\section{Discussion}

The purpose of this study was to examine the extent to which secondary school athletic programs were adhering to the recommendations regarding the prevention of sudden death and athletics, to determine the barriers prohibiting the implementation of these policies, and to determine the current perceptions and extent of implementation of the recommendations at the respective schools. The National Athletic Trainers Association (NATA), the American Academy of Family Physicians (AAFP), and the American Medical Association (AMA) have published these recommendations to reduce the legal liability to institutions (Almquist et al., 2008). This study examined specific components of these recommendations by assessing specific components including personnel, equipment, and specific policies relating to the prevention of sudden death. 


\section{Personnel}

One recommendation that has risen from the inter-association task forces regarding best practices in secondary school athletic programs is the presence of an athletic trainer at all practices and competitive events (Casa et al., 2007). The benefits of having an athletic trainer are widely described in the literature. These benefits include providing immediate care to an injured athlete (Kerr et al., 2005), increasing knowledge regarding concussions to both parents and students (Wallace, Covassin, Nogle, \& Kovan, 2017), and an increase in injury reporting (Yard, Collins, \& Comstock, 2009). Despite the recommendation that an athletic trainer be present for all secondary school athletic programs, the actual implementation of this practice is still significantly low.

Previous authors have identified only $37 \%$ of public schools utilized the services of an athletic trainer (Pryor et al., 2015) with an even lower percentage of $28 \%$ when examining the presence of an athletic trainer at private schools (Pike, Pryor, Mazerolle, Stearns, \& Casa, 2016). While this study did not specifically examine the difference between public schools and private schools, we did examine the differences of an athletic trainer being present between different urbanization classifications of the school. We found that there was a significant difference between the presence of an athletic trainer at both practices and games between small town/rural communities and communities with larger population centers, with larger urban areas being more likely to utilize the services during a game and practice. This lack of athletic trainers in the rural setting has been previously described by Pike, Pryor, Vandermark, Mazerolle, \& Casa (2017).

The underrepresentation of healthcare providers in rural communities is a commonly known issue. Authors have noted the disparities that currently exist between 
rural communities and their urban counterparts (Wilson et al., 2009). It cannot be ignored that rural communities present a significant barrier to hiring qualified healthcare personnel to act as healthcare providers in high school athletics. One participant stated, "We can't expect them to go to the end of the world to do this," further describing the significant barrier implementing an athletic trainer in every high school across that state would pose. These non-budgetary concerns have also been described by previous authors (Mazerolle et al., 2015; Schneider et al., 2017).

However, the impact of the budgetary concerns is still the primary barrier impacting the hiring of athletic trainers (Mazerolle et al., 2015). This was also commonly cited in the interviews conducted during this study. Only one of the participants in this study had the capability to hire more than one athletic trainer, however he even stated multiple times that this was a rarity in the state to have three athletic trainer and that most schools struggled to afford one. All of the other athletic directors interviewed stated that they had to seek agreements with local hospitals in order to have an athletic trainer present at their high school. When questioned as to what was preventing them from hiring an athletic trainer money was commonly cited. One participant even mentioned that there was a need for teachers in specific content areas, and they needed to fill those first before they could even consider hiring an athletic trainer.

\section{Policies}

\section{Emergency Planning}

One specific recommendation embedded in the best practices as described by Casa et al., (2012) is the presence of an Emergency Action Plan (EAP) that is specific to 
each individual site. The NATA position statement regarding EAPs provides the details that should be included in this plan (Andersen et al., 2002). This study did not seek to examine the extent to which the emergency plan met the recommendations put forth in the NATA position statement, however it did inquire as to the presence of the emergency plan. The presence of an EAP was consistent across all schools. Many of the schools actually described their plans as very extensive, detailing the presence of policies in the plan regarding lightning, heat policies, concussion, active shooter, and intruder in the building. While not all of these policies pertain to health and safety specific to the original research question, the implementation of a plan and rehearsal of all aspects of the EAP is important.

\section{Education}

The education of coaches is commonly seen as a method to reduce the risk of injury, illness, and sudden death for secondary school athletes. Many states have implemented policies, either through their respective state activities association or through legislative action in the political sphere. It is widely recognized that education and knowledge for prevention and recognition of injuries is necessary in coaches. This study specifically examined the methods of that education and found that many of the coaches were offered training and education on specific aspects of health care including concussions, heat illness, and CPR training. These education policies fall within the national norm on coaching education based off of current events highlighted in the media; however, even with the state-mandated training and education, the question of the effectiveness of this training still remains. 
Previous studies have demonstrated that even with education, significant gaps in the knowledge still existed among students (Shenouda et al., 2017), and coaches (Barron et al., 2009). While this study did not seek to examine the current knowledge gaps in the treatment of injuries, it did seek to examine the extent to which coaches obtained education specific to health and safety. CPR and First Aid certification is highly recommended and even required in multiple states as an important educational training that all members of the coaching staff should obtain prior to the start of the season. This study found no differences between the coaches being certified in CPR when comparing school size and the rural/urban classifications of the respective schools. While this finding is not statistically significant, it is a significant improvement from previous research which found that many coaches, specifically in rural communities, were not required to be certified in CPR or First Aid (Schneider et al., 2017). This was further supported by the interviews in which every participant stated they required their coaches to be certified in CPR before the start of the season. Many of the Athletic Directors interviewed also stated that because of the rural nature of their school, they had become certified instructors in order to make the training more readily available to all coaches and to ensure that it was completed.

A particularly interesting finding in this study was that all of the athletic directors interviewed stated that they had a desire to improve education for both the coaches and the student athletes yet were unable to fulfill that want, citing time as a primary constraint. Participants stated that although they would like to implement education, many of their coaches are also teachers and most of the professional development had to be devoted to teaching and not coaching. In addition to the increased training for 
education, the athletic directors in this study were also focused on improving coaching techniques that would improve performance on the field and not on health and safety. This is not surprising as often the coach's performance appraisal and reputation is based on wins and losses so improving the education specific to the sport would be a focus for those individuals.

When asked questions regarding educational opportunities to student athletes, multiple participants responded similarly by stating they would prefer to implement education regarding diet and sleep for the student athletes. This was particularly interesting, in that only one of the respondents mentioned education specifically to the commonly cited mechanisms of athletic related injuries as a technique that he or she would implement. One individual did mention the impact of overuse injuries and specializing in one sport as a major concern for risk of the development of chronic injuries. A few of the respondents who mentioned diet, specifically mentioned the cutting of weight and eating habits of female athletes. One potential explanation for this response is that interviews were conducted during the winter when weight regulating sports like wrestling are more prominent.

\section{Conclusions}

The need for improved and standardized policies impacting the healthcare secondary school athletes receive is a prominent need across the United States. Under current regulations, each state is responsible for developing legislation impacting the secondary schools in their jurisdiction creating inconsistent policies and procedures. While budget constraints are likely not going to change as each of these items and personnel continue to increase in cost, determining methods to locate and secure funding 
for these services should be a priority of athletic directors. Two primary

recommendations were identified based on this research to assist with this

recommendation. First, athletic directors should creatively seek external funding where available to assist with improving the healthcare currently being offered. This can be done through corporate sponsorships, such as casinos, community programming through local hospitals and fire departments to secure needed equipment, and even through fundraising through the current Sports Medicine structure at the school. A failure to secure the needed funding through external revenue sources could place the school at increased risk for negligence and liability.

\section{Limitations}

There were a few limitations with this study. The response rate for this survey was exceptionally low, so these results should be carefully interpreted, and further examination may be needed to generalize regarding this region. Also, because the selection of interview participants was done anonymously and on a random basis, all but one of the interviews occurred with athletic directors from small rural schools and two of them were from the same state. This study also had a heavy population of rural schools and was conducted in a rural region of the United States. This would make it hard to generalize this information to a more urbanized part of the country. 


\section{References}

Alexander, E. (2017, June 16). Kent State football player Tyler Henitz primary cause of death ruled hyperthermia. Retrieved from

http://www.cleveland.com/sports/college/index.ssf.2014/06/hypothermia_and_foo $\underline{\text { tball_a_dan.html }}$

Andersen, J. C., Courson, R. W., Kleiner, D. M., \& McLoda, T. A. (2002). National Athletic Trainers' Association position statement: emergency planning in athletics. Journal of Athletic Training, 37(1), 99.

Barron, M.J., Powell, J. W., Weing, M. E., Nogle, S. E., \& Branta, C. F. (2009). First aid and injury prevention knowledge of youth basketball, football, and soccer coaches. International Journal of Coaching Science. 3(1). 55-67.

Batra, A. S., Hohn, A. R. (2003). Consultation with the specialist populations, syncope, and sudden cardiac death in children: who's at risk? Pediatrics in Review, 24(8),269-275.

Beach, A. F. (2003). Dying to play: School liability and immunity for injuries that occur as a result of school-sponsored athletic events. Sports Lawyers Journal 10, 275294.

Blanchard, J. (2012). A comparative study of K-12 and higher education sport related negligence litigation. Journal for the Study of Sports and Athletes in Education, 6(2), 201-220.

Bonza, J. E., Fields, S. K., Yard, E. E., \& Dawn Comstock, R. (2009). Shoulder injuries among United States high school athletes during the 2005-2006 and 2006-2007 school years. Journal of athletic training, 44(1), 76-83. 
Buxton, B. P., Okasaki, E. M., Ho, K. W., McCarthy, M. R. (1995). Legislative funding of athletic training positions in public secondary schools. Journal of Athletic Training, 30(2), 115.

Cournoyer, J., \& Tripp, B. L. (2014) Concussion knowledge in high school football players. Journal of Athletic Training, 49(5), 654-658.

Casa, D. J., Almquist, J., Anderson, S. A., Baker, L., Bergeron, M. F., Biagioli, B., ... Valentine, V. (2013). The inter-association task force for preventing sudden death in secondary school athletic programs: Best practice recommendations. Journal of Athletic Training, 48 (4), 546-553.

Casa, D. J., Anderson, S. A., Baker, L., Bennett, S., Bergeron, M. F., Connollly, D., ... \& Fleck, S. (2015). The inter-association task force for preventing sudden death in collegiate conditioning sessions: best practice recommendations. Journal of Athletic Training, 48(4), 546-553.

Casa, D. J., Guskiewicz, K. M., Anderson, S. A., Courson, R. W., Heck, J. F., Jimenez, C. C., ... Walsh, K. M. (2012). National Athletic Trainers Association position statement: preventing sudden death in sports. Journal of Athletic Training, 47(1), 96-118.

Courson, R., Goldenberg, M., Adams, K. G., Anderson, S. A., Colgatell, B., Cooper, L., ... Turbak, G. (2014). Inter-association consensus statement on best practices for sports medicine management for secondary schools and colleges. Journal of Athletic Training, 49(1). 128-137.

Dewitt, T. L., Unruh, S. A., \& Seshadri, S. (2012). The level of medical services and secondary school aged athletes. Journal of Athletic Training, 47(1) 91-95. 
Drezner, J. A., Rao, A. L., Heistand, J., Bloomingdale, M. K. \& Harmon, K. G. (2009). Effectiveness of emergency response planning for sudden cardiac arrest in United States high schools with automated external defibrillators. Circulation, 120(6), $518-525$.

Fletcher, E. N., McKenzie, L. B., \& Comstock, R. D. (2014) Epidemiological comparison of injured high school basketball athletes reporting to emergency departments and the athletic training setting. Journal of Athletic Training 49(3), 381-388.

Greenfield, S. (2013). Law's impact on youth sport: should coaches be 'concerned about litigation'? Sports Coaching Review 2(2) 114-123.

Guskiewicz, K. M., Weaver, N. L., Padua, D. A., \& Garrett, W. E. (2000). Epidemiology of concussion in collegiate and high school football players. The American journal of sports medicine, 28(5), 643-650.

Harmon, K. G., Asif, I. M., Klossner, D., Drezner, J. A. (2011). Incidence of sudden cardiac death in National Collegiate Athletic Association athletes. Circulation, $123,1594-1600$.

Harmon, K. G., Drezner, J. A., Wilson, M. G. \& Sharma (2014). Incidence of sudden cardiac death in athletes: a state of the art review. British Journal of Sports Medicine, doi doi:10.1136/bjsports-2014-093872

Herndon, D. (2017, March 21). School mourns as Lincoln Park sophomore dies during basketball tryout. News Harold. Retrieved from http://www.thenewsherald.com/news/school-mourns-as-lincoln-park-sophomoredies-during-basketball-tryout/article_cb062f02-0e74-11e7-afad0740425baa35.html 
Johnson, S. T., Norcross, M. F., Bovbjerg, V. E., Hoffman, M. A., Chang, E. \& Koester, M. C., (2017). Sports-related emergency preparedness in Oregon high schools. Sports Health, 9(2), 181-184.

Keeton, P. W., Dobbs, W. L., Keeton, R. E., Owen, D. G. (1984). Prosser and Keeton on the law of torts, USA: West Pub Co.

Kelto, A. (2015, September 4). How likely is it, really, that your athletic kid will turn pro? NPR. Retrieved from http://www.npr.org/sections/healthshots/2015/09/04/432795481/how-likely-is-it-really-that-your-athletic-kid-will$\underline{\text { turn-pro }}$

Kerr, Z. Y., Dompier, T. P., Dalton, S. L., Miller, S. J., Hayden, R., \& Marshall, S. W. (2015). Methods and descriptive epidemiology of services provided by athletic trainers in high schools: the National Athletic Treatment, Injury and outcomes Network study. Journal of Athletic Training, 50(12), 1310-1318.

Lear, A., Hoang, M., \& Zyzanski, S. J. (2015). Preventing sudden cardiac death: automated external defibrillators in Ohio High Schools. Journal of Athletic Training 50(10), 1054-1058.

Long, A., Scifers, J. R., Eilbacher, C. (2017). How do economic variables predict access to athletic training services? Athletic Training and Sports Health Care, 9(2), 6470.

Lynch, J., Smith G.D., Harper, S. A., Hillemeier, M., Ross, N., Kaplan, G. A., \& Wolfson, M. (2004). Is income inequality a determinant of population health? Part 1. A systematic review. The Milbank Quarterly, 82(1) 5-99. 
Marar, M., McIlvain, N. M., Fields, S. K., \& Comstock, R. D. (2012). Epidemiology of concussions among United States high school athletes in 20 sports. The American journal of sports medicine, 40(4), 747-755.

Maron, B. J., Doerer, J. J., Haas, T. S., Tierney, D.M., \& Mueller, F. O. (2009). Sudden deaths in young competitive athletes: Analysis of 1866 deaths in the United States, 1980-2006. Circulation, 119(8), 1085-1092.

Maron, B. J., Haas, T. S., Murphy, C. J., Ahluwalia, A., \& Rutten-Ramos, S. (2014). Incidence and causes of sudden death in US college athletes. Journal of the American College of Cardiology, 63(16), 1636-1643.

Matthews, T. J., \& Waller, L. (2016). Coaches and the law: a study of the training of coaches in the United States. Mediterranean Journal of Social Sciences 7(1), 475479.

McCrea, M., Hammeke, T., Olsen, G., Leo, P., \& Guskiewicz, K. (2004). Unreported concussion in high school football players: implications for prevention. Clinical Journal of Sport Medicine, 14(1), 13-17.

Meredith, M. L., Watson, A. M., Gregory, A., Givens, T. G., Abramo, T. J., \& Kannankeril, P. J. (2013). Sudden cardiac arrests, automated external defibrillators, and medical response plans in Tennessee high schools. Pediatric Emergency Care 29(3). 352-356.

Miles, S. H., \& Prasad, S. (2016). Medical Ethics and School Football. The American Journal of Bioethics, 16, 6-10. doi: 10.1080/15265161.2016.1128751

NATA. (n.d.) Retrieved from http://www.nata.org 
Pike, A., Pryor, R. R., Mazerolle, S. M., Stearns, R. L., \& Casa, D. J. (2016). Athletic trainer services in US private secondary schools. Journal of Athletic Training 51(9), 717-726.

Pike, A., Pryor, R. R., Vandermark, L. W., Mazerolle, S. M., \& Casa, D. J. (2017). Athletic trainer services in public and private secondary schools. Journal of Athletic Training 52(1), 5-11.

Pryor, R. R., Casa, D. J., Vandermark, L. W., Stearns, R. L., Attanasio, S. M., Fontaine, G. J., Wafer, A. M. (2015). Athletic training services in public secondary schools: A benchmark study. Journal of Athletic Training 50(2), 156-162.

Powell, J. W., \& Barber-Foss, K. D. (2000). Sex-related injury patterns among selected high school sports. The American Journal of Sports Medicine, 28(3), 385-391.

Ransone, J., \& Dunn-Bennett, L.R. (1999). Assessment of first-aid knowledge and decision making of high school athletic coaches. Journal of Athletic Training. 34(3), 267-271.

Rechel, J. A., Yard, E. E., \& Comstock, R. D. (2008) An epidemiologic comparison of high school sports injuries sustained in practice and competition. Journal of Athletic Training, 43(2), 197-204.

Reschovsky, J. D., \& Staiti, A. B. (2005). Access and quality: does rural America lag behind?. Health Affairs, 24(4), 1128-1139.

Rieder, R. W., \& Woodward Jr, W. B. (1993). University liability for sports injuries. NASPA Journal, 31(1), 56-63. 
Rothmier, J. D., Drezner, J. A., \& Harmon, K. G. (2007). Automated external defibrillators in Washington state schools. British Journal of Sports Medicine, 41(5), 301-305.

Schmied, C., \& Borjesson, M. (2014). Sudden cardiac death in athletes. Journal of internal medicine, 275(2), 93-103.

Schneider, K. R., Meeteer, W., Nolan, J. A., \& Campbell, H. D. (2017). Health care in high school athletics in West Virginia. Rural and Remote Health. 17 (3879).

Skinner, A. C., \& Slifkin, R. T. (2007). Rural/urban differences in barriers to and burden of care for children with special health needs. The Journal of Rural Health, 23(2), $150-157$.

Swenson, D. M., Collins, C. L., Best, T. M., Flanigan, D. C., Fields, S. K. \& Comstock, R. D., (2013). Epidemiology of knee injuries among US high schools athletes 2005/2006-2010/11. Medicine and Science in sports and exercise, 45(3), 462.

Tjong, V. K., Murnaghan, M. L., Nyhof-Young, J. M., \& Ogilvie-Harris, D. J. (2014). A qualitative investigation of the decision to return to sport after anterior cruciate ligament reconstruction: to play or not to play. The American journal of sports medicine, 42(2), 336-342.

United States Department of Agriculture. (2016, October). Rural Urban Commuting Area Codes. Retrieved from https://www.ers.usda.gov/data-products/rural-urbancommuting-area-codes.aspx

Valovich McLeod, T. C., Schwartz, C., \& Bay, C. (2007). Sport related concussion misunderstanding among youth coaches. Clinical Journal of Sports Medicine. 17(2), 140-142. 
Valovich Mcleod, T.C., Cardenas, J.F. (2018). Emergency Preparedness of Secondary School Athletic Programs in Arizona. Journal of Athletic Training. 53(11).

Wasilko, S. M., \& Lisle, D. K. (2013) Automated external defibrillators and emergency planning for sudden cardiac arrest in Vermont high schools: a rural states perspective. Sports Health, 5(6), 548-552. 


\section{Section VI -}

Scholarly Practitioner Reflection 
Section VI -

\section{Scholarly Practitioner Reflection}

\section{How has this dissertation influenced your practice as an educational leader?}

As an educational leader, this process has changed the way in which I can professionally advocate for the well-being of young athletes in the secondary school setting and use my role as a leader in Athletic Training to assist in facilitating change. As a researcher and advocate in improving the policies relating to sudden death and adherence to best practice recommendations, I can take this research and work to help high schools enhance current policies and look for alternative methods to implement the policies that are currently recommended. This process has made me re-evaluate and look at the problem through a broader lens in an effort to understand the true barriers that exist regarding the implementation of these best practice recommendations. This research has highlighted the need to improve educational programs and increase the opportunities for education for a variety of populations. The information gathered here has provided me with an initial idea on the items that needed to improve the healthcare and safety of these student athletes and serve as an advocate for change.

As discussed in the research, the problem of changing the current culture in athletics is not going to be easy. Many of the coaches are still in the mindset of win at all costs, and parents and students are still attempting to reach the goal of a scholarship to a Division I institution and the potential professional contract. This has made me aware of the issues facing the high school athletic programs and allowed me to make informed recommendations that are not only impactful but also feasible for these institutions. 


\section{How has this dissertation process influenced you as a scholar?}

It has always been my goal of utilizing this doctoral program to advance my career in higher education. I have conducted some research before with my master's degree and even in the academic world, but during that time I have been solely a quantitative researcher. I have experience working with quantitative data and until completing this dissertation, I had no experience working with qualitative data collection methods. This research has opened my eyes to the qualitative approach to data collection and research. Initially I was very hesitant to implement the interview process and the qualitative piece, but after the urging of members of my committee I accepted the recommendation and the data and end product were significantly improved.

This has also inspired me to continue to expand on this research area and become an expert and professional advocate regarding sudden death in young children. This information has already driven my interest to approach this research in a variety of questions, including the adherence to best practice recommendations in youth club sports, and even among physical education programs across the United States. This program has shown me the importance of opening my eyes to the questions at hand and not limiting myself to just one approach. Upon completion of this program, I have been approached by some of the individuals that assisted me through this process and assisted me with the data collection to continue this important research. I look forward to continuing to contribute to the literature and the profession in the future. 


\section{Appendix 1: Survey Instrument}

\section{Emergency Planning Policies Assessment}

\section{SECTION I: Demographics}

1. Your school is a:
a. Public School
b. Private School
c. Charter School
d. Other (Please Specify)

2. Which of the following describes the population/enrollment of your school?
a. $<150$
b. $151-300$
c. $301-500$
d. 501-750
e. $751-1,000$
f. $1,001-1,500$
g. $>1,500$

3. Which of the following groups makes up the highest percentage of your student population?
a. African American
b. Caucasian (Non-Hispanic)
c. Hispanic
d. Native American
e. Other

4. What is the postal code (Zip code) your school is located in?

5. Your school is in a:
a. Rural Setting
b. Suburban Setting
c. Urban Setting

6. Is your school classified as a Title I school?
a. Yes
b. No

7. What is the job title for your current position?
a. Principal
b. Vice Principal
c. Athletic Director
d. Athletic Trainer
e. Other (Please Specify)
f.

\section{Section II: Interscholastic Sports}

8. Does your school offer football as an interscholastic sport?
a. Yes
b. No

9. How many interscholastic sports does your school offer? 
Please Answer the following questions utilizing the following scale:

$$
\begin{gathered}
1=\text { Always }(100 \% \text { of the time) } \\
2=\text { Usually (More than } 50 \% \text { of the time but less than } 100 \%) \\
3=\text { Sometimes (Approximately } 50 \% \text { of the time) } \\
4=\text { Rarely (Less than } 50 \% \text { of the time) } \\
0=\text { Never (0\% of the time) } \\
\text { N/A = Unsure }
\end{gathered}
$$

\section{SECTION III: Policies and Procedures}

10. All coaching personnel involved with the athletic teams (including volunteer coaches) possess up to date First Aid \& Cardiopulmonary Resuscitation (CPR) certification.
43
2
$1 \quad 0$
N/A

11. The playing/practice field is inspected before games/practices for potential hazards. (i.e. holes, dangerous objects, etc).

$$
\begin{array}{llllll}
4 & 3 & 2 & 1 & 0 & \text { N/A }
\end{array}
$$

12. Inclement weather conditions (i.e. lightning, severe storms) are monitored utilizing a standardized protocol or weather monitoring service.

$$
\begin{array}{llllll}
4 & 3 & 2 & 1 & 0 & \text { N/A }
\end{array}
$$

13. The inclement weather/lightning safety policy, if applicable, is reviewed with all members of the coaching staff annually.

$$
\begin{array}{llllll}
4 & 3 & 2 & 1 & 0 & \text { N/A }
\end{array}
$$

14. Extreme heat and humidity conditions are monitored utilizing a standardized protocol or weather monitoring service.

$$
\begin{array}{lllllll}
4 & 3 & 2 & 1 & 0 & \text { N/A }
\end{array}
$$

15. Practice and game times are modified and/or reduced in length when heat conditions exceed recommended values (80 degrees Fahrenheit and 75\% humidity).

$$
\begin{array}{llllll}
4 & 3 & 2 & 1 & 0 & \text { N/A }
\end{array}
$$

16. An annual pre-participation physical, conducted by a licensed health care provider, is required for all student athletes wishing to participate in interscholastic sports on campus.

$$
\begin{array}{lllllll}
4 & 3 & 2 & 1 & 0 & \text { N/A }
\end{array}
$$


17. All students participating in interscholastic sports are required to provide proof of medical insurance before any participation (including try-outs).

$$
\begin{array}{llllll}
4 & 3 & 2 & 1 & 0 & \text { N/A }
\end{array}
$$

18. Parent and/or guardian consent files are kept on file for all student athletes permitting treatment in an emergency situation.

$$
\begin{array}{llllll}
4 & 3 & 2 & 1 & 0 & \text { N/A }
\end{array}
$$

19. A written site specific Emergency Action Plan (EAP) is posted in an accessible location, known to all coaching staff, at all athletic sites on your campus. (This includes practice and game facilities).

$$
\begin{array}{llllll}
4 & 3 & 2 & 1 & 0 & \text { N/A }
\end{array}
$$

\section{SECTION IV: Equipment}

20. A working and reliable communication system is in place at each athletic venue (Cellular phone or landline phone) to permit immediate access to emergency medical services in the area.

$$
\begin{array}{lllllll}
4 & 3 & 2 & 1 & 0 & \text { N/A }
\end{array}
$$

21. An Automated External Defibrillator (AED) is present on site and accessible for use during all practices and games.

$$
\begin{array}{lllllll}
4 & 3 & 2 & 1 & 0 & \text { N/A }
\end{array}
$$

22. How many Automated External Defibrillators (AED's) are dedicated and available to use by the athletics department?

\section{SECTION V: Personnel}

23. An Athletic Trainer is present or on campus during home competitions for all teams.

$\begin{array}{llllll}4 & 3 & 2 & 1 & 0 & \text { N/A }\end{array}$

24. An Athletic Trainer is present or on campus during practices for all teams.

$$
\begin{array}{llllll}
4 & 3 & 2 & 1 & 0 & \text { N/A }
\end{array}
$$

25. Emergency Medical Services (EMS) are on site for the duration of all home football games (If applicable).

$$
\begin{array}{lllllll}
4 & 3 & 2 & 1 & 0 & \text { N/A }
\end{array}
$$

Would you be willing to participate in an approximately 15 minute interview over videoconferencing to expand on your answers? 
If yes, please provide your e-mail address for follow-up. 


\section{Appendix 2:}

\section{Qualitative Interview Questions}

1. What written policies do you have that pertain to safety for students who participate in athletics at your school? (Lightning, Heat, Concussion, etc).

a. If have some - What do you think about them? What do the coaches think about them? - Would you change anything about the policies if you could?

b. If not - If you were in the position to recommend a specific policy be implemented what would you advocate for?

c. If state policies - tell me a little more about the state policies. Are they working for your programs and schools? Is there any that you think are better than others?

2. Can you tell me about the educational programs/professional development programs required of your coaching staff relating to health and safety?

a. If none - What would you recommend adding if you could add any programs for the coaches?

b. IF some - Are they working for your coaches? What do the coaches think about the programs? How often are they put on? Who all has to attend?

3. Can you tell me about the structure of your sports medicine program. (i.e. Who is the primary person responsible?, Who is involved? What are their roles, Are they FT?, ) If no one is present what has prevented you from providing this service?

a. IF AT - How do you determine coverage? Who makes the recommendations for the coverage?

b. What aspects would you change to improve the medical care being provided to your athletes?

4. Are your student athletes required to complete any educational programming regarding safety and health issues in sports before participating? If so, can you please explain what those are.

a. Is there any changes you would make to that?

b. What programs would you add to enhance the student athlete's healthcare?

5. When providing financial resources to the Sports Medicine Program, how are decisions made on what to purchase?

a. What limitations exist in purchasing emergency equipment (i.e. Spine boards, AEDs, and other emergency supplies)?

b. Budget -

i. How is the budget set up?

ii. How is the budget determined for the Sports Medicine Program

iii. IS there anything you would change about the budgeting procedures for safety and first aid? 


\section{Appendix 3: Table: Themes from Qualitative Interview}

\begin{tabular}{|c|c|c|}
\hline Theme & Subtheme & Supporting Quotes \\
\hline \multicolumn{3}{|c|}{ Mandates } \\
\hline & State Mandates & $\begin{array}{l}\text { "We have the state mandate where } \\
\text { everyone has to do a Heads-Up } \\
\text { Concussion form they read and sign." - } \\
\text { "There's a lot that are state mandated.... } \\
\text { Concussions, extreme heat, cardiac } \\
\text { arrest." -5 } \\
\text { "All of our coaches have to take a course } \\
\text { annually... and we have an auditor from } \\
\text { the state that comes in to take a look at } \\
\text { those." -5 } \\
\text { "ImPact testing.... It's not required by law } \\
\text { to have it, its just highly suggested but we } \\
\text { can't force them.... If they choose to opt } \\
\text { out there is nothing we can do."- } 4 \\
\text { "The state has this sort of legislation to } \\
\text { what their return to play looks like and } \\
\text { you can actually have a lot of these } \\
\text { documents morphed together and have one } \\
\text { signature instead of like five or six."- }-2 \\
\text { "We have a state mandate where everyone } \\
\text { has to do a Heads-Up concussion form } \\
\text { that we have to do and give each parent... } \\
\text { we make them turn it in, in the written } \\
\text { form." - } 3 \\
\text { "Basically all we do is follow the state } \\
\text { guidelines, in terms of what they are } \\
\text { required to do." - } 1\end{array}$ \\
\hline & $\begin{array}{l}\text { National } \\
\text { Federation }\end{array}$ & $\begin{array}{l}\text { "The National Federation requires them } \\
\text { (coaches) to take the heart health and the } \\
\text { program on concussions, I do check off } \\
\text { and mandate that every person who deals } \\
\text { with athletics in my school." - } 4\end{array}$ \\
\hline \multicolumn{3}{|l|}{ Policies } \\
\hline & Concussion & $\begin{array}{l}\text { "as soon as the concussion is thought to be } \\
\text { discovered, we take the student out, and if } \\
\text { it is diagnosed.... They stay out."- } \\
\text { "They have to pass that official testing } \\
\text { (Concussion) or screening so to speak so }\end{array}$ \\
\hline
\end{tabular}




\begin{tabular}{|c|c|c|}
\hline & & they can return to play. - 2 \\
\hline & Environmental & $\begin{array}{l}\text { "If bad weather stuff moves in, all } \\
\text { students are brought in the school and put } \\
\text { through like we would if a tornado drill." } \\
-4 \\
\text { "For all our events we are set with a } \\
\text { lighting detector." - } 4 \\
\text { "Lightning that's a little different in the } \\
\text { fact that it is state mandated." - } 3 \\
\text { "If lightning strikes within } 10 \text { miles that's } \\
\text { when we have to come in and we shut it } \\
\text { down." - } 5\end{array}$ \\
\hline & Pre-Participation & $\begin{array}{l}\text { "we have the Heads-up Concussion, we } \\
\text { have the physical they get from the doctor } \\
\text { that they have to get." - } 4 \\
\text { "We will go over the concussion policy, } \\
\text { and the protocols, and its just } \\
\text { documentation that they have to read.... } \\
\text { We won't allow any kids to practice until } \\
\text { it's all done." - } 5 \\
\text { "When they get the physical and the } \\
\text { doctor says we really think someone needs } \\
\text { to listen to their heart.... It will show up } \\
\text { on our system and they are unavailable } \\
\text { until they get that done." - } 5 \\
\text { "They all take the ImPact Test in seventh } \\
\text { grade, ninth, and eleventh grade....we } \\
\text { have } 100 \% \text { participation." - } 4\end{array}$ \\
\hline & $\begin{array}{l}\text { Emergency Action } \\
\text { Plan }\end{array}$ & $\begin{array}{l}\text { "We have an emergency action plan that } \\
\text { covers every venue and what the } \\
\text { guidelines are from which coaches are } \\
\text { responsible down to what materials are } \\
\text { taken." - } 4 \\
\text { "We have an emergency plan that is in } \\
\text { place during the day that's like building } \\
\text { wide and it's color based... It's pretty } \\
\text { good... extensive which is good." - } 2\end{array}$ \\
\hline \multicolumn{3}{|l|}{ Responsibilities } \\
\hline & Athletic Directors & $\begin{array}{l}\text { "We don't have a call on that as an AD, as } \\
\text { soon as we see it... we call it and get } \\
\text { everyone off the field." - } 4 \\
\text { "There needs to be some situations where } \\
\text { you just have to be able to make the best }\end{array}$ \\
\hline
\end{tabular}




\begin{tabular}{|c|c|c|}
\hline & & $\begin{array}{l}\text { call." -4 } \\
\text { "I understand where there's the rules, but } \\
\text { sometimes I'd rather have some leeway on } \\
\text { it but I don't know how to do that either." } \\
-4 \\
\text { "When you get spread so thin, some of the } \\
\text { details were talking about are not gonna be } \\
\text { as great." - } 5 \\
\text { "The relationship you have as the AD, } \\
\text { how you communicate with people who } \\
\text { come to your campus... and understanding } \\
\text { that's just part of the position." - } 2\end{array}$ \\
\hline & Coaches & $\begin{array}{l}\text { "What we've actually done... is trained } \\
\text { two of our coaches to be ImPACT testers } \\
\text { so we can give our own." - } 4 \\
\text { "When the weather is bad we have two of } \\
\text { them (lightning detectors).... And our } \\
\text { coaches are responsible on days we have } \\
\text { storm warnings." - } 4 \\
\text { "Our coaches can continue to coach } \\
\text { without having to try and be the athletic } \\
\text { trainer and defensive coordinator at the } \\
\text { same time." - } 2 \\
\text { "All of our coaches have the lightning app } \\
\text { on their phone... if lighting strikes within } \\
10 \text { miles... we all come in. We are all } \\
\text { aware of it.. -5 } \\
\text { "I think that it's the demands we are } \\
\text { placing on coaches are so great for the } \\
\text { small amount of money they make." - } 5\end{array}$ \\
\hline & Athletic Trainer & $\begin{array}{l}\text { "One of the first things, I hired a trainer to } \\
\text { help with the protocols and follow all of } \\
\text { the new legislation." - } 4 \\
\text { " } 99 \% \text { of that (supplies purchasing) is } \\
\text { based on her recommendation." - } 1 \\
\text { "We lean on them for those decisions } \\
\text { (Safety)." - } 5\end{array}$ \\
\hline \multicolumn{3}{|l|}{ Education } \\
\hline & Parents & \\
\hline & Coaches & $\begin{array}{l}\text { "If the coaches have done it (Concussion } \\
\text { training) they cannot start the season, so } \\
\text { that makes sure it get's done." - } 2 \\
\text { "In certification for first aid, yea I think its }\end{array}$ \\
\hline
\end{tabular}




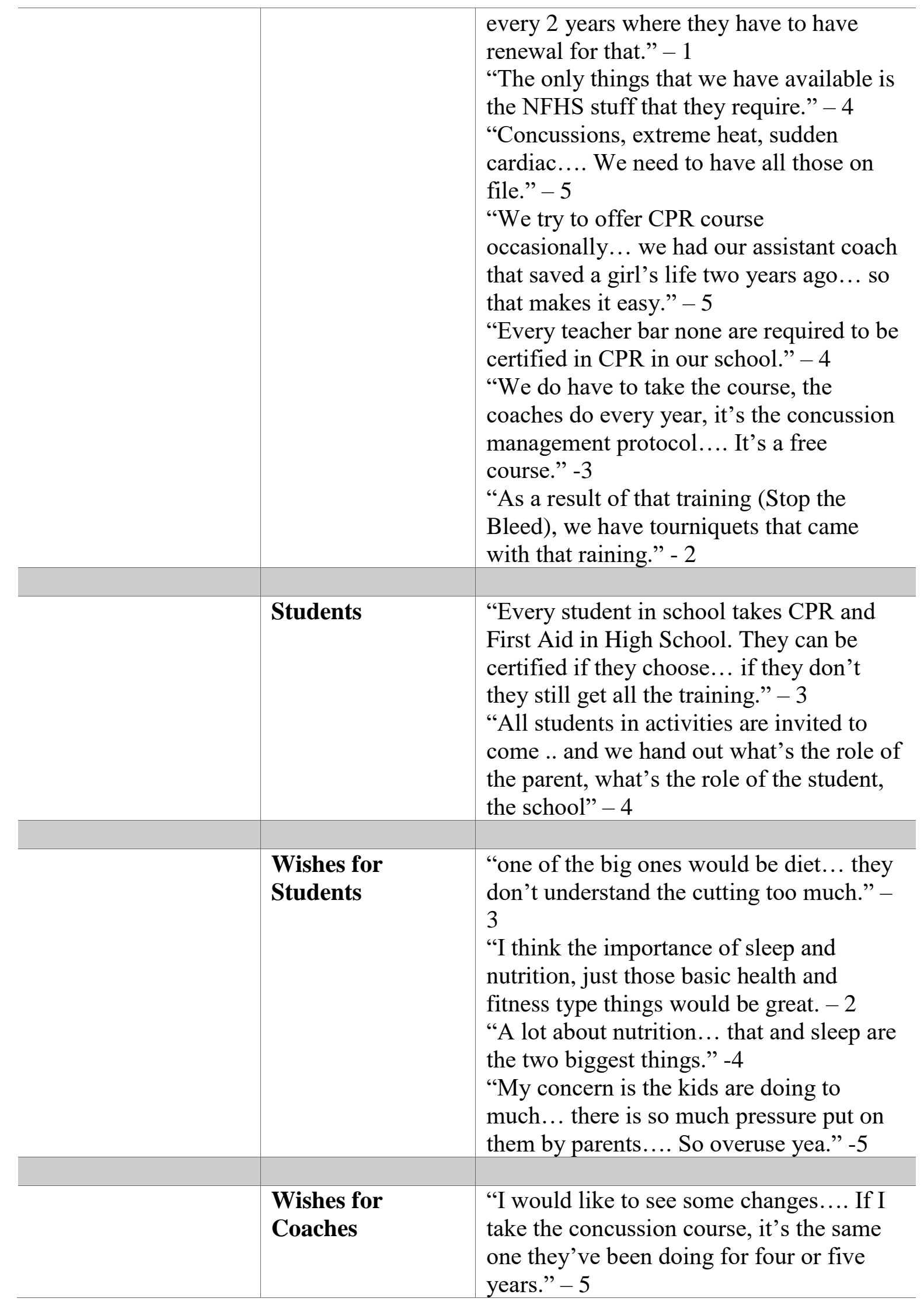




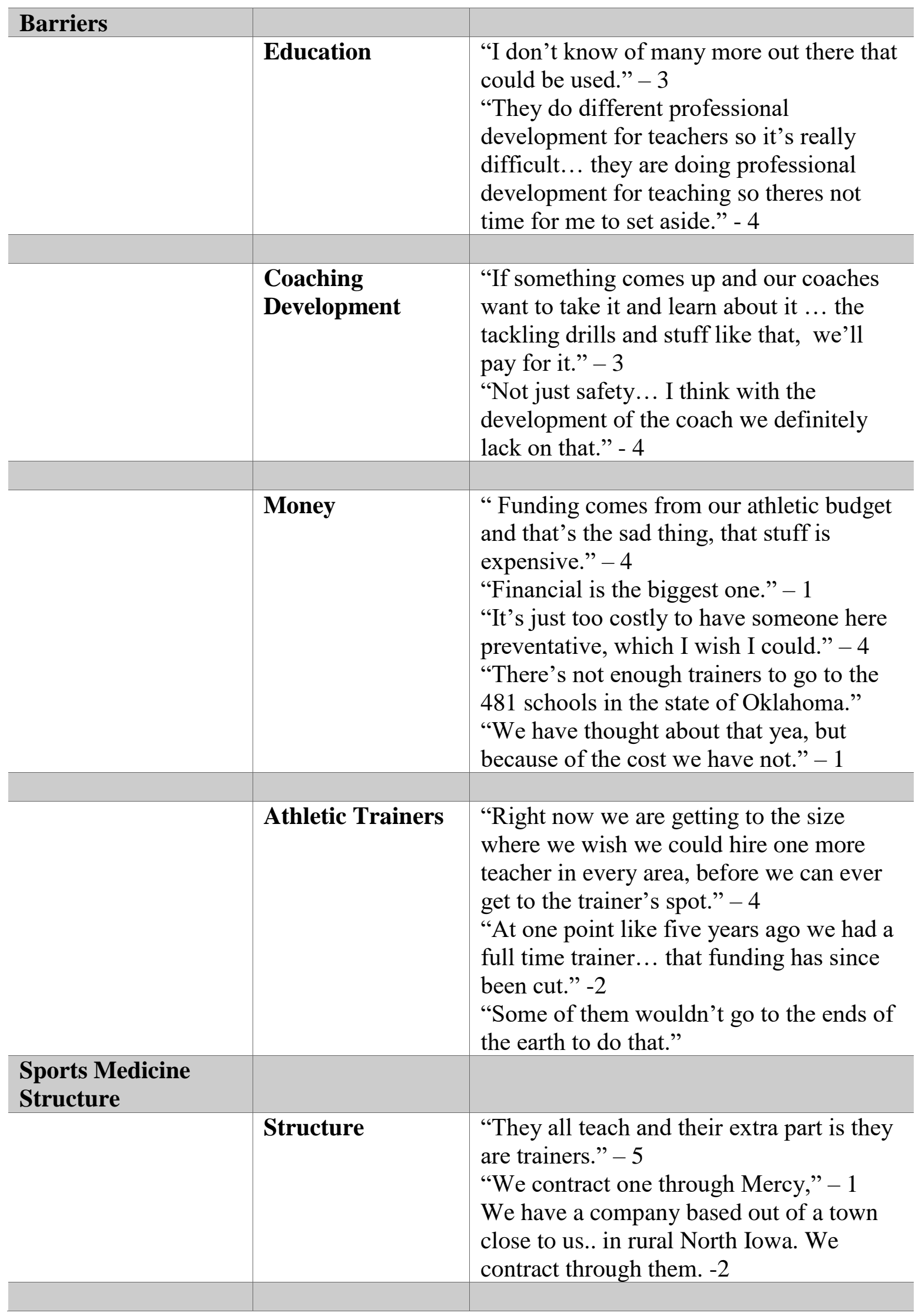




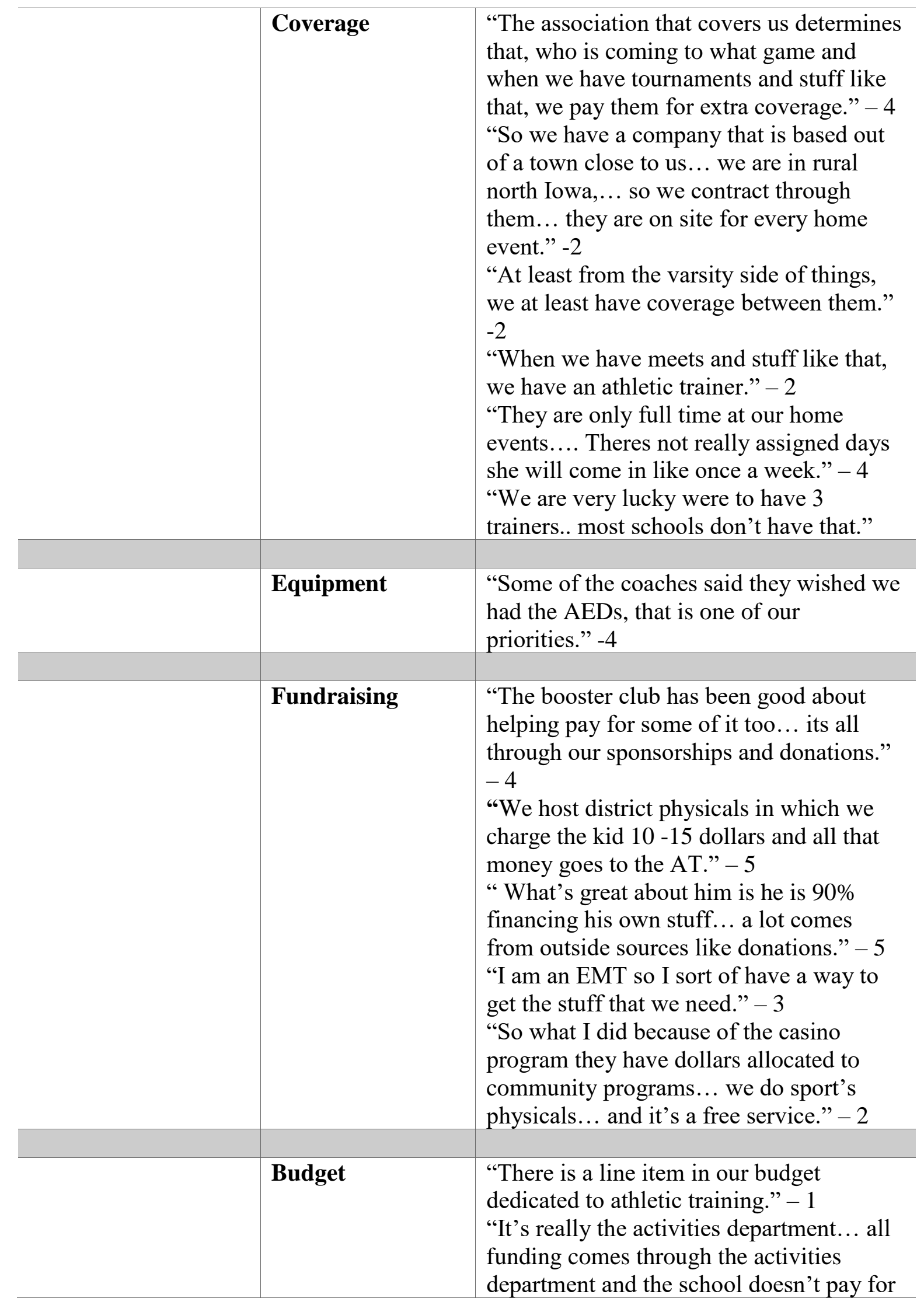




\begin{tabular}{l|l}
\hline \multicolumn{1}{|l|}{} & $\begin{array}{l}\text { anything else." }-4 \\
\text { "I would love to have a set amount of your } \\
\text { general budget, but that's never gonna } \\
\text { happen... its all one pile of money." - 4 } \\
\text { "When your talking about the safety and } \\
\text { well-being of kids it doesn't matter.... } \\
\text { We're gonna get it done." -5 } \\
\text { "I feel like right now it works for us you } \\
\text { know."-2 } \\
\text { "An injury can take care of a season, if } \\
\text { you can prevent it, I'm gonna spend the } \\
\text { money."-4 }\end{array}$ \\
\hline
\end{tabular}


Appendix 4: Figure - Athletic Trainer by Urbanization 


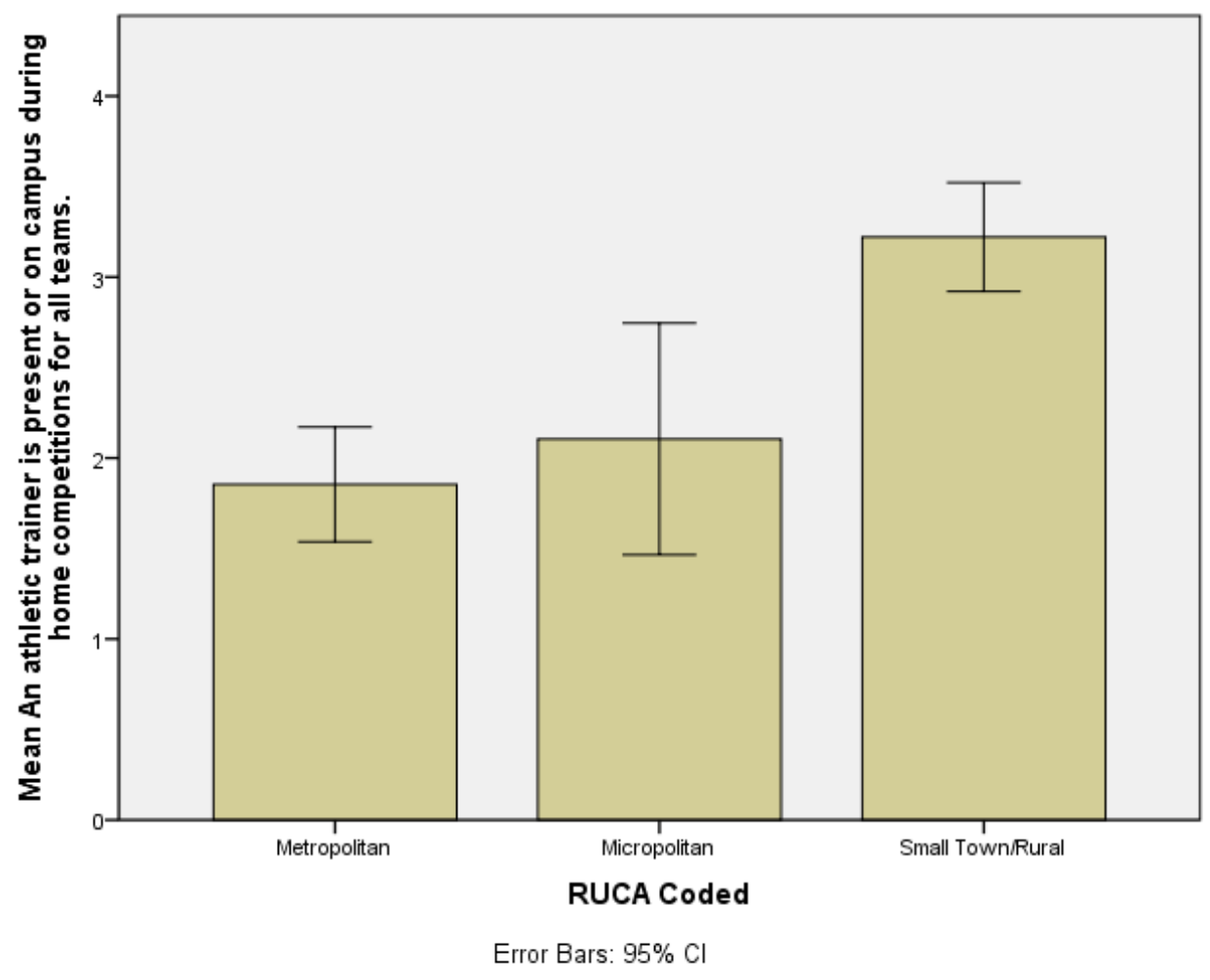

There

was a statistically significant difference between urbanization classification and the presence of an athletic trainer on campus for all home competitions $\left(\mathrm{F}\left(\mathrm{df}-2, \mathrm{df}_{2}=48.897\right)=20.364, \mathrm{p}=.000\right)$ and the presence of an athletic trainer on campus during team practices $\left(\mathrm{F}\left(\mathrm{df}=2, \mathrm{df}_{2}=43.576\right)=\right.$ 20.364, $\mathrm{p}=.000$ ). Tukey post-hoc analysis revealed differences between the presence of the athletic trainer at home competitions in small town/rural communities $($ mean $=3.22, \mathrm{sd}=1.324)$ and both micropolitan $($ mean $=2.11, \mathrm{sd}=1.330)$ and metropolitan communities $($ mean $=1.85, \mathrm{sd}$ =1.091). Tukey post hoc analysis also revealed differences between the presence of athletic trainers at all practices between small town/rural communities (mean $=4.23, \mathrm{sd}=1.062)$ and both micropolitan communities $($ mean $=3.00, \mathrm{sd}=1.667)$ and metropolitan communities $($ mean $=$ $2.50, \mathrm{sd}=1.305)$. There was no significant difference between the presence of an athletic trainer between micropolitan and metropolitan communicates.

\section{Appendix 5: Figure - Athletic Trainer by School Size}




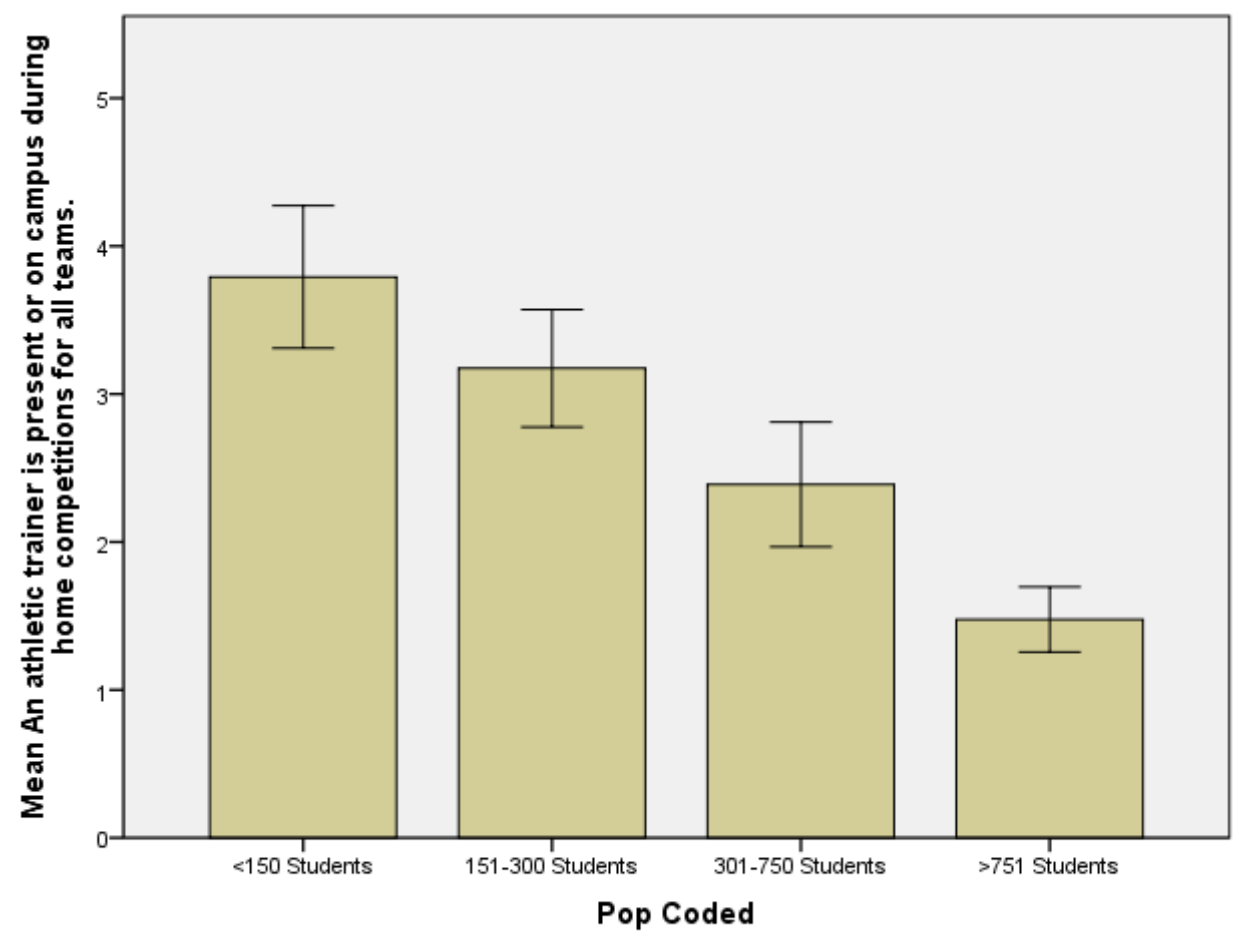

Error Bars: $95 \% \mathrm{Cl}$

There was a significant difference in the school enrollment size and the presence of an athletic trainer during home competitions for all teams $\left(\mathrm{F}\left(\mathrm{df}=3, \mathrm{df}_{2}=144\right)=26.866\right.$, $\mathrm{p}=.000$ ). Post hoc analysis revealed significant differences between schools with the smallest enrollment size $($ mean $=3.79, \mathrm{sd}=1.14)$ and schools with $301-750$ students $($ mean $=2.39, \mathrm{sd}=1.25)$ and schools larger than 750 students $($ mean $=$ mean $1.48, \mathrm{sd}$ $=.707$ ). Differences also existed between schools of 301-750 students and all other groups. There was also a significant difference between schools of more than 750 students and schools of all other sizes with larger schools reporting having an athletic trainer more often than smaller schools (See Appendix F)

There was a significant difference in the school enrollment size and the presence of an athletic trainer during all practices $\left(\mathrm{F}\left(\mathrm{df}=3, \mathrm{df}_{2}=144\right)=50.182, \mathrm{p}=.000\right)$. Tukey post hoc analysis revealed significant differences between schools with the smallest enrollment 
size $($ mean $=4.71, \mathrm{sd}=.550)$, schools with $301-750($ mean $=3.47, \mathrm{sd}=1.25)$ students and schools larger than 750 students $($ mean $=1.98, \mathrm{sd}=1.20)$. There was also a significant difference between schools of more than 750 students and schools of all other sizes with a majority of the schools

Appendix 6: Figure - Emergency Plan by Urbanization 


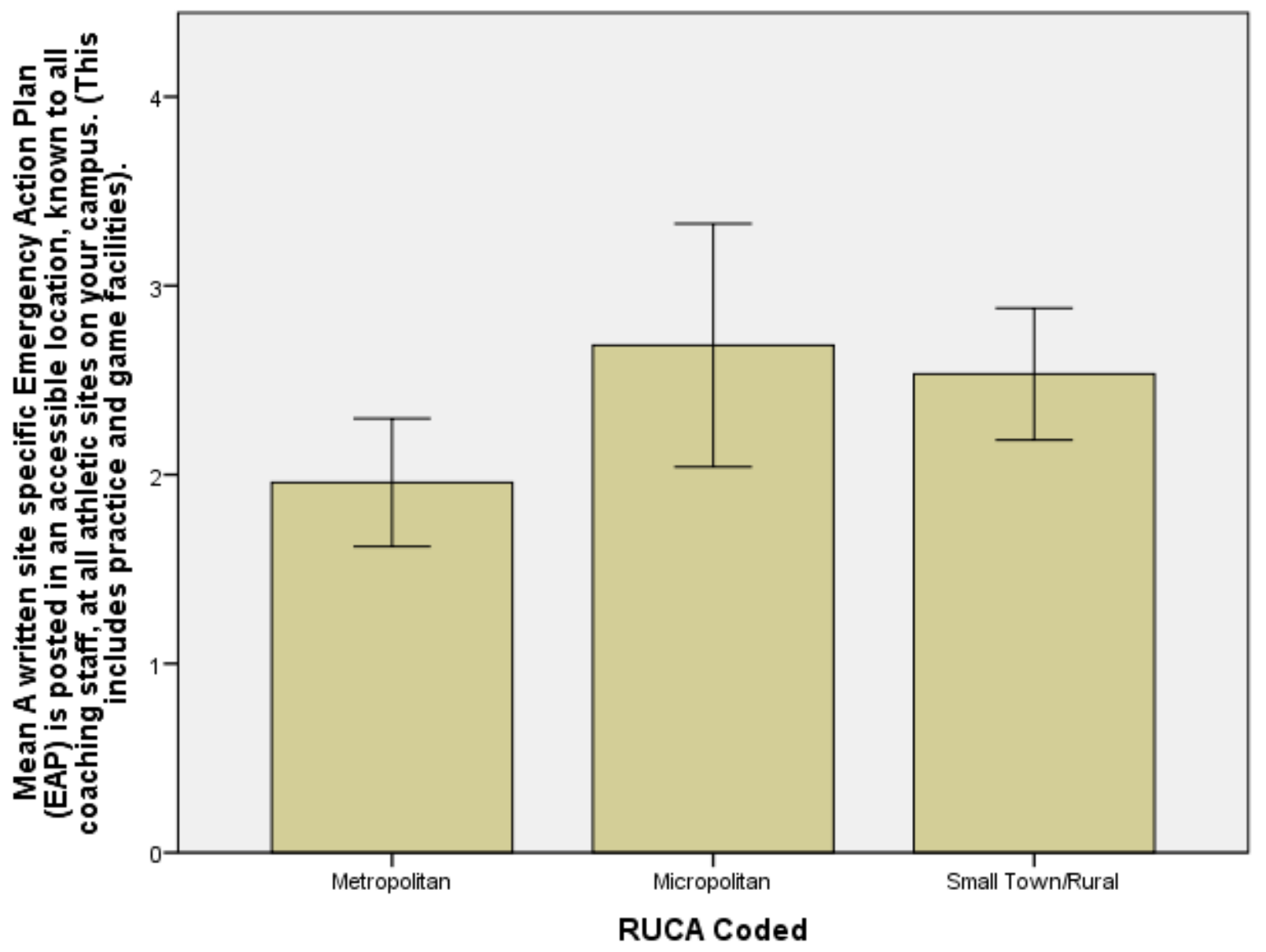

Error Bars: $95 \% \mathrm{Cl}$

Appendix Figure 7: Emergency Action Plan by School Size 


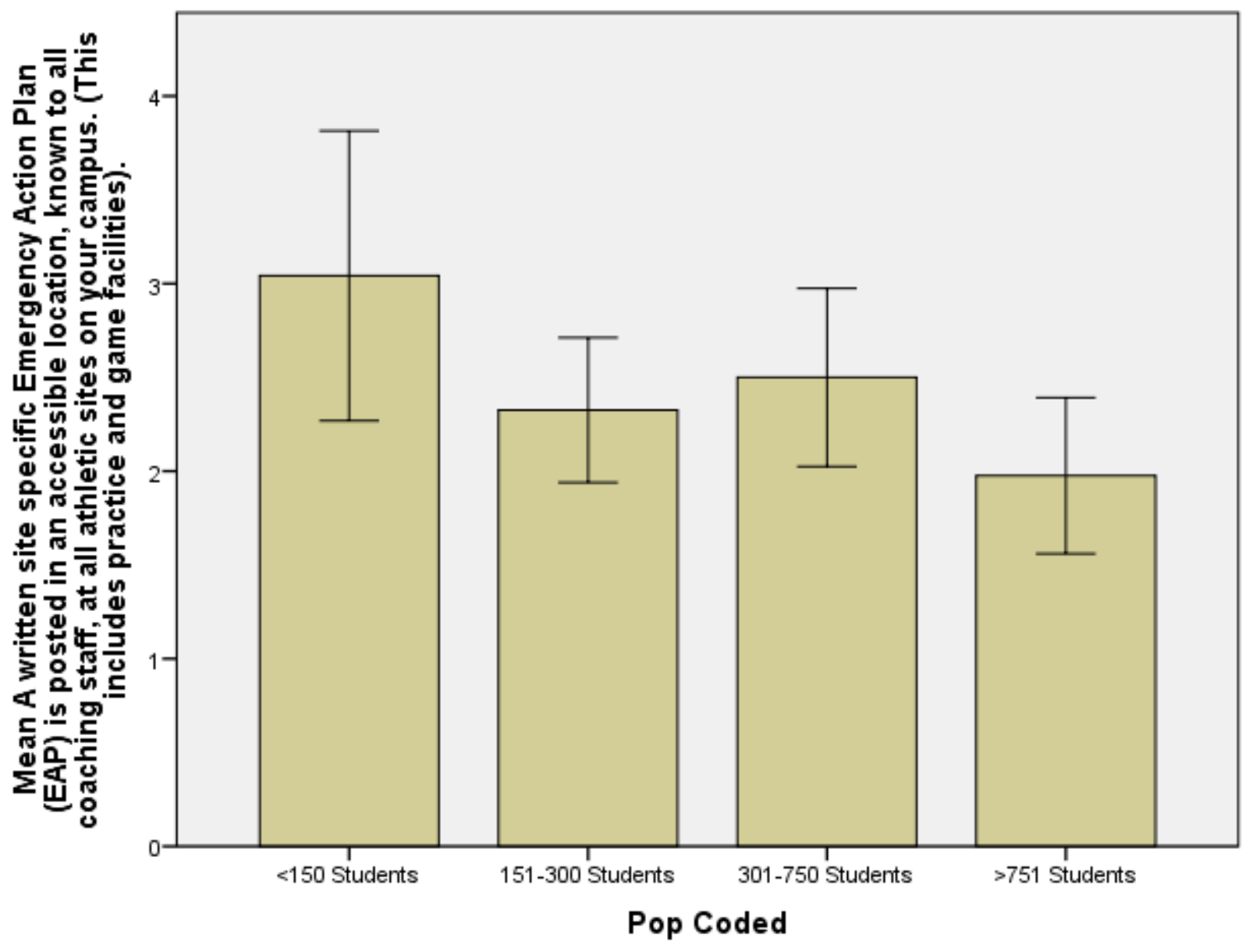

Error Bars: $95 \% \mathrm{Cl}$ 
Appendix 8: Number of AEDs

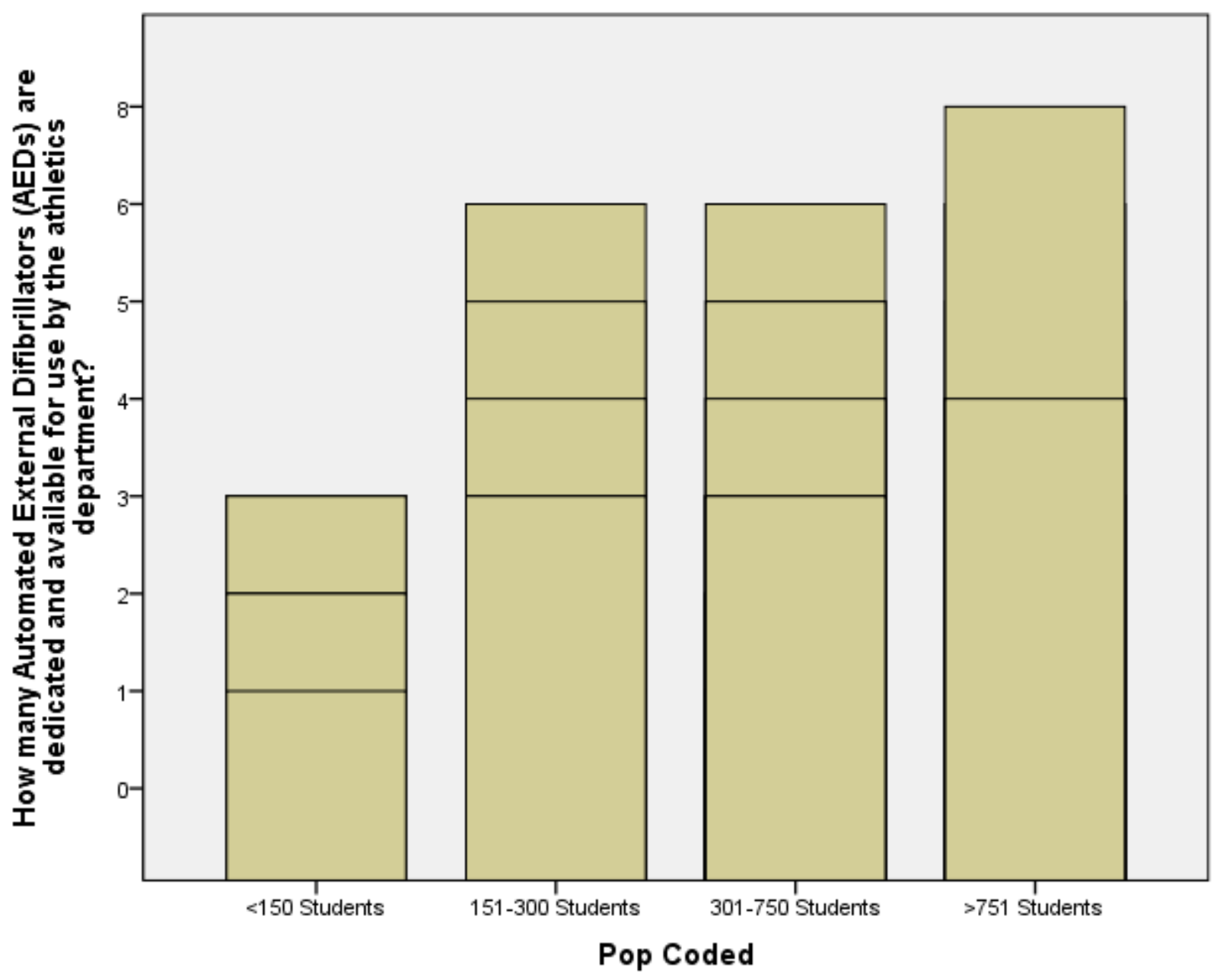


Appendix 9 Figure: CPR Certification by Urbanization

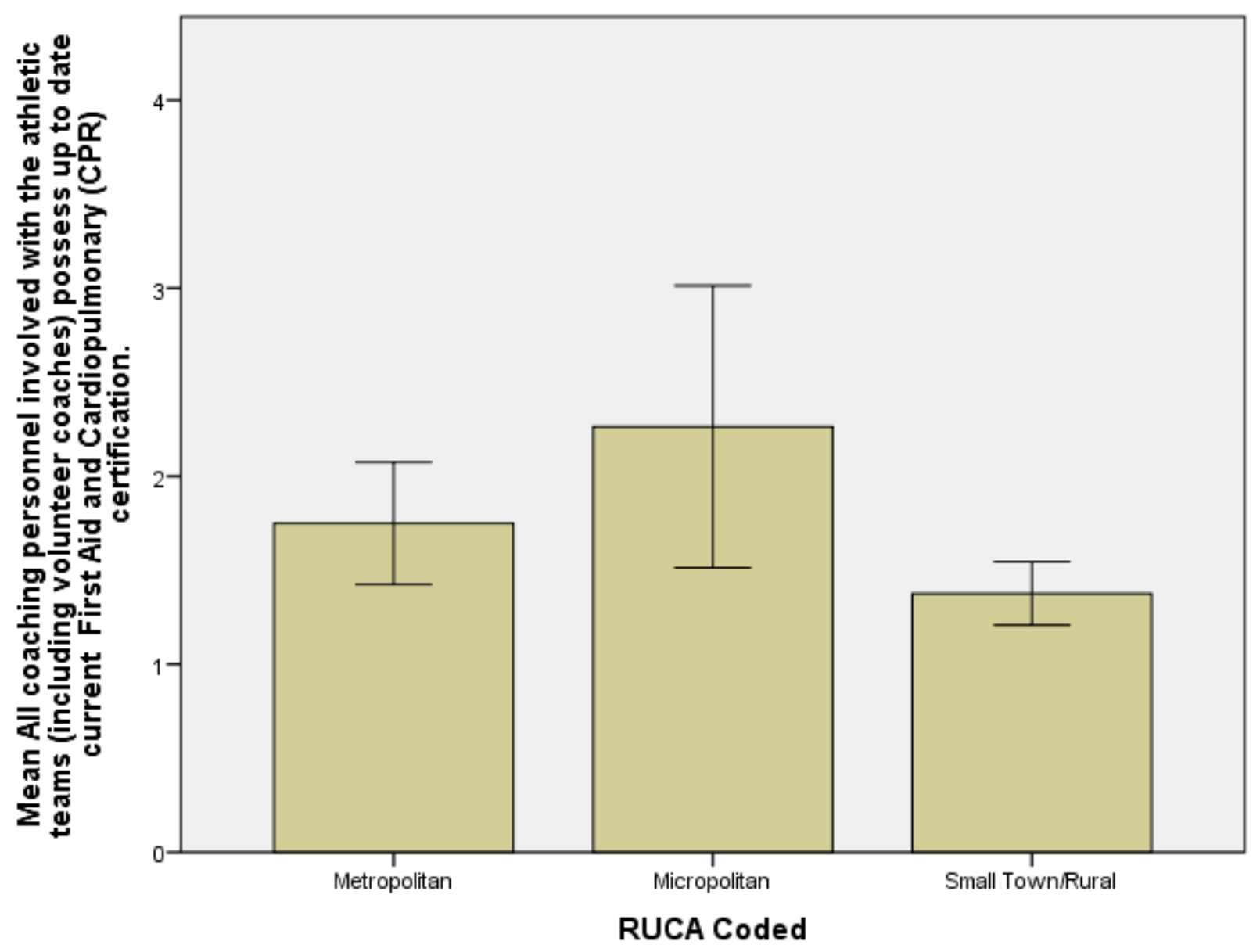

Error Bars: $95 \% \mathrm{Cl}$ 
Appendix 10 - Demographic Information

Pop Coded

\begin{tabular}{|c|c|c|c|c|c|}
\hline & & Frequency & Percent & $\begin{array}{c}\text { Valid } \\
\text { Percent }\end{array}$ & $\begin{array}{c}\text { Cumulative } \\
\text { Percent }\end{array}$ \\
\hline \multirow[t]{5}{*}{ Valid } & $<150$ Students & 24 & 15.9 & 16.1 & 16.1 \\
\hline & 151-300 Students & 46 & 30.5 & 30.9 & 47.0 \\
\hline & 301-750 Students & 37 & 24.5 & 24.8 & 71.8 \\
\hline & >751 Students & 42 & 27.8 & 28.2 & 100.0 \\
\hline & Total & 149 & 98.7 & 100.0 & \\
\hline \multirow[t]{2}{*}{ Missing } & System & 2 & 1.3 & & \\
\hline & Total & 151 & 100.0 & & \\
\hline
\end{tabular}




\section{Appendix 11}

Demographics Data: Highest Represented Ethnic Group

\begin{tabular}{|c|c|c|c|c|c|}
\hline & & Frequency & Percent & $\begin{array}{c}\text { Valid } \\
\text { Percent }\end{array}$ & $\begin{array}{c}\text { Cumulative } \\
\text { Percent }\end{array}$ \\
\hline \multirow[t]{5}{*}{ Valid } & African American & 5 & 3.3 & 3.4 & 3.4 \\
\hline & $\begin{array}{c}\text { Caucasian (Non- } \\
\text { Hispanic) }\end{array}$ & 138 & 91.4 & 93.2 & 96.6 \\
\hline & Hispanic & 2 & 1.3 & 1.4 & 98.0 \\
\hline & Native American & 3 & 2.0 & 2.0 & 100.0 \\
\hline & Total & 148 & 98.0 & 100.0 & \\
\hline \multirow[t]{2}{*}{ Missing } & System & 3 & 2.0 & & \\
\hline & Total & 151 & 100.0 & & \\
\hline
\end{tabular}




\section{Appendix 12}

Demographic Data: RUCA Coded

\begin{tabular}{|c|c|c|c|c|c|}
\hline & & Frequency & Percent & $\begin{array}{c}\text { Valid } \\
\text { Percent }\end{array}$ & $\begin{array}{c}\text { Cumulative } \\
\text { Percent }\end{array}$ \\
\hline \multirow[t]{4}{*}{ Valid } & Metropolitan & 48 & 31.8 & 33.3 & 33.3 \\
\hline & Micropolitan & 19 & 12.6 & 13.2 & 46.5 \\
\hline & $\begin{array}{c}\text { Small } \\
\text { Town/Rural }\end{array}$ & 77 & 51.0 & 53.5 & 100.0 \\
\hline & Total & 144 & 95.4 & 100.0 & \\
\hline Missing & System & 7 & 4.6 & & \\
\hline & Total & 151 & 100.0 & & \\
\hline
\end{tabular}




\section{Appendix 13}

\section{Demographic Data - Title I Status}

Is your school classified as a Title I school?

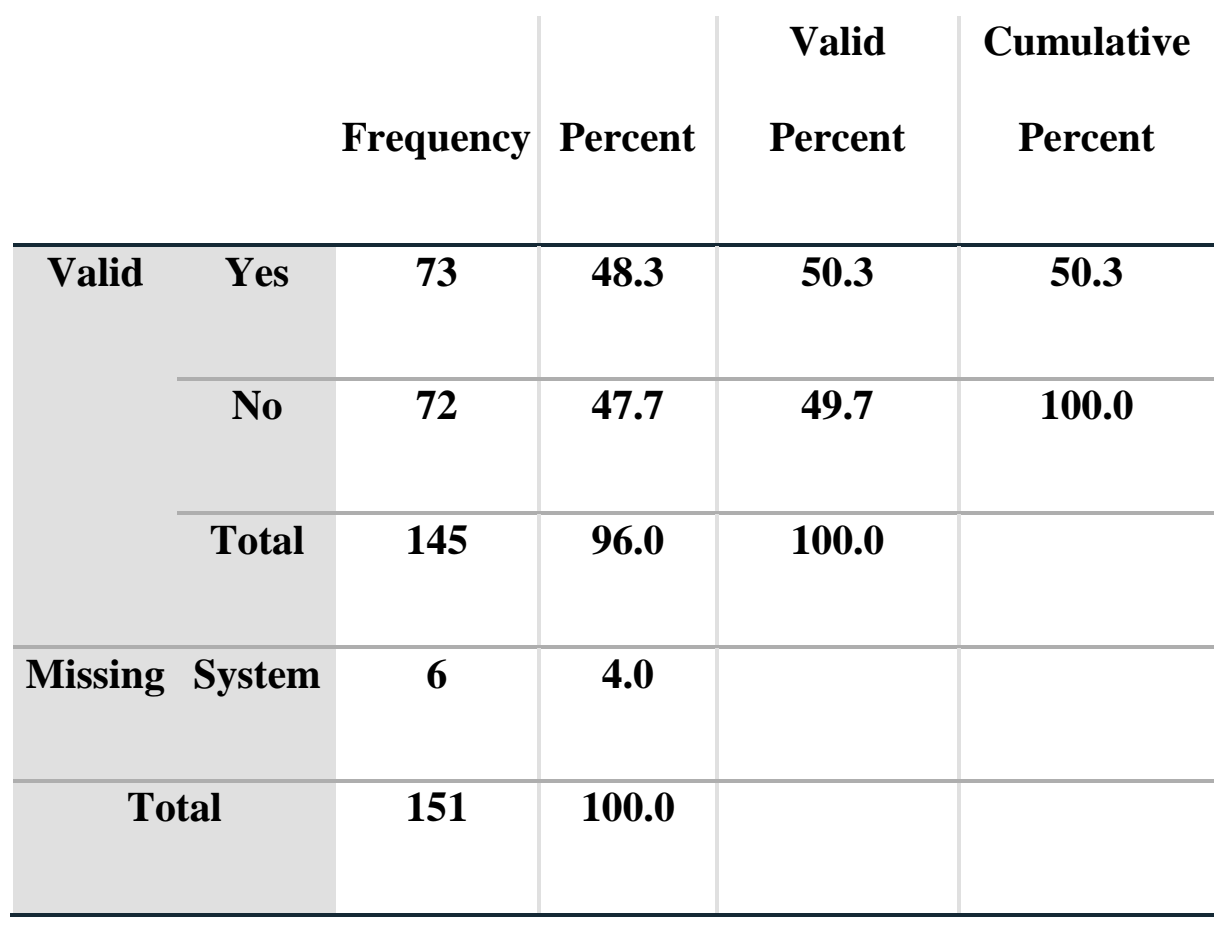




\section{VITA}

Kyle Schneider is the Director of the Athletic Training Program at Southeast Missouri State University in Cape Girardeau, MO. Prior to this current position, Kyle was the Coordinator of Clinical Education at Southeast Missouri State University from 20132018 and held the same position at Concord University in Athens, WV from 2009-2013. Kyle graduated with a Bachelor of Science Degree in Athletic Training (BSAT) from Millikin University in 2007 and received his Master of Science in Education in Athletic Training from Old Dominion University in 2009. Kyle has been a certified and licensed athletic trainer for 12 years and has worked with a variety of different patient populations. Kyle currently resides in Cape Girardeau, MO. 